\title{
Jogos topológicos e metrizabilidade
}

\author{
Dione Andrade Lara
}



Assinatura:

\title{
Dione Andrade Lara
}

\section{Jogos topológicos e metrizabilidade}

\author{
Tese apresentada ao Instituto de Ciências \\ Matemáticas e de Computação - ICMC-USP, \\ como parte dos requisitos para obtenção do título \\ de Doutor em Ciências - Matemática. VERSÃO \\ REVISADA
}

Área de Concentração: Matemática

Orientador: Prof. Dr. Leandro Fiorini Aurichi

\section{USP - São Carlos}

Novembro de 2016 
Ficha catalográfica elaborada pela Biblioteca Prof. Achille Bassi e Seção Técnica de Informática, ICMC/USP, com os dados fornecidos pelo(a) autor(a)

Lara, Dione Andrade
Jogos topológicos e metrizabilidade / Dione
Andrade Lara; orientador Leandro Fiorini Aurichi.
- São Carlos - SP, 2016.
$79 \mathrm{p.}$
Tese (Doutorado - Programa de Pós-Graduação em
Matemática) - Instituto de Ciências Matemáticas e de
Computação, Universidade de São Paulo, 2016.
1. Espaços Métricos. 2. Jogos Topológicos.
3. Teoria de Conjuntos. 4. Topologia. I. Aurichi,
Leandro Fiorini, orient. II. Título.




\section{Dione Andrade Lara}

\section{Topological games and metrizibility}

Doctoral dissertation submitted to the Instituto de Ciências Matemáticas e de Computação - ICMCUSP, in partial fulfillment of the requirements for the degree of the Doctorate Program in Mathematics. FINAL VERSION

Concentration Area: Mathematics

Advisor: Prof. Dr. Leandro Fiorini Aurichi 

Gostaria de agradecer, primeiramente, à minha família, que me ajudou mais do que eu merecia. Sem o apoio deles não seria possível nem ir morar em Franca-SP e me preparar para tentar realizar aquele sonho, até então distante, de passar no vestibular.

À minha companheira Mailce, que sempre me apoiou e teve muita paciência para escutar as minhas lamentações. Me ajudou e continua a me ajudar a tomar as melhores decisões nos momentos difíceis. Além de, a cada dia, me ajudar a crescer como ser humano.

Ao meu orientador, Leandro Fiorini Aurichi. Começamos a trabalhar juntos há seis anos, no mestrado. Apesar de toda a dificuldade para compreender as ferramentas básicas da área e algumas sequelas matemáticas que ainda persistiam o Prof. Leandro sempre estava disponível para sanar dúvidas de qualquer natureza, por mais pífias que fossem. Comecei o mestrado desacreditado de minhas capacidades e nunca imaginava que conseguiria terminar uma dissertação de mestrado, quiçá uma tese de doutorado. Porém, se não fosse pela sua paciência, dedicação e a sua crença nesse aprendiz, nada disso seria possível. Aproveito esse espaço para manifestar uma profunda gratidão que possuo pelo Prof. Leandro que foi muito mais que um orientador pra mim. Foi um exemplo que como devo manter a minha conduta em minha docência.

Ao meu amigo Renan que sempre esteve diponível para me ajudar para demonstrar teoremas e a construir piadas novas.

Às minhas amigas, Catiane, Edivânia, e aos meus amigos André e Danilo que compartilharam tristezas e felicidades em momentos que antecederam à universidade.

Às minhas amigas, Fabiana (Fabi) e Flora (Furora-chan) e ao meu amigo Daniel (Folgado) em que tive o prazer de compartilhar os melhores anos minha gradução e, apesar da distância que nos separam hoje, mantemos os mesmos laços de antes.

Ao meu querido amigo e confidente Rodrigo Lopes que tive o prazer de ter um convívio mais próximo nesses últimos anos.

Ao meu amigo Camilo, fonte de conhecimento e ótimas discussões. À minha querida amiga Mariana de Castro, e sua família, que sempre me trataram com muito carinho. E também, às minhas amigas Daniele, Maiza e Pâmela (Pâm).

Aos novos amigos feitos no ICMC que levarei para a vida toda: Ana Maria (Aninha), Camila, Carol (Carolzinha), Pryscilla, Fábio (Badaró), Felipe, Fernando (Fer), Ginnara, Henrique (Minêro), Henry, Jackson, Jaqueline, Jorge (Mendes), Jorgeane, Juliana Lima, Laís, Leandro 
Nery, Maria Carolina, Markus, Nelson, Paty (Tempestade), Pedro, Rafaella, Rodolfo (Mirna), Thaís Jordão, Thales, Thiago (Fera), Victor (Argola) e Wilker (Zé).

Aos meus amigos da minha cidade Pratápolis-MG: Bruno, Danilo (Brou), Diego, Eduardo (Dudu), Fernanda, Rafaela, Sandro e Tharles. Aos meus amigos Alexandre e Luiz Fernando, que atualmente moram em Curitiba-PR.

Aos companheiros do Bloco 36 da moradia da UFSCar, que sempre me apoiaram e dividiram alguns fardos que sozinho com certeza não iria aguentar: Alexandre (Jesus), Augusto (Glu Glu), Bruno (Rolete), Cassio (Carrerinha), Carlos (Herbie), Carlos Eduardo (Carlão), Cesar (Mineiro), Daniel (tackleberry), Everaldo (01), Fabiano (Bino), Guilherme, Guilherme Kubo, Paulo (Sexto), Rodolfo (Xico), Rogério (Corvo), Tiago (Tiii), Victor (RIP) e Welton (Goiano) que fizeram muita diferença no período em que estive como morador ou agregado. E a nova geração que ainda mantêm o espírito alegre daquele bloco: Lucas, Matheus, Vinícius e Tânia.

Aos professores da UFSCar, Adriana Ramos, Daniel Vendrúscolo, Ivo Machado, João Sampaio, Marcos Vinícius e Pedro Malagutti. Tive a honra de absorver uma pequena parte de seus conhecimentos, contribuindo para chegar academicamente onde cheguei. Além do conhecimento técnico, aprendidos em sala de aula, aprendi muito com as conversas fora dela.

Gostaria de agradecer ao programa de pós graduação do USP-ICMC (Instituto de Matemática Aplicada e Computação). Aos professores e funcionários que contribuiram para a confecção dessa tese.

À todos os citados e as pessoas que não mencionei, mas que fizeram parte da minha trajetória, fica registrado o meu muito obrigado. Graças à todos vocês foi possível essa trajetória de onze anos ser concretizada!

À CAPES pelo apoio financeiro. 


\section{RESUMO}

LARA, D. A.. Jogos topológicos e metrizabilidade. 2016. 79 f. Tese (Doutorado em Ciências

- Matemática) - Instituto de Ciências Matemáticas e de Computação (ICMC/USP), São Carlos SP.

Neste trabalho apresentaremos o princípio seletivo $S_{1}(\mathscr{O}, \mathscr{H})$ que caracteriza a propriedade da diagonal $G_{\delta}$. Iremos também apresentar um jogo topológico $G_{1}(\mathscr{O}, \mathscr{H})$ induzido por esse princípio seletivo e estudaremos as relações entre esse jogo e a propriedade da diagonal $G_{\delta}$. Além disso, apresentaremos outros jogos topológicos e mostraremos quais são as relações destes com o jogo $G_{1}(\mathscr{O}, \mathscr{H})$. Finalmente, daremos algumas aplicações desses jogos e exemplos.

Palavras-chave: Espaços Métricos, Jogos Topológicos, Teoria de Conjuntos, Topologia. 



\section{ABSTRACT}

LARA, D. A.. Jogos topológicos e metrizabilidade. 2016. 79 f. Tese (Doutorado em Ciências

- Matemática) - Instituto de Ciências Matemáticas e de Computação (ICMC/USP), São Carlos SP.

In this work we present a selection principle $S_{1}(\mathscr{O}, \mathscr{H})$ that characterizes the $G_{\delta}$-diagonal property. We also present a topological game $G_{1}(\mathscr{O}, \mathscr{H})$ induced by this selection principle and we study the relations between this game and the $G_{\delta}$-diagonal property. Besides that, we present other topological games and we show which are the relations between those topological games and the game $G_{1}(\mathscr{O}, \mathscr{H})$. Finally, we give some applications and examples.

Keywords: Metric Spaces, Set Theory, Topology, Topological games. 

INTRODUÇÃO . . . . . . . . . . . . . . . . . 13

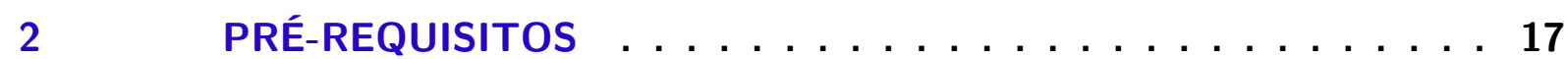

$2.1 \quad$ Ordens Parciais e Conjuntos . . . . . . . . . . . . . . . 17

$2.2 \quad$ Ordinais, Cardinais . . . . . . . . . . . . . 19

$2.3 \quad$ Notações . . . . . . . . . . . . . . . . . . . 22

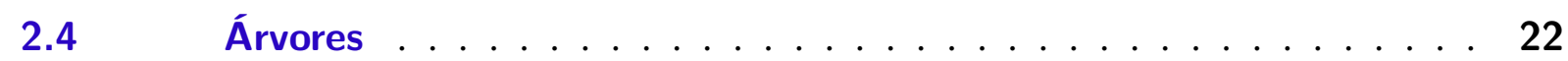

$2.5 \quad$ Noções Básicas de Topologia . . . . . . . . . . . . . . . . . 26

2.6 Jogos Topológicos e Princípios Seletivos . . . . . . . . . . . . . . . . 31

2.6.1 Alguns Exemplos de Jogos Topológicos e Princípios Seletivos . . . . 31

2.6.2 Propriedades e Aplicações do Jogo de Choquet . . . . . . . . . . . . 33

$3 \quad$ o JOGO $G_{1}(\mathscr{O}, \mathscr{H}) \ldots \ldots \ldots$

$3.1 \quad 0$ jogo $G_{1}(\mathscr{O}, \mathscr{H})$ e algumas propriedades . . . . . . . . . 38

3.1.1 A equivalência para espaços de Lindelöf . . . . . . . . . . . . . . . . 40

3.2 A equivalência para espaços hereditariamente metacompactos . . . 44

4 OUTROS JOGOS E ALGUMAS RELAÇÕES . . . . . . . . . . . 49

$4.1 \quad$ Os jogos $G(X)$ e $P^{\prime}(X) \ldots \ldots \ldots \ldots \ldots$

$4.2 \quad$ Jogos duais aos jogos $G_{1}(\mathscr{O}, \mathscr{H})$ e $P(X) \ldots \ldots \ldots$

$4.3 \quad 0$ jogo $G_{1}(\mathscr{O}, \mathscr{K}) \ldots \ldots \ldots \ldots$

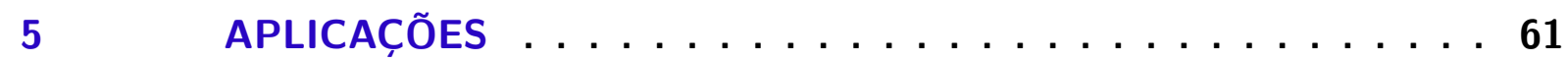

$5.1 \quad$ Aplicações de $G_{1}(\mathscr{O}, \mathscr{H}) \ldots \ldots \ldots \ldots \ldots$

$5.2 \quad$ Aplicações do jogo $G(X) \ldots \ldots \ldots \ldots \ldots$

5.2.1 Substituição de $\sigma$-Choquet por $G(X) \ldots \ldots$. . . . . . . . 66

5.2.2 Aplicação de $G(X)$ em espaços métricos . . . . . . . . . . . . . 68

6 CONSIDERAÇÕES FINAIS ................. 71

REFERÊNCIAS . . . . . . . . . . . . . . . . . 75

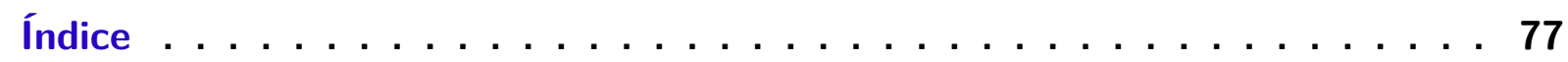





\section{1}

\section{INTRODUÇÃO}

Intuitivamente, um jogo topológico é uma maneira de "enxergar" um espaço (ou propriedade topológica) de um jeito mais simples, por meio de jogadores (nos jogos que falaremos serão dois, jogadores I e II) que executam suas jogadas, estas podendo ser conjuntos, pontos, conjuntos abertos, coberturas abertas, etc. É dito quantas jogadas serão necessárias para encerrar o jogo, podendo ser uma quantidade finita, enumerável ou também não-enumerável. E é dito também o critério sobre quem é o vencedor.

O termo jogo topológico foi introduzido pela primeira vez por Berge em 1957 e em 1965 seu formalismo foi feito por Pears. Rastislav Telgársky em 1975 e 1977 definiu o conceito de "propriedades topológicas definidas por jogos" e mais tarde "espaços definidos por jogos topológicos". Depois de mais de 35 anos, o termo "jogo topológico" generalizou-se e apareceram centenas de publicações. Veremos agora que a ideia de jogos topológicos é anterior ao formalismo de Berge.

No artigo de (TELGÁRSKY, 1987) vemos que primeiro jogo topológico que se tem notícia foi o de Banach Mazur que apareceu pela primeira vez no famoso Livro Escocês (Scottish Book). Esse livro tem uma história interessante, foi criado entre 1935-1941 na cidade de Lwów que naquele tempo fazia parte da Polônia. Um grupo de pessoas que trabalhava na Universidadede Lwów, entre eles nomes que são bem conhecidos como S. Banach, S. Mazur, S. Ulam, H. Steinhaus e outros, frequentemente se reunia para discutir informalmente problemas de matemática no The Scottish Caffé House (daí o nome do livro). Seguindo a ideia de Banach, um caderno foi comprado e deixado aos cuidados do garçom do estabelecimento. Cada problema proposto (ou solução) era guardada nesse caderno. Dizem que o prêmio para as soluções dos problemas propostos era uma garrafa de vinho ou uma de cerveja (será que dependia da dificuldade do problema?).

O Problema 43 do Livro Escocês foi proposto por Mazur: Considere dois jogadores (Mazur denotou por $A$ e $B$ ) e seja $E$ um subconjunto de $\mathbb{R}$. O jogo é definido da seguinte forma: $A$ 
toma um intervalo não vazio $D_{1}$, então $B$ toma um sub-intervalo não vazio $D_{2}$ de $D_{1}$. $A$ continua com $D_{3}$ sub-intervalo de $D_{2}$ e assim por diante. O jogador $A$ vence se a intersecção de todos intervalos $D_{1}, D_{2}, \ldots$ possui um ponto em comum com $E$. Caso contrário, $B$ vence. Mazur tinha observado o seguinte: se o complementar de $E$ é de $1^{\text {a }}$ categoria ${ }^{1}$ em algum intervalo, então o jogador $A$ possui uma regra que dará a sua vitória nesse jogo. Agora, se $E$ for de $1^{\text {a }}$ categoria em $\mathbb{R}$, então o jogador $B$ possuirá uma regra que lhe dará a vitória nesse jogo. A questão proposta por Mazur (que valia uma garrafa de vinho!) era se essas duas condições eram necessárias para a vitória dos jogadores $A$ e $B$ respectivamente. A resposta foi dada em 4 de agosto de 1935 por Banach e era verdadeira, porém a prova de Banach nunca foi publicada.

O objetivo dessa tese é mostrar as relações que alguns jogos topológicos possuem com propriedades oriundas de espaços métricos.

No Capítulo 2 faremos os pré-requisitos necessários para ajudar na compreensão dos demais capítulos. Estabeleceremos as definições e resultados básicos de teoria de conjuntos que serão usados no corpo da tese. Assumiremos que o leitor tenha uma certa familiaridade com a teoria de conjuntos e por isso alguns resultados básicos serão omitidos. Em seguida, introduziremos conceitos básicos de topologia geral. No final de tal capítulo daremos definições e exemplos de alguns princípios seletivos, jogos topológicos e aplicações em topologia.

No terceiro capítulo iremos tratar do jogo toplógico $G_{1}(\mathscr{O}, \mathscr{H})$ que é inspirado pela propriedade da diagonal $G_{\delta}$. Esse jogo e suas consequências fazem parte do trabalho (AURICHI; LARA, 2016) que submetemos no início deste ano. Uma das funções deste capítulo é fazer uma análise mais detalhada do que foi apresentado no nosso artigo. A primeira aparição da propriedade da diagonal $G_{\delta}$ foi no trabalho de (ŠNEIDER, 1945). Neste artigo foi provado que se $X$ é compacto então $X$ é metrizável se, e somente se, $X$ possui a propriedade da diagonal $G_{\delta}$. Mostraremos que a classe de espaços no qual o Jogador I possui estratégia vencedora em $G_{1}(\mathscr{O}, \mathscr{H})$ é estritamente maior que a classe de espaços que possuem a propriedade da diagonal $G_{\delta}$. Em outras palavras, mostraremos que, em geral, se um espaço $X$ possui a propriedade da diagonal $G_{\delta}$ então o Jogador I possui estratégia vencedora em $G_{1}(\mathscr{O}, \mathscr{H})$ e que a recíproca desse argumento não é verdadeira para $\omega_{1}$. Porém, tanto para espaços de Lindelöf como para espaços hereditariamente metacompactos, conseguimos mostrar que se o Jogador I possui estratégia vencedora em $G_{1}(\mathscr{O}, \mathscr{H})$ então os espaços possuem a propriedade da diagonal $G_{\delta}$.

No quarto capítulo vamos definir outros jogos e analisar quais relações existem entre eles e quais relações possuem com o jogo $G_{1}(\mathscr{O}, \mathscr{H})$. Ao final do capítulo definiremos um novo princípio seletivo $S_{1}(\mathscr{O}, \mathscr{K})$, no qual, por sua vez, é motivado pelos espaços de Moore. Veremos quais relações existem entre os jogos $G_{1}(\mathscr{O}, \mathscr{H})$ e $G_{1}(\mathscr{O}, \mathscr{K})$.

Finalmente, no último capítulo mostraremos algumas aplicações do jogo $G_{1}(\mathscr{O}, \mathscr{H})$ e

Seja $X$ um espaço topológico. Dizemos que $A \subset X$ é nunca denso (ou raro) se o interior de $\bar{A}$ é vazio. Um subconjunto de $X$ é dito ser de $\mathbf{1}^{\text {a }}$ categoria (ou magro) em $X$ se é composto por uma união enumerável de conjuntos nunca densos. 
dos demais jogos vistos no Capítulo 4. Começaremos mostrando uma aplicação que também faz parte do nosso artigo (AURICHI; LARA, 2016) inspirado no trabalho de Buzyakova. No trabalho de (BUZYAKOVA, 2006) é mostrado que todo espaço regular c.c.c. (countable chain condition) satisfazendo a propriedade da diagonal $G_{\delta}$ tem tamanho no máximo $2^{\omega}$. Substituindo a propriedade c.c.c. e a regularidade pelo espaço ser metacompacto, separável e o Jogador I possuir estratégia vencedora em $G_{1}(\mathscr{O}, \mathscr{H})$, mostramos que o espaço tem tamanho no máximo $2^{\omega}$. Ainda com esse jogo mostramos algumas aplicações com relação ao grau de Lindelöf do espaço. No capítulo anterior é definido o jogo $G(X)$, neste capítulo apresentaremos duas aplicações deste jogo. A primeira aplicação será envolvendo uma propriedade relativa a continuidade de funções da forma $f: X \times Y \rightarrow Z$ e segunda aplicação nos fornecerá um critério para que um espaço métrico seja completo. 

O intuito desse capítulo é estabelecer as definições e resultados básicos que serão usados no corpo da tese. Assumiremos que o leitor tenha uma certa familiaridade com a teoria de conjuntos e topologia e por isso alguns resultados básicos serão omitidos. As principais referências usadas nesse capítulo são (ENGELKING, 1989), (JECH, 2003), (KUNEN, 2011) e na sexta seção quando estivermos falando sobre o jogo de Choquet usaremos (KECHRIS, 1995).

\subsection{Ordens Parciais e Conjuntos}

Essa seção é a base para tudo que será feito nessa tese. Os objetos que definiremos posteriormente como os ordinais, cardinais e árvores são obtidos por meio de ordens parciais. Aqui definiremos também ferramentas que serão usadas constantemente como o Lema de Zorn, ou o Princípio da Boa Ordem.

Definição 2.1.1. Dizemos que uma relação $\leq e ́$ uma relação de pré-ordem sobre um conjunto P se são satisfeitas as seguintes condições:

1. para todo $a \in P$ temos que $a \leq a$ (reflexiva);

2. para todo $a \in P$, para todo $b \in P$ e para todo $c \in P$, se $a \leq b$ e $b \leq c$, então $a \leq c$ (transitiva).

O conjunto $(P, \leq)$ é chamado de conjunto pré-ordenado.

Se, além disso, tivermos que para todo $a \in P$, para todo $b \in P$ se $a \leq b$ e $b \leq a$, então $a=b$ (antissimétrica). Dizemos que $\leq e ́$ uma ordem.

Um conjunto $(P, \leq)$ é totalmente ordenado se, para todo $a, b \in P, a \leq b$, ou $b \leq a$, ou seja, todos os elementos são comparáveis. 
Definição 2.1.2. Dizemos que uma relação <é uma relação de ordem estrita sobre P se são satisfeitas as seguintes condições:

1. para todo $a \in P$ não ocorra $a<$ a (irreflexiva);

2. para todo a $\in$, para todo $b \in P$ e para todo $c \in P$, se $a<b$ e $b<c$, então $a<c$ (transitiva).

Observe que a partir de uma ordem podemos obter uma ordem estrita e vice e versa.

Em determinados conjuntos observamos que existe um elemento que é "menor" que os demais, como por exemplo o $0 \mathrm{em}(\mathbb{N}, \leq)$, ou um elemento que seja maior que o restante, por exemplo o 1 em $([0,1], \leq)$.

Definição 2.1.3. Seja $(P, \leq)$ um conjunto ordenado e seja $A \subset P$ não vazio e $m \in P$. Então:

Dizemos que m é o elemento mínimo de A se $m \in A$ e para todo $x \in A$ temos que $m \leq x$.

Dizemos que $m$ é um elemento minimal de A se $m \in A$ e não existe $x \in A$ tal que $x<m$.

Dizemos que m é o elemento máximo de A se $m \in A$ e para todo $x \in A$ temos que $x \leq m$.

Dizemos que m é o elemento maximal de A se $m \in A$ e não existe $x \in A$ tal que $m<x$.

Dizemos que mé um limitante inferior de A se para todo $x \in A$ temos que $m \leq x$.

Dizemos que m é um limitante superior de A se para todo $x \in A$ temos que $x \leq m$.

Se A possui um limitante superior dizemos que A é limitado superiormente. Se A possui um limitante inferior dizemos que A é limitado inferiormente.

Geralmente o primeiro contato que temos com o conceito de boa ordem é quando estamos estudando a construção dos números naturais. A definição de boa ordem por si é de extrema importância para a teoria de conjuntos. Além disso, em ZFC temos o Princípio da Boa Ordem: todo conjunto pode ser bem ordenado ${ }^{1}$.

Definição 2.1.4. Seja $(P, \leq)$ um conjunto ordenado. Dizemos que $\leq e ́$ uma boa ordem se, para qualquer $A \subset X$ não vazio, A possui elemento mínimo. Dizemos que $(P, \leq)$ é um conjunto bem ordenado se $\leq$ for uma boa ordem.

Observe que um conjunto bem ordenado $(P, \leq)$ é totalmente ordenado. De fato, sejam $a, b \in P$ e considere o subconjunto $\{a, b\}$. Como $P$ é bem ordenado então $\{a, b\}$ possui um elemento mínimo. Logo $a \leq b$ ou $b \leq a$

\footnotetext{
1 Também conhecido como o Teorema de Zermelo, tal resultado é equivalente ao Axioma da Escolha em $Z F$.
} 
Definição 2.1.5. Seja $(P, \leq)$ um conjunto ordenado. Dizemos que $D \subset P$ é denso em $P$ se, para todo $p \in P$, existe $d \in D$ tal que $d \leq p$.

Definição 2.1.6. Seja $(P, \leq)$ um conjunto ordenado. Um subconjunto $C \subset P$ onde $(C, \leq) e ́$ totalmente ordenado é chamado de cadeia. Dizemos que $A \subset P$ é uma anticadeia se seus elementos são dois a dois incompativeis, isto é, dados $a, b \in A$ distintos, não existe $c \in P$ tal que $c \leq$ a e $c \leq b$. Dizemos que a e b são comparáveis se $a \leq b$ ou $b \leq a$. Devemos tomar cuidado para não confudir incomparabilidade com incompatibilidade. Se dois elementos são incomparáveis nada nos garante que existe um terceiro elemento "abaixo" desses dois.

Com isso podemos enunciar o Lema de Zorn que, assim como o Princípio da Boa Ordem, é equivalente ao Axioma da Escolha.

Lema 2.1.7 (Lema de Zorn). Seja $(P, \preceq)$ um conjunto não vazio e ordenado. Se toda cadeia possui um limitante superior, então o conjunto $P$ possui elemento maximal.

Definição 2.1.8. Seja $(P, \leq)$ um conjunto ordenado. Seja $A \subset P$. O supremo de $A(\sup A)$ é $o$ mínimo, caso exista, do conjunto dos limitantes superiores de $A$, i.e., $\sup A=\min \{x \in P: a \leq x$ para todo $a \in A\}$. $O$ ínfimo de $A(\inf A)$ é o máximo, caso exista, do conjunto dos limitantes inferiores de $A$, i.e., $\inf A=\max \{x \in P: x \leq$ a para todo $a \in A\}$.

\subsection{Ordinais, Cardinais}

Os números ordinais, intuitivamente, são uma generalização dos números naturais. Para os ordinais também temos um processo de "adição" e isso se dá por meio da Definição 2.2.4 onde temos a definição de ordinal sucessor. Muito mais do que isso, os ordinais são os representantes "canônicos" dos conjuntos bem ordenados, tendo em vista que todo conjunto bem ordenado é isomorfo a um único ordinal (ou seja, existe uma bijeção que preserva a ordem) $)^{2}$.

Agora, faremos os pré requisitos necessários para a definição de um número ordinal.

Definição 2.2.1. Seja $X$ um conjunto. Seja $\in_{X}=\{(x, y) \in X \times X: x \in y\}$.

Definição 2.2.2. Seja $X$ um conjunto. Dizemos que $X$ é transitivo se, para todo $x \in X$ e para todo $y \in x$, tivermos que $y \in X$.

Definição 2.2.3. Seja $\alpha$ um conjunto. Dizemos que $\alpha$ é um número ordinal se $\alpha$ é transitivo $e$ $\left(\alpha, \in_{\alpha}\right)$ é bem ordenado e $\alpha=\{\beta: \beta \in \alpha\}$

Definição 2.2.4. Seja $\alpha$ um ordinal. Definimos o sucessor de $\alpha$ como sendo $\alpha+1=\alpha \cup\{\alpha\}$.

Definição 2.2.5. Um ordinal $\alpha$ é um ordinal sucessor se $\alpha=\beta+1$, para algum ordinal $\beta$. Caso contrário, $\alpha$ é um ordinal limite.

2 Veja (KUNEN, 2011). 
Definição 2.2.6. Sejam $\alpha$ e $\beta$ números ordinais. Denotamos por $\alpha<\beta$ se, e somente se, $\alpha \in \beta$. Além disso, representaremos " $\in$ ou $=$ " por " $\leq$ ".

Sejam $\alpha$ e $\beta$ ordinais então $\alpha \cup \beta=\max \{\alpha, \beta\}$ e $\alpha \cap \beta=\min \{\alpha, \beta\}$. Observe que se $X$ é um conjunto de ordinais, então $\bigcap X$ e $\bigcup X$ são ordinais ${ }^{3}$.

Com isso podemos caracterizar o supremo e o ínfimo de um conjunto de ordinais.

Definição 2.2.7. Se $X$ é um conjunto de ordinais, então $\sup X=\bigcup X$ e se $X \neq \emptyset$ temos que $\inf X=\bigcap X$.

De maneira análoga com os números naturais, temos o princípio de indução para números ordinais. Somente enunciaremos o teorema de maneira informal, para acompanhar os detalhes de sua demonstração, veja a página 23 de (JECH, 2003).

Teorema 2.2.8 (Indução Transfinita). Seja X uma coleção de ordinais e assuma que:

1. $0 \in X$;

2. se $\alpha \in X$, então $\alpha+1 \in X$;

3. se $\alpha$ é um ordinal limite e $\beta \in X$ para todo $\beta<\alpha$, então $\alpha \in X$.

Então X é a coleção de todos os ordinais ${ }^{4}$.

Vamos definir o que é um número cardinal.

Definição 2.2.9. Seja $\gamma$ um ordinal. Então $\gamma$ é um número cardinal se não existe bijeção $f: \gamma \rightarrow \beta \operatorname{com} \beta<\gamma$.

Definição 2.2.10. Seja $\kappa$ um cardinal. Definimos o cardinal sucessor de $\kappa$ como sendo $\kappa^{+}=$ $\min \{\beta: \beta$ é cardinal e $\kappa<\beta\}$.

Agora iremos definir dois ordinais/cardinais muito especiais que serão muito úteis nos capítulos posteriores. Seja $(\mathbb{N}, \leq)$ com a ordem usual ${ }^{5}$. Daqui para frente vamos renomeá-lo para $\omega$ ou $\omega_{0}$. Denfinimos $\omega_{1}$ como sendo o primeiro ordinal/cardinal não enumerável ${ }^{6}$. Ou seja, podemos encarar $\omega_{1}$ como sendo a reta real bem ordenada.

3 Veja (JECH, 2003) ou (KUNEN, 2011)

4 Neste caso $X$ não é formalmente um conjunto, $X$ seria a classe de todos os ordinais. Veja (JECH, 2003).

5 Note que $(\mathbb{N}, \leq)$ é bem ordenado. Porém $(\mathbb{R}, \leq)$ com a ordem usual não é bem ordenado, basta tomar o subconjunto $] 0,1[\subset \mathbb{R}$ que não possui elemento mínimo.

6 Podemos também definir $\omega_{1}$ de outra maneira. Para isso, seja $(X, \leq)$ um conjunto bem ordenado com $X$ não enumerável. Como foi dito $(\mathbb{R}, \leq)$ com a ordem usual não serviria para esse propósito. Porém podemos "bem ordená-lo" com o princípio da boa ordem. Seja $x_{0}=\min \{x \in X:\{y \in X: y<x\}$ é não enumerável $\}$. Logo, $\omega_{1}=\left\{y \in X: y<x_{0}\right\}$. 
Definição 2.2.11. Sejam $\alpha$ e $\beta$ ordinais e seja $f: \beta \rightarrow \alpha$. Dizemos que $f$ é ilimitada se para cada $\zeta<\alpha$, existe $\xi<\beta$ tal que $\zeta \leq f(\xi)<\alpha$.

Definição 2.2.12. Seja $\alpha$ um ordinal. A cofinalidade de $\alpha(c f(\alpha))$ é o menor ordinal $\beta$, tal que existe uma função $f: \beta \rightarrow \alpha$ crescente e ilimitada em $\alpha$.

A cofinalidade só será interessante nos casos em que $\alpha$ for ordinal limite. Observe que a função identidade $f: \alpha \rightarrow \alpha$, é crescente e ilimitada. Por isso $c f(\alpha) \leq \alpha$.

Note que, a princípio, para mostrar que a cofinalidade de um ordinal $\alpha$ é $\beta$ basta que exista uma função $f: \beta \rightarrow \alpha$ ilimitada, pois sempre podemos definir uma função auxiliar $\tilde{f}(\xi)=\sup \{f(\eta): \eta<\xi\}$ que será crescente e ilimitada.

Proposição 2.2.13. Seja $\alpha$ um ordinal limite e c $f(\alpha)=\beta$. Então $c f(\beta)=\beta$.

Demonstração. Seja $\gamma=c f(\beta)$, logo, pela observação acima $\gamma \leq \beta$. Vamos mostrar que $\beta \leq \gamma$. Temos que:

- $\beta$ é o menor ordinal tal que exista $f: \beta \rightarrow \alpha$ crescente e ilimitada.

- $\gamma$ é o menor ordinal tal que exista $g: \gamma \rightarrow \beta$ crescente e ilimitada.

Seja $h=f o g: \gamma \rightarrow \alpha$

1. $h$ é crescente. Sejam $x<y<\gamma$. Como $g$ é crescente, segue que $g(x)<g(y)$ e como $f$ é crescente temos que $f(g(x))<f(g(y))$.

2. $h$ é ilimitada. Seja $\zeta<\alpha$. Por $f$ ser ilimitada, existe $\xi<\beta$ tal que $\zeta \leq f(\xi)<\alpha$. Por $g$ ser ilimitada, temos que existe $\eta<\gamma$ tal que $\xi \leq g(\eta)<\beta$. Como $f$ é crecente temos que $\zeta \leq f(\xi) \leq f(g(\eta))<\alpha$. Logo, dado $\zeta<\alpha$ temos que existe $\eta<\gamma$ tal que $\zeta \leq h(\eta)<\alpha$.

Como $\beta$ é o menor ordinal tal que existe $f: \beta \rightarrow \alpha$ crescente e ilimitada segue que $\beta \leq \gamma$. Portanto $\gamma=\beta$.

Definição 2.2.14. Seja $\kappa$ um cardinal. Dizemos que $\kappa$ é um cardinal regular se $c f(\kappa)=\kappa$.

Num primeiro contato com teoria de conjutos nos é apresentado que o infinito não enumerável é "maior" que o infinito enumerável. Um pergunta bem natural seria se não existe um conjunto com a sua cardinalidade sendo estritamente intermediária a esses dois "infinitos". A Hipótese do Contínuo $(\mathrm{CH})$ afirma que não existe de tal conjunto. Note que, se assumirmos $\mathrm{CH}$, teremos que $\omega_{1}=2^{\omega}$. Durante a década de 30, Kurt Gödel mostrou a consistência de $\mathrm{CH}$, ou seja, se assumirmos $\mathrm{CH}$ como um axioma extra de ZFC não teremos contradições, ou pelo 
menos não teremos novas contradições ${ }^{7}$. Somente na década de 60 que o matemático Paul Cohen usando a técnica de forcing, criada por ele mesmo, demonstrou a consistência da negação de $\mathrm{CH}$. Algumas referências interessantes sobre esse assunto são as notas de aula do curso Introdução ao Forcing do Prof. Leandro (AURICHI, 2014), (KUNEN, 2011) e (JECH, 2003).

\subsection{Notações}

Fixaremos aqui algumas notações e comentaremos sobre alguns abusos de notação que faremos.

Usaremos as notações usuais de teoria de conjuntos. Usaremos "chaves" para conjuntos e "parêntesis" quando quisermos deixar claro uma estrutura de ordenação, como no caso de sequências, ou elementos de produtos cartesianos. Por exemplo, seja $a_{n} \in \mathbb{N}$ tal que

$$
a_{n}=\left\{\begin{array}{l}
0 \text { se } n=0 \text { ou } n \text { é par } \\
1 \text { se } n \text { é impar }
\end{array}\right.
$$

Então $\left(a_{n}: n \in \omega\right)$ é diferente de $\left\{a_{n}: n \in \omega\right\}$, uma vez que $\left(a_{n}: n \in \omega\right)=(0,1,0,1,0,1, \ldots)$ e $\left\{a_{n}: n \in \omega\right\}=\{0,1\}$.

Seja $X$ um conjunto não vazio. Formalmente, dado um cardinal $\kappa$, uma sequência em $X$ é uma função $f: \kappa \rightarrow X$. Porém, ao invés de usar a notação de função para sequências, adotaremos a seguinte notação $\left(x_{\xi}: \xi<\kappa\right) \subset X$. Para o caso de sequências enumeráveis em $X$ usaremos $\left(x_{n}: n \in \omega\right) \subset X$.

Assim como os ordinais são os representantes canônicos para conjuntos bem ordenados os cardinais são os representantes canônicos para as cardinalidades dos conjuntos. Muitos autores preferem fazer uma distinção entre as notações de ordinais e cardinais. Nos ordinais é usado a letra grega " $\omega$ ” e para cardinais é utilizada a letra hebraica " $\aleph$ ”. Neste texto faremos o abuso de usar somente $\omega$ e deixaremos claro no contexto se o seu uso será de ordinal ou cardinal.

\section{4 Árvores}

Podemos ver uma árvore como um exemplo de conjunto parcialmente ordenado. Uma vantagem de se trabalhar com árvores é o seu recurso visual, pois podemos imaginar que começamos com um ponto (chamado de raíz ${ }^{8}$ ) e o restante dos pontos "sobem" em várias ramificações, tendo em mente que essas ramificações não se cruzam.

Definição 2.4.1. Seja $(T, \leq)$ um conjunto ordenado. Dizemos que $(T, \leq)$ é uma árvore se, para qualquer $t \in T$, o conjunto $\{s \in T: s \leq t\}$ é bem ordenado por $\leq$.

7 Equivalentemente, é o mesmo em dizer que a negação de $\mathrm{CH}$ não pode ser demonstrada pelos axiomas de ZFC.

8 Na verdade, pode não existir raíz. 
Definição 2.4.2. Dada $(T, \leq)$ uma árvore, dizemos que $R \subset T$ é um ramo se for uma cadeia maximal. Dizemos que $r \in T$ é raiz de $T$ se $r=\min T$. Note que $T$ pode não ter raiz. Caso $T$ não tenha uma raíz, podemos definir em $T$ um elemento $r$ menor que todos os minimais de $T$.

Proposição 2.4.3. Se $(T, \leq)$ é uma árvore e $p, q \in T$ são incomparáveis, então não existe $t \in T$ tal que $p, q \leq t$.

Demonstração. Suponha que exista $t \in T$ tal que $p, q \leq t$. Então, como $T$ é árvore, por hipótese temos que o conjunto $A=\{s \in T: s \leq t\}$ é bem ordenado. Note que $p, q \in A$. Daí o subconjunto $\{p, q\}$ possui um menor elemento e disso segue que $p$ e $q$ são comparáveis, o que é uma contradição.

Daremos um exemplo de árvore.

Exemplo 2.4.4. Considere o seguinte conjunto $\omega^{<\omega}=\bigcup\left\{\omega^{n}: n \in \omega\right\}$, onde $\omega^{n}$ é o cojunto das funções finitas $f: n=\{0, \ldots, n-1\} \rightarrow \omega$. Considere $\left(\omega^{<\omega}, \leq\right)$ com a ordem " $\leq$ " dada por $f \leq g$ se, e somente se, $f \subset g$ (g estende $f)$. Então $\left(\omega^{<\omega}, \leq\right)$ é uma árvore ${ }^{9}$.

De fato, seja $f \in \omega^{<\omega}$ e considere o conjunto $A_{f}=\left\{s \in \omega^{<\omega}: s \leq f\right\}$. Note que $A_{f} \neq \emptyset$. Seja $B \subset A_{f} \operatorname{com} B \neq \emptyset$. Como $B$ é não vazio, basta tomar a restrição de $f$ com menor domínio que pertença a $B$.

Note que $\omega^{<\omega}$ é enumerável. Para ver isso, basta notar que $\omega^{<\omega}=\bigcup\left\{\omega^{n}: n \in \omega\right\}$, por sua vez, que cada $\omega^{n}$ é enumerável.

Proposição 2.4.5. Se $R \subset \omega^{<\omega}$ é um ramo, então $\bigcup R^{10}$ é uma função de $\omega$ em $\omega$.

Demonstração.

1. $\bigcup R$ é uma função. De fato, sejam $(a, b),(a, c) \in \bigcup R$. Então existem $s, t \in R$ tal que $(a, b) \in s$ e $(a, c) \in t$. Sem perda de generalidade, suponha que $s \subset t^{11}$. Então $(a, b) \in t$ e, como $t$ é função, segue que $(a, b)=(a, c)$.

2. $\operatorname{dom} \bigcup R=\omega$. De fato, suponha que não. Seja $a \in \omega$ tal que $a$ seja o menor elemento que não esteja no domínio da função $\bigcup R$. Note que toda $f \in R$ é tal que $\operatorname{dom} f \subset a$.

Tome $f: a \rightarrow \omega$ tal que $f \in R$. Note que tal $f$ existe, pois $R$ é um ramo. Defina $g: a+1 \rightarrow \omega$ tal que $g(n)=f(n)$ se $n<a$ e $g(n)=7$ se $n=a$, por exemplo. Daí para todo $t \in R, t \subset g$ e $g \notin R$. Assim, $R \cup\{g\}$ é uma cadeia que contém $R$ o que é uma contradição com a maximalidade de $R$. Portanto, o domínio de $\bigcup R$ é todo o $\omega$.

Portanto $\bigcup R$ é uma função de $\omega$ em $\omega$ para cada $R$ ramo.

\footnotetext{
9 Para essa proposição e resultados futuros pensamos em funções como conjuntos de pares ordenados.

$10 \bigcup R$ é só uma notação curta para $\bigcup\{r: r \in R\}$.

$11 R$ é um conjunto totalmente ordenado por $\subset$.
} 
Note que, se tomarmos ramos diferentes, teremos funções diferentes.

Definição 2.4.6. Seja $(T, \leq)$ uma árvore. Dado $t \in T$, dizemos que $s \in T$ é um sucessor de $t$ se $t<s$ e, dado $r \in T$ tal que $t \leq r \leq s$, então $r=t$ ou $r=s$. Seja $p \in T$ definimos o conjunto dos sucessores de p como suc $(p)=\{t \in T: t$ é sucessor de $p\}$.

Proposição 2.4.7 (Lema de König (KÖNIG, 1926)). Se (T, $\leq$ ) é uma árvore infinita com uma raíz tal que o conjunto dos sucessores de cada elemento é finito, então $T$ tem um ramo infinito.

Demonstração. Seja $r$ a raiz de $T$ e para cada $p \in T$ defina os seguintes conjuntos:

$$
\begin{gathered}
\operatorname{suc}(p)=\{t \in T: t \text { é sucessor de } p\} \\
A_{p}=\{t \in T: p<t\}
\end{gathered}
$$

Vamos fazer a prova por indução. Chame $p_{0}=r$. Por hipótese, $\operatorname{suc}\left(p_{0}\right)$ é finito. Então escolha $p_{1} \in \operatorname{suc}\left(p_{0}\right)$ tal que $A_{p_{1}}$ seja infinito. Note que isso é possível, pois $T$ é infinita. Suponha feita a mesma construção até $p_{n}$, então escolha $p_{n+1} \in \operatorname{suc}\left(p_{n}\right)$ tal que $A_{p_{n+1}}$ seja infinito. Então $R=\left\{p_{n}: n \in \omega\right\}$ é um ramo infinito.

Definição 2.4.8. Dada uma árvore $(T, \leq)$, dizemos que $A \subset T$ é uma anticadeia no sentido de árvore se para todo $a, b \in A$ distintos, temos que a e b são incomparáveis.

Definição 2.4.9. Seja $(T, \leq)$ uma árvore. Chamamos de altura de $t \in T$ o (único) ordinal a que $\{s \in T: s<t\}$ é isomorfo (notação $h(t)$ ). Dado um ordinal $\alpha$, denotamos por Lev $\alpha(T) o$ conjunto $\{t \in T: h(t)=\alpha\}$ e chamamos de nível $\alpha$ da árvore $T$. Chamamos de altura de $T$ (notação $h(T)$ ) o primeiro ordinal $\alpha$ tal que $\operatorname{Lev}_{\alpha}(T)=\emptyset$.

Proposição 2.4.10. $\omega^{<\omega}$ é uma árvore de altura $\omega$ e possui infinitos ramos onde cada ramo tem tamanho enumerável.

Demonstração. Pela Exemplo 2.4.4 temos que $\omega^{<\omega}$ é uma árvore. Mostremos que $h\left(\omega^{<\omega}\right)=\omega$. Para isso, suponha que exista $t \in \omega^{<\omega}$ tal que $h(t)=\omega$, ou seja, o conjunto $\left\{s \in \omega^{<\omega}: s<t\right\}$ é isomorfo a $\omega$. Porém, $|t|=n$, para algum $n \in \omega$, e com isso, $\left\{s \in \omega^{<\omega}: s<t\right\}$ é finito. Portanto, $\left\{t \in \omega^{<\omega}: h(t)=\omega\right\}=\emptyset$.

Agora, suponha que exista $k<\omega$ tal que $\left\{t \in \omega^{<\omega}: h(t)=k\right\}=\emptyset$. Considere $s=$ $\{(0,0), \ldots,(k-1,0)\}$ e note que $h(s)=k$. Portanto, $\omega$ é o primeiro ordinal tal que $\operatorname{Lev}_{\omega}\left(\omega^{<\omega}\right)=$ $\emptyset$.

Finalmente, para cada função $f$ de $\omega$ em $\omega$ seja $R_{f}=\{f \mid n: n \in \omega\}$, ou seja, o conjunto das restrições finitas de $f^{12}$. Note que $R_{f}$ é um ramo e $\left|R_{f}\right|=\omega$.

$\left.\overline{12 \text { Podemos enxergar } R_{f} \text { como }\{\{(0, f(0))\}},\{(0, f(0)),(1, f(1))\},\{(0, f(0)),(1, f(1)),(2, f(2))\}, \ldots\right\}$. 
Os próximos resultados motivam a definição de anticadeia em árvores.

Proposição 2.4.11. Dada uma árvore $(T, \leq)$. Então $\preceq$ dada por $a \preceq b$ se $b \leq$ a é uma ordem. Vamos chamar esta de ordem reversa.

Demonstração.

1. $a \preceq a$, pois $a \leq a$ para todo $a \in T$;

2. $a \preceq b$ e $b \preceq a$ implica que $a=b$, pois $b \leq a$ e $a \leq b$ implicam que $a=b$.

3. $a \preceq b$ e $b \preceq c$ implica que $a \preceq c$, pois $b \leq a$ e $c \leq b$ implicam que $c \leq a$.

Proposição 2.4.12. Seja $(T, \leq)$ uma árvore e seja $A \subset T$. Então A é anticadeia no sentido de árvore se, e somente se, A é anticadeia no sentido de ordem, mas usando a ordem reversa.

Demonstração. Seja $A$ uma anticadeia no sentido de árvore e sejam $a, b \in A$. Então, pela Proposição 2.4.3, não existe $t \in T$ tal que $a, b \leq t$. Em termos de ordem reversa, isso implica que não existe $t \in T$ tal que $t \preceq a, b$. Portanto $A$ é uma anticadeia no sentido de ordem reversa. Reciprocamente, seja $A$ uma anticadeia no sentido de ordem reversa. Suponha que $A$ não seja uma anticadeia no sentido de árvore. Então existe $a, b \in A$ tal que $a \leq b$, então $a, b \leq b$ que implica $b \preceq a, b$ o que é um absurdo.

Corolário 2.4.13. Seja $(T, \leq)$ uma árvore. Dados $a, b \in T$ distintos. Então $a, b \in(T, \leq)$ são incomparáveis se, e somente se, $a, b \in(T, \preceq)$ são incompatíveis.

Definição 2.4.14. Seja $(T, \leq)$ uma árvore. Uma sub-árvore de $T$ é um subconjunto $T^{\prime} \subset T$ com a ordem induzida tal que para todo $x \in T^{\prime}$ e para todo $y \in T$ com $y \leq x$ temos que $y \in T^{\prime}$.

Definição 2.4.15. Uma árvore bem podada $(T, \leq)$ é uma árvore tal que $\mid$ Lev $_{0}(T) \mid=1$ (ou seja, tem raíz) e, para todo $x \in T$ e para todo $\alpha$ tal que $h(x)<\alpha<h(T)$, existe $y \in$ Lev $_{\alpha}(T)$ tal que $x<y$.

Proposição 2.4.16. Seja $(T, \leq)$ uma árvore de altura $\omega_{1}$ tal que para todo $\alpha<\omega_{1}$ temos $\left|\operatorname{Lev}_{\alpha}(T)\right|<\omega_{1}$. Então $T$ possui uma sub-árvore $T^{\prime}$ bem podada de altura $\omega_{1}$.

Demonstração. Seja $T^{\prime}=\left\{x \in T:|\{z \in T: x<z\}|=\omega_{1}\right\}$. 
1. $T^{\prime}$ é uma sub-árvore de $T$.

Sejam $x \in T^{\prime}$ e $y \in T$ com $y<x$, então $\{z \in T: y<z\} \supset\{z \in T: x<z\} \operatorname{logo} \mid\{z \in T:$ $y<z\}|\geq|\{z \in T: x<z\} \mid$. Como $|\{z \in T: x<z\}|=\omega_{1}$, então $|\{z \in T: y<z\}| \geq \omega_{1}$. Portanto $y \in T^{\prime}$.

2. $T^{\prime}$ é bem podada.

Sejam $x \in T^{\prime}$ fixo e $\alpha$ tal que $h(x)<\alpha<\omega_{1}$. Seja $Y=\left\{y \in \operatorname{Lev}_{\alpha}(T): x<y\right\}$. Pela definição de $T^{\prime}$ e pelo fato de que cada $\left|\operatorname{Lev}_{\beta}(T)\right|<\omega_{1}$ e $\mid\{z \in T: x<z$ e $\alpha<h(z)\} \mid=\omega_{1}$ temos que cada elemento deste último conjunto está acima de algum elemento de $Y$.

Como $|Y|<\omega_{1}$, existe $y \in Y$ tal que $|\{z \in T: z>y\}|=\omega_{1}$ e então $y \in T^{\prime}$ e $x<y$.

Note que por $T^{\prime}$ ser bem podada temos que $h\left(T^{\prime}\right)=\omega_{1}$.

\subsection{Noções Básicas de Topologia}

Esta seção tem como objetivo introduzir conceitos básicos de topologia geral que serão utilização ao longo da tese.

Definição 2.5.1. Dizemos que $(X, \tau)$ é um espaço topológico se $X$ é um conjunto e $\tau \subset \wp(X) e ́$ tal que satisfaz:

1. $X, \emptyset \in \tau$;

2. se $A, B \in \tau$, então $A \cap B \in \tau$;

3. se $\mathscr{A} \subset \tau$, então $\bigcup \mathscr{A} \in \tau$.

Cada elemento de $\tau$ é chamado de aberto.

Alguns problemas envolvendo topologia podem ser difíceis de trabalhar ou simplesmente intratáveis, em certos contextos, devido à grande quantidade de abertos que a topologia possui. Seria muito bom se pudéssemos lidar com uma quantidade menor abertos e isso refletir em toda topologia. Felizmente, existem tais objetos e são conhecidos como base de um espaço topológico.

Definição 2.5.2. Dado um conjunto $X$ e uma família de $\mathscr{B}$ subconjuntos de $X$, chamamos de topologia gerada por $\mathscr{B}$ o conjunto $[\mathscr{B}]=\bigcap\{\tau: \tau \in T\}$, onde $T=\{\tau \subset \wp(X): \tau$ é topologia sobre $X$ e $\mathscr{B} \subset \tau\}$. Em outras palavras, $[\mathscr{B}]$ é a menor topologia que contém $\mathscr{B}$.

Definição 2.5.3. Seja $(X, \tau)$ um espaço topológico. Dado $x \in X$, dizemos que $V \subset X$ é uma vizinhança de $X$ se existe um aberto $A \in \tau$ tal que $x \in A \subset V$. 
Definição 2.5.4. Seja $(X, \tau)$ um espaço topológico. Dizemos que $\mathscr{B} \subset \tau$ é uma base para $(X, \tau)$ se, para todo $x \in X$ e para todo $A \in \tau$ com $x \in A$, existir $B \in \mathscr{B}$ tal que $x \in B \subset A$.

Proposição 2.5.5. Uma família $\mathscr{B}$ de subconjuntos de $\tau$ é uma base para $(X, \tau)$, se, e somente se, para todo $A \in \tau \backslash\{\emptyset\}$ existir $\mathscr{B}^{\prime} \subset \mathscr{B}$ tal que $A=\bigcup \mathscr{B}^{\prime}$.

Demonstração. Suponha que $\mathscr{B}$ seja uma base de $\tau$ e seja $A \in \tau \backslash\{\emptyset\}$. Para cada elemento $x \in A$, existe um conjunto $B_{x} \in \mathscr{B}$ tal que $x \in B_{x} \subset A$. Segue, então, que $A=\bigcup_{x \in A} B_{x}$.

Reciprocamente, seja $x \in X$ e $A \in \tau \operatorname{com} x \in A$. Como podemos escrever $A=\bigcup \mathscr{B}^{\prime}$, tomamos $B \in \mathscr{B}^{\prime}$ tal que $x \in B$. Além disso, temos que $B \subset A$.

O conjunto $\mathbb{R}$ é um espaço topológico, com a topologia $\tau=\{A \subset \mathbb{R}:$ para todo $x \in A$ existe $\varepsilon>0$ tal que $] x-\varepsilon, x+\varepsilon[\subset A\}$. Esta é chamada de topologia usual em $\mathbb{R}$.

Agora, daremos um exemplo que será muito importante nesse texto, tal espaço será muito útil no Capítulo 5.

Definição 2.5.6. A reta $\mathbb{R}$ munido da topologia

$$
\tau=\{A \subset \mathbb{R}: \text { para todo } x \in A, \text { existe } r>0 \text { tal que }[x, x+r[\subset A\}
$$

é chamado de reta de Sorgenfrey e denotamos por $\mathbb{R}_{s}$.

Definição 2.5.7. Seja $(X, \leq)$ um conjunto totalmente ordenado. Chamamos de topologia da ordem sobre $(X, \leq)$ a topologia gerada pelos seguintes conjuntos (para todo $a, b \in X$ ):

1. $] a, b[=\{x \in X: a<x<b\}$;

2. $[a, b[=\{x \in X: a \leq x<b\}$, caso $a=\min X$;

3. $] a, b]=\{x \in X: a<x \leq b\}$, caso $b=\max X$.

As topologias usuais sobre $\mathbb{R}, \mathbb{Q}, \mathbb{N}$ e $[0,1]$ são topologias induzidas pelas ordens usuais dos respectivos conjuntos.

Definição 2.5.8. Seja $(X, \tau)$ espaço topológico. Dizemos que $X$ é conexo se, dados quaisquer abertos $A$ e $B$ de $X$ disjuntos tais que $A \cup B=X$ temos que $A=\emptyset$ ou $B=\emptyset$.

Observe que a reta de Sorgenfrey não é conexa. Basta notar que $\{x \in \mathbb{R}: x<0\} \cup\{x \in$ $\mathbb{R}: 0 \leq x\}=\mathbb{R}, \operatorname{com}\{x \in \mathbb{R}: x<0\},\{x \in \mathbb{R}: 0 \leq x\}$ abertos disjuntos e não vazios.

Proposição 2.5.9. Seja $(X, \leq)$ totalmente ordenado, conexo na topologia da ordem. Então qualquer $A \subset X$ não vazio e limitado possui supremo. 
Demonstração. Seja $A \subset X$ não vazio e limitado. Seja $B$ o conjunto dos limitantes superiores de $A$, i.e., para cada $b \in B$ temos que $a \leq b$ para todo $a \in A$.

Observe que :

- Se existir $a^{\prime} \in A$ tal que $a^{\prime}$ seja o máximo de $A$, então $a^{\prime}=\sup A$.

- Se existir $b^{\prime} \in B$ tal que $b^{\prime}$ seja o mínimo de $B$, então $b^{\prime}=\sup A$.

Agora, suponha que $A$ não tenha elemento máximo e que $B$ não tenha elemento mínimo. Note que $B \neq \emptyset$, pois caso contrário teríamos que $A=X$ e, como $A$ é limitado (digamos por $b$ ) e $b \in X$, segue que $b \in A, \operatorname{logo} A$ possuiria elemento máximo.

Seja $\tilde{A}=\{x \in X$ : existe $a \in A$ tal que $x \leq a\}$. Note que $\tilde{A} \neq \emptyset$, pois $A \subset \tilde{A}, B \neq \emptyset$, $X=A \cup B$ e $A \cap B=\emptyset$, pois $A$ não possui elemento máximo e $B$ não possui elemento mínimo. Afirmamos que $\tilde{A}$ e $B$ são abertos.

Para mostrar que $\tilde{A}$ é aberto. Seja $c \in \tilde{A}$. Se $\tilde{A}$ não for limitado inferiormente, existirá $\xi^{\prime \prime} \in \tilde{A}$ tal que $\xi^{\prime \prime}<c$. Como $A$ não possui elemento máximo e $A \subset \tilde{A}$, existe $\xi^{\prime} \in \tilde{A}$ tal que $c<\xi^{\prime}$. Assim $\left.c \in\right] \xi^{\prime \prime}, \xi^{\prime}\left[\subset \tilde{A}\right.$. Se $\tilde{A}$ for limitado inferiormente por $c$ então $c \in\left[c, \xi^{\prime}[\subset \tilde{A}\right.$. Portanto $\tilde{A}$ é aberto. De maneira análoga mostramos que $B$ é aberto. Logo, exibimos uma cisão não trivial de $X$ o que é um absurdo tendo em vista que $X$ é conexo. Portanto existe $\sup A$.

Definição 2.5.10. Seja $\mathscr{F}$ uma família de funções da forma $f_{\alpha}: X \rightarrow Y_{\alpha}, \alpha \in A$, em que X é um conjunto e cada $\left(Y_{\alpha}, \tau_{\alpha}\right)$ é um espaço topológico. Chamamos de topologia fraca induzida por $\mathscr{F}$ a topologia sobre $X$ gerada pelos conjuntos da forma $f_{\alpha}^{-1}[V]$, onde $\alpha \in A$ e $V \in \tau_{\alpha}$.

Definição 2.5.11. Seja $\left(\left(X_{\alpha}, \tau_{\alpha}\right)\right)_{\alpha \in A}$ uma família de espaços topológicos. Defina o produto $\operatorname{dos}\left(\left(X_{\alpha}, \tau_{\alpha}\right)\right)_{\alpha \in A}$ como

$$
\prod_{\alpha \in A} X_{\alpha}=\left\{x: A \rightarrow \bigcup_{\alpha \in A} X_{\alpha}: x(\alpha) \in X_{\alpha} \text { para todo } \alpha \in A\right\}
$$

com a topologia fraca induzida pelas funções $\left(\pi_{\alpha}: \alpha \in A\right)$ onde cada $\pi_{\alpha}: \prod\left\{X_{\beta}: \beta \in\right.$ $A\} \rightarrow X_{\alpha}$ é dada por $\pi_{\alpha}(x)=x(\alpha)$.

Esta topologia é chamada de topologia produto sobre $\prod_{\alpha \in A} X_{\alpha}$ (ou topologia de Tychonoff).

Definição 2.5.12. Sejam $(X, \tau)$ um espaço topológico. Dizemos que $F \subset X$ é um conjunto fechado se $X \backslash F$ é aberto.

Em qualquer espaço topológico $(X, \tau), X$ e $\emptyset$ são fechados, pois seus complementares são abertos (em particular, $X$ e $\emptyset$ são abertos e fechados).

Em $\mathbb{R}$, o intervalo fechado $[0,1]$ é fechado na topologia usual. 
Proposição 2.5.13. Seja $s \in 2^{<\omega}$ e seja $[s]=\left\{f \in 2^{\omega}: s \subset f\right\}^{13}$. Então $\left\{[s]: s \in 2^{<\omega}\right\}$ é uma base para a topologia produto de $2^{\omega}$

Demonstração. Seja $f \in 2^{\omega}$ e seja $V$ um aberto da topologia produto tal que $f \in V$. Por $V$ ser um aberto da topologia produto, podemos escrevê-lo como $V=\prod_{n \in \omega} V_{n}$, onde temos que $V_{n}=\{0\}$ ou $V_{n}=\{1\}$ para $n \in\left\{n_{1}, \ldots, n_{k}\right\}$ e $V_{n}=2$ para $n \notin\left\{n_{1}, \ldots, n_{k}\right\}$. Sem perda de generalidade, suponha que $n_{1}<\cdots<n_{k}$ e tome $s: n_{k} \rightarrow 2\left(s \in 2^{<\omega}\right)$ tal que $s(n)=f(n)$ para todo $n \in$ $\left\{n_{1}, \ldots, n_{k}\right\}$. Portanto $f \in[s] \subset V$.

Definição 2.5.14. Seja $(X, \tau)$ um espaço topológico. Dizemos que Á é uma cobertura (ou recobrimento) de $X$ se $\bigcup \mathscr{A}=X$. Chamamos de cobertura aberta se os elemento de $\mathscr{A}$ são abertos.

Definição 2.5.15. Dizemos que o espaço topológico $(X, \tau)$ é um espaço compacto se toda cobertura aberta $\mathscr{A}$ possui uma subcobertura $\mathscr{A}^{\prime}$ (i.e., $\mathscr{A}^{\prime} \subset \mathscr{A}$ e $\left.\cup \mathscr{A}^{\prime}=X\right)$ finita.

Definição 2.5.16. Dizemos que o espaço topológico $(X, \tau)$ é um espaço localmente compacto se para todo ponto $x$ existe uma vizinhança $U$ contendo o ponto $x$ tal que $\bar{U}$ é um subespaço compacto de X.

Definição 2.5.17. Seja $(X, \tau)$ um espaço topológico e $\mathscr{C}$ uma cobertura aberta para X. Dizemos que $\mathscr{R} \subset \tau$ é um refinamento da cobertura $\mathscr{C}$ se dado $R \in \mathscr{R}$ existe $C \in \mathscr{C}$ tal que $R \subset C$. Seja $\mathscr{A} \subset \wp(X)$. Dizemos que $\mathscr{A}$ é localmente finito se para cada $x \in X$ existe uma vizinhança $V$ de $x$ tal que $\{V \cap A: A \in \mathscr{A}\}$ é finito. Um espaço é dito ser paracompacto se toda cobertura aberta admite um refinamento aberto localmente finito.

Definição 2.5.18. Um espaço topológico X é de Lindelöf se toda cobertura aberta possui uma subcobertura enumerável.

Note que todo espaço compacto é de Lindelöf. A reta de Sorgenfrey e $\omega^{\omega}$ são espaços de Lindelöf.

Definição 2.5.19. Seja $(X, \tau)$ um espaço topológico e $A \subset X$. Definimos o fecho de $A$ como sendo $\bar{A}=\bigcap\{F \subset X: F$ éfechado e $A \subset F\}$

Teorema 2.5.20. Se Xé regular e Lindelöf então X é paracompacto.

Demonstração. Seja $\mathscr{U}$ uma cobertura aberta para o espaço $X$. Como $X$ é regular temos que, para cada $x \in X$, existem abertos $U_{x}, V_{x} \subset X$ tais que $x \in U_{x} \subset \overline{U_{x}} \subset V_{x}$ e $V_{x}$ está contido em $13[s]$ é o cinjunto das funções de $2^{\omega}$ que estendem $s$. 
algum elemento de $\mathscr{U}$. Seja $\left\{U_{x_{n}}: n \in \omega\right\}$ uma subcobertura enumerável de $\left\{U_{x}: x \in X\right\}$. Então para cada $n \in \omega$ os conjuntos

$$
W_{n}=V_{x_{n}} \backslash\left(\overline{U_{x_{1}}} \cup \overline{U_{x_{2}}} \cup \cdots \cup \overline{U_{x_{n-1}}}\right)
$$

são abertos e formam uma cobertura para $X$. De fato seja $x \in X$ então temos que $x \in W_{n(x)}$, onde $n(x)$ é o menor número natural $n$ tal que $x \in V_{n}$. A cobertura $\left\{W_{x_{n}}: n \in \omega\right\}$ é um refinamento de $\mathscr{U}$ que é localmente finito pelo fato de que $U_{x_{j}} \cap W_{i}=\emptyset$ para $i>j$.

Definição 2.5.21. Seja $(X, \tau)$ um espaço topológico. Dizemos que X é separável se existe um subconjunto enumerável $D \subset X$ e denso em $X$, i.e., $\bar{D}=X$.

Lema 2.5.22. Seja X um espaço topológico separável. Seja $A \subset X$ subespaço aberto, então A é separável.

Demonstração. Seja $D \subset X$ denso enumerável. Vamos mostrar que $A \cap D$ é denso em $A$. Seja $U$ um aberto em $X$ tal que $U \cap A \neq \emptyset$ (com isso $U \neq \emptyset$ ). Como $U \cap A$ é aberto e não vazio em $X$ (pois $A$ é aberto em $X$ ) segue que $(U \cap A) \cap(A \cap D)=(U \cap A) \cap D \neq \emptyset$.

Definição 2.5.23. $O$ espaço $(X, \tau)$ é $T_{0}$ se para $x, y \in X$ distintos existir um aberto $U$ tal que $(x \in U$ e $y \notin U)$ ou $(x \notin U$ e $y \in U)$. Dizemos que $(X, \tau)$ é $T_{1}$ se para $x, y \in X$ distintos existir um aberto $U$ tal que $x \in U$ e y $\notin U$. Dizemos que $(X, \tau)$ é $T_{2}$ ou de Hausdorff se, para $x, y \in X$ distintos, existirem abertos $U$ e $V$ tais que $x \in U$ e $y \in V \operatorname{com} U \cap V=\emptyset$.

Consideraremos todos os espaços em que trabalharemos $T_{1}$, caso contrário mencionaremos isso.

Definição 2.5.24. Dizemos que $(X, \tau)$ é regular se para quaisquer $x \in X$ e $F \subset X$ fechado tais que $x \notin F$, existirem $A, B$ abertos tais que $x \in A, F \subset B$ e $A \cap B=\emptyset$.

Num espaço topológico regular, os abertos "separam” pontos de fechados.

Proposição 2.5.25. Sejam $(X, \tau)$ um espaço topológico. O espaço $(X, \tau)$ é regular se, e somente se, para todo $x \in X$ e para todo aberto $V$ tal que $x \in V$, existir um aberto A tal que $x \in A \subset \bar{A} \subset V$.

Demonstração. Suponha que $(X, \tau)$ seja regular. Sejam $x \in V$ e $V \in \tau$ tal que $x \in V$. Note que $X \backslash V$ é um fechado e $x \notin X \backslash V$. Então existem $A, B$ abertos disjuntos tais que $x \in A$ e $X \backslash V \subset B$.

Mostremos que $\bar{A} \subset V$ : De fato, $X \backslash B \subset V$ e $A \subset X \backslash B$ (pois $A \cap B=\emptyset$ ). Como $X \backslash B$ é fechado, temos $\bar{A} \subset X \backslash B \subset V$, e assim $x \in A \subset \bar{A} \subset V$.

Reciprocamente, mostremos que $(X, \tau)$ é regular. Sejam $x \in X$ e $F \subset X$ fechado tal que $x \notin F$. Então $X \backslash F$ é aberto e contém $x$. Logo, existe $A$ aberto tal que $x \in A \subset \bar{A} \subset X \backslash F$. Note que $x \in A, F \subset X \backslash \bar{A}$ e $A \cap(X \backslash \bar{A})=\emptyset$. 


\subsection{Jogos Topológicos e Princípios Seletivos}

Os conceitos de jogos topológicos, princípios seletivos e estratégias serão apresentados nessa seção de maneira informal e por meio de exemplos. No final do capítulo daremos uma aplicação muito interessante do Jogo de Choquet. Este jogo será usado para demonstrar as versões do Teorema de Baire para espaços localmente compactos e métricos.

\subsubsection{Alguns Exemplos de Jogos Topológicos e Princípios Seletivos}

Veremos, agora, alguns exemplos de princípios seletivos e jogos topológicos.

Definição 2.6.1. Seja X um espaço topológico. Definimos o jogo de Choquet em $X$ da seguinte forma: Na 0-ésima rodada, o Jogador I joga um aberto não vazio $U_{0}$ e o Jogador II joga um aberto não vazio $V_{0} \subset U_{0}$. Na próxima rodada o Jogador I joga um aberto não vazio $U_{1} \subset V_{0} e$ o Jogador II, por sua vez, joga um aberto não vazio $V_{1} \subset U_{1}$. Na n-ésima rodada o Jogador I joga um aberto não vazio $U_{n} \subset V_{n-1}$. O Jogador II toma um aberto não vazio $V_{n} \subset U_{n}$. Dizemos que o Jogador II vence se $\bigcap\left\{V_{n}: n \in \omega\right\}=\bigcap\left\{U_{n}: n \in \omega\right\} \neq \emptyset$. Portanto, o Jogador I vence se $\bigcap\left\{V_{n}: n \in \omega\right\}=\bigcap\left\{U_{n}: n \in \omega\right\}=\emptyset$.

Uma estratégia para o Jogador I nesse jogo é uma "regra" que nos diz como o Jogador I deve jogar tendo em vista as jogadas anteriores feitas pelo Jogador II e feitas por "ele" próprio. $\mathrm{Na}$ verdade este conceito pode ser aplicado a todos os jogos topológicos. Além disso, de maneira análoga podemos definir uma estratégia para o Jogador II.

Formalmente, uma estratégia $\sigma$ para o jogo de Choquet é uma função que sai do conjunto de jogadas válidas e chega na topologia. A estratégia $\sigma$, digamos para o Jogador I, funciona da seguinte maneira: O Jogador I começa jogando $\sigma(\emptyset)=U_{0}$ aberto não vazio, então o Jogador II responde com algum aberto não vazio $V_{0} \subset \sigma(\emptyset)$. Na próxima rodada o Jogador I responde joga um aberto não vazio $\sigma\left(V_{0}\right) \subset V_{0}$. Na $n$-ésima rodada o Jogador I joga $\sigma\left(V_{0}, \ldots, V_{n-1}\right)$ e o Jogador II toma $V_{n} \subset \sigma\left(V_{0}, \ldots, V_{n-1}\right)$. Nos capítulos seguintes adotaremos essa notação de estratégia.

Por mais pedante que possa soar, diremos que uma estratégia para o Jogador I (ou para o Jogador II) é vencedora se ela garante a vitória para o Jogador I (ou para o Jogador II). Seja $J(X)$ um jogo topológico com dois jogadores. Em alguns momentos, usaremos I $\uparrow J(X)$ (ou II $\uparrow J(X)$ ) para representar que o Jogador I (ou o Jogador II) possui estratégia vencedora no jogo $J(X)$.

Além dos jogos topológicos, existem objetos similares chamados de princípios seletivos. Sejam $(X, \tau)$ um espaço topológico e $\mathscr{A}, \mathscr{B}$ conjuntos ${ }^{14}$. Diremos que $S_{1}(\mathscr{A}, \mathscr{B})$ é a seguinte afirmação: Dado $\left(\mathscr{C}_{n}: n \in \omega\right) \subset \mathscr{A}$, para cada $n \in \omega$, existe $A_{n} \in \mathscr{C}_{n}$ tal que $\left(A_{n}: n \in \omega\right) \in \mathscr{B}$. Vejamos alguns exemplos de princípios seletivos:

14 Podendo ser classes próprias também. 
Seja $X$ um espaço topológico e $\mathscr{O}$ o conjunto das coberturas abertas para o espaço $X$. Considere o seguinte princípio $S_{1}(\mathscr{O}, \mathscr{O})$. Essa notação nos diz que dada uma sequência de coberturas abertas $\left(\mathscr{C}_{n}: n \in \omega\right)$, para cada $n \in \omega$ existe $C_{n} \in \mathscr{C}_{n}$ tal que $\left\{C_{n}: n \in \omega\right\}$ é uma cobertura aberta para $X$. Seja $\mathscr{D}$ o conjunto dos subconjuntos densos de $X$ e considere o princípio $S_{1}(\mathscr{D}, \mathscr{D})$. Esse princípio nos diz que, dada uma sequência de densos $\left(D_{n}: n \in \omega\right)$, para cada $n \in \omega$ existe um ponto $d_{n} \in \mathscr{D}_{n}$ tal que $\left\{d_{n}: n \in \omega\right\}$ é denso em $X$.

Note que se mudarmos o número " 1 " do índice, por exemplo para "2", teremos o princípio $S_{2}(\mathscr{A}, \mathscr{B})$ e isso significa que, dado $\left(\mathscr{C}_{n}: n \in \omega\right) \subset \mathscr{A}$, para cada $n \in \omega$ existem $A_{n}, B_{n} \in \mathscr{C}_{n}$ tais que $\left\{A_{n}, B_{n}: n \in \omega\right\} \in \mathscr{B}$. Além desses princípios podemos definir o princípio seletivo $S_{\text {fin }}(\mathscr{A}, \mathscr{B})$, que nos diz que, dado $\left(\mathscr{C}_{n}: n \in \omega\right) \subset \mathscr{A}$, para cada $n \in \omega$ existe $F_{n} \subset \mathscr{C}_{n}$ onde $F_{n}$ é finito tal que $\bigcup\left\{F_{n}: n \in \omega\right\} \in \mathscr{B}$.

Dado um princípio seletivo $S_{1}(\mathscr{A}, \mathscr{B})$ temos o jogo $G_{1}(\mathscr{A}, \mathscr{B})$ associado a este. O jogo $G_{1}(\mathscr{A}, \mathscr{B})$ também será realizado por meio dos jogadores I e II em enumeráveis rodadas. Na $n$-ésima rodada o Jogador I jogará $\mathscr{C}_{n} \in \mathscr{A}$ e o Jogador II escorelhá $A_{n} \in \mathscr{C}_{n}$. Diremos que o Jogador II vence se $\left\{A_{n}: n \in \omega\right\} \in \mathscr{B}$. Os jogos $G_{k}(\mathscr{A}, \mathscr{B})$ para algum $k \in \omega$ e $G_{\text {fin }}(\mathscr{A}, \mathscr{B})$ são derivados de maneira análoga dos princípios $S_{k}(\mathscr{A}, \mathscr{B})$ e $S_{\text {fin }}(\mathscr{A}, \mathscr{B})$.

Como se relacionam os princípios seletivos com os jogos topológicos derivados deste? Basta notar que, em geral, a negação do princípio $S_{k}(\mathscr{A}, \mathscr{B})$ implica que o Jogador I possui estratégia vencedora em $G_{k}(\mathscr{A}, \mathscr{B})$ para algum $k \in \omega$. De maneira análoga, a negação do princípio $S_{\text {fin }}(\mathscr{A}, \mathscr{B})$ implica que o Jogador I possui estratégia vencedora em $G_{\text {fin }}(\mathscr{A}, \mathscr{B})$.

Os jogos $G_{1}(\mathscr{O}, \mathscr{O})$ e $G_{f i n}(\mathscr{O}, \mathscr{O})$ são conhecidos como jogo de Rothberger e jogo de Menger respectivamente. No jogo de Rothberger o Jogador I joga coberturas abertas para o espaço $X$ e o Jogador II escolhe um elemento de cada cobertura. O Jogador II vence se o conjunto dos elementos que ele escolheu forma uma cobertura aberta. No jogo de Menger, o Jogador I joga coberturas abertas para o espaço $X$ e o Jogador II escolhe uma quantidade finita de elementos de cada cobertura. O Jogador II vence se o conjunto dos elementos que ele escolheu forma uma cobertura aberta. Além disso, temos o jogo $G_{1}(\mathscr{D}, \mathscr{D})$. Neste jogo em cada rodada o Jogador I joga um subconjunto denso de $X$ e o Jogador II responde escolhendo um ponto desse subconjunto denso jogado pelo Jogador I. O jogador II vence se o conjunto formado pelos pontos que escolheu é denso em $X$.

Em geral, não é verdade que se o Jogador I possui estratégia vencedora em $G_{k}(\mathscr{A}, \mathscr{B})$ para algum $k \in \omega$, então vale a negação de $S_{k}(\mathscr{A}, \mathscr{B})$. Da mesma forma, em geral, não é verdade que se o Jogador I possui estratégia vencedora em $G_{\text {fin }}(\mathscr{A}, \mathscr{B})$, então vale a negação de $S_{\text {fin }}(\mathscr{A}, \mathscr{B})$. Porém no artigo de (PAWLIKOWSKI, 1994) foi mostrado que para os jogos de Rothberger e Menger essa implicação é válida.

Nem todos os jogos topológicos são facilmente derivados de princípios seletivos. Além do jogo de Choquet, no próximo capítulo veremos o jogo $P(X)$ e nesse jogo o Jogador I na 
primeira rodada joga uma cobertura aberta $\mathscr{C}_{0}$ para o espaço $X$ e o Jogador II escolhe um elemento $C_{0}$ dessa cobertura. Na rodada seguinte, o Jogador I joga uma cobertura aberta $\mathscr{C}_{1}$ para $C_{0}$ e o Jogador II escolhe $C_{1} \in \mathscr{C}_{1}$ e assim por diante. O que esses dois jogos tem em comum? Nos dois jogos o Jogador I joga dentro dos elemento escolhido pelo Jogador II na rodada anterior. Sendo assim fica muito difícil explicitar um conjunto $\mathscr{A}$ para que tenhamos, por exemplo, $S_{1}(\mathscr{A}, \mathscr{B})$ levando em conta todas as possibilidades.

\subsubsection{Propriedades e Aplicações do Jogo de Choquet}

Veremos algumas propriedades do Jogo de Choquet e algumas aplicações em topologia, em particular, na demonstração do Teorema de Baire.

Definição 2.6.2. Um espaço topológico não vazio é dito ser um espaço de Choquet se o Jogador II possui estratégia vencedora no jogo de Choquet.

Proposição 2.6.3. O produto de dois espaços de Choquet é um espaço de Choquet.

Demonstração. Denotaremos o jogo de Choquet jogado no espaço $X$ como $G_{X}$ e o jogo de Choquet jogado no espaço $Y$ como $G_{Y}$. Denotamos por $\mathrm{I}_{X}, \mathrm{II}_{X}$ os respectivos jogadores I e II do jogo $G_{X}$ e denotaremos por $\mathrm{I}_{Y}, \mathrm{II}_{Y}$ os respectivos jogadores I e II do jogo $G_{Y}$. Sejam $X$ e $Y$ espaços topológicos de Choquet, i.e., o Jogador $\mathrm{II}_{X}$ possui estratégia vencedora em $G_{X} \mathrm{e}$ o Jogador $\mathrm{II}_{Y}$ possui estratégia vencedora em $G_{Y}$. Agora considere $G_{X \times Y}$ o jogo de Choquet jogado no espaço $X \times Y$. Sejam $\mathrm{I}_{X \times Y}, \mathrm{II}_{X \times Y}$ os respectivos jogadores I e II do jogo $G_{X \times Y}$.

Seja $U_{0}$ a primeira jogada do Jogador $\mathrm{I}_{X \times Y}$, então podemos tomar $U_{0}^{X} \times U_{0}^{Y} \subset U_{0}$ onde $U_{0}^{X} \subset X$ e $U_{0}^{Y} \subset Y$ são abertos não vazios. Usando as respectivas estratégias vencedoras do Jogador $\mathrm{II}_{X}$ em $G_{X}$ e do Jogador $\mathrm{II}_{Y}$ em $G_{Y}$, temos que o Jogador $\mathrm{II}_{X}$ responde $\operatorname{com} V_{0}^{X} \subset U_{0}^{X}$ e o Jogador $\mathrm{II}_{Y}$ responde com $V_{0}^{Y} \subset U_{0}^{Y}$. Então o Jogador $\mathrm{II}_{X \times Y}$ escolhe $V_{0}:=V_{0}^{X} \times V_{0}^{Y} \subset$ $U_{0}^{X} \times U_{0}^{Y} \subset U_{0}$ no jogo $G_{X \times Y}$. Agora, o Jogador $\mathrm{I}_{X \times Y}$ joga com $U_{1} \subset V_{0}$. Novamente, podemos tomar $U_{1}^{X} \times U_{1}^{Y} \subset U_{1}$ e assim o Jogador $\mathrm{II}_{X}$ responde com $V_{1}^{X} \subset U_{1}^{X}$ e o Jogador $\mathrm{II}_{Y}$ responde com $V_{1}^{Y} \subset U_{1}^{Y}$. Logo, o Jogador $\mathrm{II}_{X \times Y}$ ecolhe $V_{1}:=V_{1}^{X} \times V_{1}^{Y} \subset U_{1}^{X} \times U_{1}^{Y} \subset U_{1}$.

Continuando esse processo recursivavente teremos:

$$
U_{0} \supset V_{0} \supset U_{1} \supset V_{1} \supset \cdots U_{n} \supset V_{n} \supset \cdots
$$

$\operatorname{com} \bigcap\left\{U_{n}: n \in \omega\right\}=\bigcap\left\{V_{n}: n \in \omega\right\}=\bigcap\left\{V_{n}^{X} \times V_{n}^{Y}: n \in \omega\right\}=\left(\bigcap\left\{V_{n}^{X}: n \in \omega\right\}\right) \times\left(\bigcap\left\{V_{n}^{Y}: n \in\right.\right.$ $\omega\})$. Como $\bigcap\left\{V_{n}^{X}: n \in \omega\right\} \neq \emptyset$ e $\bigcap\left\{V_{n}^{Y}: n \in \omega\right\} \neq \emptyset$, temos que $\bigcap\left\{U_{n}: n \in \omega\right\}=\bigcap\left\{V_{n}: n \in\right.$ $\omega\} \neq \emptyset$.

Agora, mostraremos uma aplicação muito interessante do Jogo de Choquet. Para isso, considere a seguinte definição: 
Definição 2.6.4. Dizemos que $(X, \tau)$ é um espaço de Baire se, para toda família $\left\{A_{n}: n \in \omega\right\}$ de abertos densos em $X$, tivermos que $\bigcap\left\{A_{n}: n \in \omega\right\}$ é denso em $X$.

Este próximo resultado mostra que o Jogo de Choquet está relacionado com espaços de Baire.

Teorema 2.6.5 (Oxtoby). Um espaço topológico não vazio X é de Baire se, e somente se, o Jogador I não possui estratégia no jogo de Choquet.

Demonstração. Dada uma estratégia vencedora $\sigma$ para o Jogador I, para este Teorema, enxergaremos essa estratégia da seguinte maneira: $\mathrm{O}$ jogador I começa jogando $U_{0}$ onde $\left(U_{0}\right) \in \sigma$, então o Jogador II responde com algum aberto não vazio $V_{0} \subset U_{0}$. Temos $\left(U_{0}, V_{0}\right) \in \sigma$. Sendo assim, o Jogador I responde jogando um aberto não vazio $U_{1} \subset V_{0}$ tal que $\left(U_{0}, V_{0}, U_{1}\right) \in \sigma$. E assim por diante.

Suponha que $X$ não seja de Baire e vamos mostrar que o Jogador I possui estratégia vencedora. Se $X$ é um espaço que não é de Baire, temos que existe $U_{0} \subset X$ aberto não vazio e $\left\{G_{n}: n \in \omega\right\}$ uma família de abertos densos em $X$ tais que $U_{0} \cap\left(\cap\left\{G_{n}: n \in \omega\right\}\right)=\emptyset$. Então o Jogador I começa jogando $U_{0}$ e o Jogador II responderá com $V_{0} \subset U_{0}$. Note que $V_{0} \cap G_{0} \neq \emptyset$, então na próxima rodada o Jogador I jogará $U_{1}=V_{0} \cap G_{0} \subset V_{0}$ e o Jogador II escolherá $V_{1} \subset U_{1}$. Na rodada seguinte o Jogador I jogará $U_{2}=V_{1} \cap G_{1} \subset V_{1}$ o Jogador II responderá com $V_{2} \subset U_{2}$ e assim por diante. No final do jogo teremos que $\bigcap\left\{U_{n}: n \in \omega\right\} \subset \bigcap\left\{G_{n} \cap V_{n}: n \in \omega\right\} \subset$ $\bigcap\left\{G_{n} \cap U_{0}: n \in \omega\right\}=\emptyset$. Com isso descrevemos uma estratégia vencedora para o Jogador I.

Agora, suponha que o Jogador I possui uma estratégia vencedora $\sigma$ e vamos mostrar que $X$ não é de Baire. Para isso, construiremos uma sub-árvore ${ }^{15}$ não vazia e bem podada $S \subset \sigma$ tal que para qualquer $p=\left(U_{0}, V_{0}, \ldots, U_{n}\right) \in S$ o conjunto $\mathscr{U}_{p}=\left\{U_{n+1}:\left(U_{0}, V_{0}, \ldots, U_{n}, V_{n}, U_{n+1}\right) \in S\right\}$ consiste de abertos dois a dois disjuntos e $\bigcup \mathscr{U}_{p}$ é denso em $U_{n}$. Assumindo possível a construção de $S$, seja $W_{n}=\bigcup\left\{U_{n}:\left(U_{0}, V_{0}, \ldots, U_{n}\right) \in S\right\}$. Segue que $W_{n}$ é aberto e denso em $U_{0}$ para cada $n \in \omega^{16}$, onde $U_{0}$ é o primeiro movimento de acordo com $\sigma$. Afirmamos que $\bigcap\left\{W_{n}: n \in \omega\right\}=\emptyset$. Caso contrário, se $x \in \bigcap\left\{W_{n}: n \in \omega\right\}$ então $x \in W_{n}$ para todo $n \in \omega$ e assim existe $U_{n} \in W_{n}$ com $\left(U_{0}, V_{0}, \ldots, U_{n}\right) \in S$ tal que $x \in U_{n}$ e isso implica que $x \in U_{0}, V_{0}, \ldots, U_{n}$. Portanto existe um único $\left(U_{0}, V_{0}, U_{1}, V_{1}, \ldots\right)$ em $S$ com $x \in U_{n}$ para cada $n \in \omega$. Suponha que exista outro $\left(U_{0}^{\prime}, V_{0}^{\prime}, U_{1}^{\prime}, V_{1}^{\prime}, \ldots\right)$ em $S$ com $x \in U_{n}^{\prime}$ para cada $n \in \omega$, seja $k \in \omega$ o primeiro índice tal que $U_{k} \neq U_{k}^{\prime}$. Logo $U_{k}, U_{k}^{\prime} \in \mathscr{U}_{p}$ para $p=\left(U_{0}, V_{0}, \ldots, U_{k-1}\right)$ e isso implica que $U_{k} \cap U_{k}^{\prime}=\emptyset$. Portanto, $\bigcap\left\{U_{n}: n \in \omega\right\} \neq \emptyset$, contradizendo o fato de que $\left(U_{0}, V_{0}, U_{1}, V_{1}, \ldots\right)$ faz parte da estratégia vencedora $\sigma$ do Jogador I. Para cada $n \in \omega$ seja $\tilde{W}_{n}=W_{n} \cup\left(X \backslash \overline{U_{0}}\right)$, note que cada $\tilde{W}_{n}$ é um

\footnotetext{
15 Para o jogo de Choquet, podemos definir uma estratégia para o Jogador I como sendo uma árvore $T$. Seja $T$ a árvore das posições legais do jogo de Choquet, i.e, $T$ consiste de todas as sequências finitas $\left(W_{0}, \ldots, W_{n}\right)$, onde $W_{i}$ é um subconjunto aberto não vazio de $X$ e $W_{0} \supseteq W_{1} \supseteq \cdots \supseteq W_{n}$. Note que, de fato, $(T, \leq)$ é uma árvore, onde $\leq$ é dado por " $\supseteq$ ". Portanto, $T$ é uma árvore bem podada em $\{W \subset X: W$ é aberto não vazio de $X\}$.

16 Segue de $\bigcup \mathscr{U}_{p}$ ser denso em $U_{0}$.
} 
aberto denso em $X^{17}$. Assim, $U_{0} \cap\left(\bigcap\left\{\tilde{W}_{n}: n \in \omega\right\}\right)=U_{0} \cap\left(\bigcap\left\{W_{n}: n \in \omega\right\}\right)=\emptyset$ e portanto $\bigcap\left\{\tilde{W}_{n}: n \in \omega\right\}$ não é denso em $X$.

Para construir $S$ determinamos indutivamente sequências de $\sigma$ de tamanho $n \in \omega$ e incluimos em $S$. Se $\left(U_{0}, V_{0}, \ldots, U_{n-1}, V_{n-1}\right) \in S$, então $\left(U_{0}, V_{0}, \ldots, U_{n-1}, V_{n-1}, U_{n}\right) \in S$ para um único $U_{n} \operatorname{com}\left(U_{0}, V_{0}, \ldots, U_{n-1}, V_{n-1}, U_{n}\right) \in \sigma^{18}$. Agora, se $p=\left(U_{0}, V_{0}, \ldots, U_{n}\right) \in S$ note que para qualquer aberto não vazio $V_{n} \subset U_{n}$ se $V_{n}^{*}=U_{n+1}$ é a jogada que $\sigma$ pede que o Jogador I faça em seguida, então $U_{n+1}$ é um subconjunto aberto não vazio de $V_{n}$. Usando o Lema de Zorn (ou o argumento de exaustão transfinita) seja $\mathscr{V}_{p}$ a coleção maximal de subconjuntos abertos nãos vazios $V_{n} \subset U_{n}$ tal que $\left\{V_{n}^{*}: V_{n} \in \mathscr{V}_{p}\right\}$ são dois a dois disjuntos. Acrescente em $S$ todos $\left(U_{0}, V_{0}, \ldots, U_{n}, V_{n}, V_{n}^{*}\right) \operatorname{com} V_{n} \in \mathscr{V}_{p}$. Então $\mathscr{U}_{p}=\left\{U_{n+1}:\left(U_{0}, V_{0}, \ldots, U_{n}, V_{n}, U_{n+1}\right) \in S\right\}=$ $\left\{V_{n}^{*}: V_{n} \in \mathscr{V}_{p}\right\}$ é uma família maximal em que seus elementos são dois a dois disjuntos e $\bigcup\left\{U_{n+1} \in \mathscr{U}_{p}\right\}$ é denso em $U_{n}$ pela maximalidade de $\mathscr{V}_{p}$. Pois se $\tilde{V}_{n} \subset U_{n}$ é um aberto não vazio disjunto de $\bigcup\left\{U_{n+1} \in \mathscr{U}_{p}\right\}$, então $\mathscr{V}_{p} \cup\left\{\tilde{V}_{n}\right\}$ viola a maximalidade de $\mathscr{V}_{p}$.

Como consequência temos:

Corolário 2.6.6. Se $X$ é um espaço de Choquet então $X$ é de Baire. Alem disso, se X e $Y$ são espaços de Choquet. Então $X \times Y$ é de Baire.

Demonstração. O espaço $X$ é de Choquet se o Jogador II tem estatégia vencedora no jogo de Choquet. Isso implica que o Jogador I não possui estratégia vencedora. Então pelo Teorema de Oxtoby segue que $X$ é de Baire.

Se $X$ e $Y$ espaços de Choquet então, pela Proposição 2.6.3, o produto $X \times Y$ é de Choquet. Isso implica que o Jogador I não possui estratégia vencedora no jogo de Choquet jogado em $X \times Y$. Pelo Teorema de Oxtoby, temos que $X \times Y$ é de Baire.

Observe que, em geral, não é verdade que se $X$ é um espaço de Baire então teremos que tal espaço seja de Choquet. Suponha, por absurdo, que $X$ ser de Baire implica que $X$ seja de Choquet. Então $X \times X$ é de Choquet pela Proposição 2.6.3. Daí, novamente, pelo Corolário 2.6.6, temos que $X \times X$ é de Baire. Logo isso implicaria que o quadrado de espaços de Baire é de Baire. Mas em (COHEN, 1976) existe um exemplo de um espaço de Baire cujo o quadrado não é de Baire.

Mesmo não valendo que todo espaço de Baire é de Choquet, ainda temos, por exemplo:

Proposição 2.6.7. Seja X um espaço topológico compacto Hausdorff. Então X é de Choquet.

Demonstração. Note que por $X$ ser compacto e Hausdorff implica que $X$ é regular. Seja $U_{0} \subset X$ a primeira jogada do Jogador I. Tome $x_{0} \in U_{0}$. Então existe $V_{0} \subset U_{0}$ aberto em $X$ tal que $x_{0} \in$

17 Perceba que $\overline{W_{n}}$ em $U_{0}$ é igual à $U_{0} \cap \overline{W_{n}}$ para cada $n \in \omega$.

18 Isso se dá pela natureza do Jogo de Choquet. Onde o Jogador I escolherá um único elemento $U_{n}$ tendo em vista os movimentos realizados por ambos jogadores anteriormente. 
$V_{0} \subset \overline{V_{0}} \subset U_{0}$. Então o Jogador II responde com $V_{0} \subset U_{0}$. Na $n$-ésima jogada, tome $x_{n-1} \in U_{n-1}$ e seja $V_{n-1} \subset U_{n-1}$ tal que $x_{n-1} \in V_{n-1} \subset \overline{V_{n-1}} \subset U_{n-1}$. Assim, $\left\{V_{n}: n \in \omega\right\}$ corresponde a todas as jogadas do Jogador II com $V_{n} \subset \overline{V_{n}} \subset U_{n} \subset V_{n-1} \subset \overline{V_{n-1}}$ para todo $n \in \omega$. Daí $\bigcap\left\{V_{n}: n \in \omega\right\}=$ $\bigcap\left\{\overline{V_{n}}: n \in \omega\right\}$. Como $\left\{\overline{V_{n}}: n \in \omega\right\}$ tem p.i.f. segue que $\bigcap\left\{V_{n}: n \in \omega\right\}=\bigcap\left\{\overline{V_{n}}: n \in \omega\right\} \neq \emptyset^{19}$. Portanto o Jogador II tem estratégia vencedora no jogo de Choquet.

Agora, veremos que a partir do jogo de Choquet podemos demonstrar o Teorema de Baire para espaços localmente compactos e métricos.

Corolário 2.6.8. Espaços localmente compactos e Hausdorff são de Choquet.

Demonstração. Seja $X$ um espaço localmente compacto e Hausdorff. Seja $U_{0} \subset X$ a primeira jogada do Jogador I. Seja $x^{\prime} \in U_{0}$ e seja $V$ uma vizinhança $x^{\prime}$ tal que $\bar{V}$ é um subespaço compacto de $X$. Então o Jogador II responde com $V_{0} \subset V \cap U_{0}$ tal que $x^{\prime} \in V_{0} \subset \overline{V_{0}} \subset V \cap U_{0}$. A escolha desse $V_{0}$ foi possível graças a compacidade do subespaço $\bar{V}$. Daí basta continuar os mesmos passos da proposição anterior.

Corolário 2.6.9 (Teorema de Baire para espaços localmente compactos). Seja X um espaço localmente compacto. Seja $\left\{A_{n}: n \in \omega\right\}$ uma família enumerável de abertos densos em X. Então $\bigcap\left\{A_{n}: n \in \omega\right\}$ é denso em $X$.

Demonstração. Basta combinar o Teorema 2.6.5 com o Corolário 2.6.8.

Proposição 2.6.10. Espaços métricos e completos são de Choquet.

Demonstração. Seja $X$ um espaço métrico. Seja $U_{0} \subset X$ a primeira jogada do Jogador I. Seja $B\left(x_{0}, r_{0}\right)$ uma bola contida em $U_{0}$ tal que $r_{0} \leq 1$. Então o Jogador II responde com $B\left(x_{0}, r_{0}\right)$. O Jogador I, por sua vez, joga $U_{1} \subset B\left(x_{0}, r_{0}\right)$ e Jogador II responde com $B\left(x_{1}, r_{1}\right) \subset U_{1}$ com $r_{1} \leq 1 / 2$. O jogo segue dessa maneira até o final. Note que $\left(x_{n}: n \in \omega\right)$ é uma sequência de Cauchy ${ }^{20}$ e portanto, converge para $x \in \bigcap\left\{U_{n}: \in \omega\right\}=\bigcap\left\{B\left(x_{n}, r_{n}\right): n \in \omega\right\}$. Logo, o Jogador II possui estratégia vencedora. Portanto $X$ é um espaço de Choquet.

Da mesma forma que para espaços localmente compactos teremos o seguinte:

Corolário 2.6.11 (Teorema de Baire para espaços métricos). Seja X um espaço métrico. Seja $\left\{A_{n}: n \in \omega\right\}$ uma família enumerável de abertos densos em $X$. Então $\bigcap\left\{A_{n}: n \in \omega\right\}$ é denso em $X$.

Demonstração. Basta combinar o Teorema 2.6.5 com a proposição aterior.

19 Seja $(X, \tau)$ um espaço topológico. Uma coleção $\mathscr{C} \subset X$ é dita ter a propriedade da intersecção finita (p.i.f) se para qualquer $C \subset \mathscr{C}$ finito, tivermos que $\cap C \neq \emptyset$. Daí usamos o seguinte resultado: Seja $X$ um espaço topológico. Então $X$ é compacto, se, e somente se, para toda coleção $\mathscr{C}$ de fechados em $X$ com p.i.f. a intersecção $\bigcap \mathscr{C} \neq \emptyset$.

20 De fato, seja $\varepsilon>0$ dado e seja $n_{0} \in \omega$ tal que $1 /\left(n_{0}+1\right)<\varepsilon$, então para cada $m, n>n_{0}$ temos que $d\left(x_{n}, x_{m}\right)<\varepsilon$. 


\section{3}

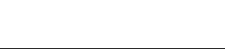

\section{O JOGO $G_{1}(\mathscr{O}, \mathscr{H})$}

O jogo topológico que iremos tratar neste capítulo é inspirado pela seguinte definição:

Definição 3.0.1. Seja $X$ um espaço topológico e seja $A \subset X$ dizemos que A é um subconjunto $G_{\delta}$ de $X$ se $A=\bigcap\left\{A_{n}: n \in \omega\right\}$, para cada $n \in \omega$ o conjunto $A_{n}$ é um aberto em $X$.

A diagonal do espaço $X \times X$ é o subconjunto $\Delta=\{(x, x): x \in X\}$. Dizemos que o espaço $X$ possui a propriedade da diagonal $G_{\delta}$ se $\Delta$ é um subconjunto $G_{\delta}$ de $X \times X$.

Note que todo espaço métrico satisfaz essa definição ${ }^{1}$. A propriedade da diagonal $G_{\delta}$ é conhecida principalmente por teoremas de metrizabilidade. A primeira aparição dessa propriedade com essa finalidade foi no trabalho de (ŠNEIDER, 1945). Neste artigo foi provado o seguinte resultado:

Teorema 3.0.2 ((ŠNEIDER, 1945)). Se X é compacto então é metrizável se, e somente se, $X$ possui a propriedade da diagonal $G_{\delta}$.

Anos mais tarde, (OKUYAMA, 1964) mostrou que,

Teorema 3.0.3 ((OKUYAMA, 1964)). Se X é um espaço paracompacto com a propriedade da diagonal $G_{\delta}$, então $X$ admite uma bijeção contínua em um espaço métrico.

No trabalho (AURICHI; LARA, 2016), elaboramos o jogo $G_{1}(\mathscr{O}, \mathscr{H})$ onde buscamos relações com a propriedade da diagonal $G_{\delta}$. Nesse capítulo faremos mais detalhadamente a primeira parte do referido artigo.

$\overline{1 \quad \text { Para ver isso basta tomar para cada } n \in \omega}$ o aberto $V_{n}=\bigcup\{B(x, 1 / n): x \in X\}$. Logo $\bigcap\left\{V_{n} \times V_{n}: n \in \omega\right\}=\Delta$. 


\subsection{O jogo $G_{1}(\mathscr{O}, \mathscr{H})$ e algumas propriedades}

Nesta seção vamos definir o jogo $G_{1}(\mathscr{O}, \mathscr{H})$. Tal jogo, como veremos, será por meio de coberturas jogadas pelo Jogador I e escolhas feitas pelo Jogador II de um elemento dessas coberturas. O leitor mais atento viu que a notação é parecida com a do jogo de Rothberger visto no capítulo referente a jogos topológicos. A motivação para tal definição, como veremos a seguir, foi a ponte que (CEDER, 1961) traçou entre a propriedade da diagonal $G_{\delta}$ e sequência de coberturas (Lema 3.1.2). Estudaremos algumas propriedades referentes ao Jogador I possuir estratégia vencedora. Além disso, atrelado a esse jogo temos o princípio seletivo $S_{1}(\mathscr{O}, \mathscr{H})$. Temos que sempre vale que $\neg S_{1}(\mathscr{O}, \mathscr{H})$ implica que o Jogador I possui estratégia vencedora em $G_{1}(\mathscr{O}, \mathscr{H})$. Uma pergunta bem natural seria se a implicação contrária vale. Nessa seção também daremos uma resposta positiva à essa pergunta para espaços de Lindelöf.

Definição 3.1.1. Seja $(X, \tau)$ espaço topológico. Denotamos por $\mathscr{O}$ o conjunto das coberturas abertas de X. Dado $\mathscr{C} \in \mathscr{O}$ denotamos por $\operatorname{St}(x, \mathscr{C})=\bigcup\{C \in \mathscr{C}: x \in C\}$.

Existe uma caracterização interna muito útil feitas em (CEDER, 1961) para espaços que possuem a propriedade da diagonal $G_{\delta}$ por meio de coleções de coberturas:

Lema 3.1.2 ((CEDER, 1961)). Seja $(X, \tau)$ um espaço topológico. Então $X \times X$ possui diagonal $G_{\delta}$ se, e somente se, existe $\left(\mathscr{C}_{n}: n \in \omega\right) \subset \mathscr{O}$ tal que, para todo $x, y \in X$ com $x \neq y$, existe $k \in \omega$ tal que $y \notin S t\left(x, \mathscr{C}_{k}\right)$. Em outras palavras, para todo $x \in X$, temos $\bigcap\left\{\operatorname{St}\left(x, \mathscr{C}_{n}\right): n \in \omega\right\}=\{x\}$.

Demonstração. Suponha que a diagonal é um conjunto $G_{\delta}$. Então, para cada $n \in \omega$, existem abertos não vazios $V_{n} \subset X^{2}$ tais que $\Delta=\bigcap\left\{V_{n}: n \in \omega\right\}$. Para cada $n \in \omega$, seja

$$
\mathscr{C}_{n}=\left\{A \in \tau: A \times A \subset V_{n}\right\} .
$$

Note que $\mathscr{C}_{n}$ é uma cobertura. De fato, seja $x \in X$. Então $(x, x) \in \Delta \subset V_{n}$ e, portanto, existem abertos $U, V \in \tau$ tais que $(x, x) \in U \times V \subset V_{n}$. $\operatorname{Logo}(x, x) \in(U \cap V) \times(U \cap V) \subset V_{n}$. Assim, $x \in U \cap V \in \mathscr{C}_{n}$. Agora mostremos que $\{x\}=\bigcap\left\{S t\left(x, \mathscr{C}_{n}\right): n \in \omega\right\}$. É imediato que $\{x\} \subset \bigcap\left\{\operatorname{St}\left(x, \mathscr{C}_{n}\right): n \in \omega\right\}$. Seja $y \in \bigcap\left\{\operatorname{St}\left(x, \mathscr{C}_{n}\right): n \in \omega\right\}$. Para cada $n \in \omega$ existe $A_{n} \in \mathscr{C}_{n}$ tal que $x, y \in A_{n}$. Logo $(x, y) \in A_{n} \times A_{n} \subset V_{n}$ e então $(x, y) \in \bigcap\left\{V_{n}: n \in \omega\right\}=\Delta$. Assim, temos que $x=y$.

Reciprocamente, seja $\left(\mathscr{C}_{n}: n \in \omega\right) \subset \mathscr{O}$ tal que, para todo $x \in X$, temos que $\{x\}=$ $\bigcap\left\{\operatorname{St}\left(x, \mathscr{C}_{n}\right): n \in \omega\right\}$. Para cada $n \in \omega$ seja $V_{n}=\bigcup\left\{A \times A: A \in \mathscr{C}_{n}\right\}$. Note que $\Delta \subset \bigcap\left\{V_{n}: n \in \omega\right\}$. Seja $(x, y) \in \bigcap\left\{V_{n}: n \in \omega\right\}$. Então, para cada $n \in \omega$, existe $A_{n} \in \mathscr{C}_{n}$ tal que $(x, y) \in A_{n} \times A_{n} \mathrm{e}$ então $x, y \in A_{n} \in \mathscr{C}_{n}$ e isso implica que $y \in S t\left(x, \mathscr{C}_{n}\right)$ para todo $n \in \omega$. Porém, $\{x\}=\bigcap\left\{\operatorname{St}\left(x, \mathscr{C}_{n}\right)\right.$ : $n \in \omega\}$ e isso implica que $x=y$.

Antes de defirmos o jogo de fato, vamos definir o princípio seletivo $S_{1}(\mathscr{O}, \mathscr{H})$ : 
Definição 3.1.3. Seja $(X, \tau)$ espaço topológico. Seja $\mathscr{H}=\left\{R \in(\tau \backslash\{\emptyset\})^{\omega}:|\cap R| \geq 2\right\}$. Denotamos por $S_{1}(\mathscr{O}, \mathscr{H})$ a seguinte afirmação: Dado $\left(\mathscr{C}_{n}: n \in \omega\right) \subset \mathscr{O}$ para cada $n \in \omega$ existe $C_{n} \in \mathscr{C}_{n}$ tal que $\left|\bigcap_{n \in \omega} C_{n}\right| \geq 2$.

Associado a esse princípio temos o jogo $G_{1}(\mathscr{O}, \mathscr{H}): N a$ n-ésima rodada o Jogador I joga $\mathscr{C}_{n} \in \mathscr{O}$ e o Jogador II toma $C_{n} \in \mathscr{C}_{n}$. O Jogador II vence se $\left|\bigcap\left\{C_{n}: n \in \omega\right\}\right| \geq 2$.

Note que podemos re-enunciar o Lema 3.1.2 da seguinte maneira:

Lema 3.1.4. Seja $(X, \tau)$ um espaço topológico. Então $X$ possui a propriedade da diagonal $G_{\delta}$ se, e somente se, não vale o princípio $S_{1}(\mathscr{O}, \mathscr{H})$.

Demonstração. Note que, se $X$ não possui a propriedade da diagonal $G_{\delta}$ é o mesmo que dizer que: Dado $\left(\mathscr{C}_{n}: n \in \omega\right) \subset \mathscr{O}$, existem $x, y \in X \operatorname{com} x \neq y$ tais que, para todo $n \in \omega$, existe $C_{n} \in \mathscr{C}_{n}$ tal que $x, y \in C_{n}$. Ou seja, $\left|\bigcap\left\{C_{n}: n \in \omega\right\}\right| \geq 2$, e isso é equivalente à $S_{1}(\mathscr{O}, \mathscr{H})$.

O que podemos garantir por enquanto é que, dado um subespaço $A \subset X$, se o Jogador I possuir estratégia vencedora no jogo em $X$, o Jogador I possuirá estratégia vencedora no jogo em $A$. De fato, note que o Jogador I fará a mesmas jogadas que ele faria se estivesse jogando em $X$, porém, agora restingindo os abertos da cobertura ao conjunto $A$. Então, na pior das hipóteses, a interceção das escolhas feitas pelo Jogador II será vazia. Será que a mesma lógica se aplica em um produto qualquer de espaços topológicos em que o jogo no produto é baseado nos jogos de cada componente?

Eis a resposta:

Proposição 3.1.5. Sejam $\left\{X_{\alpha}: \alpha<\kappa\right\}$ uma família de espaços topológicos tal que para cada $\alpha<\kappa,\left|X_{\alpha}\right| \geq 2$ e o Jogador I possui estratégia vencedora em $G_{1}(\mathscr{O}, \mathscr{H})$ em $X_{\alpha}$. Então o Jogador I possui estratégia vencedora no jogo $G_{1}(\mathscr{O}, \mathscr{H})$ em $\prod\left\{X_{\alpha}: \alpha<\kappa\right\}$ se $|\kappa| \leq \boldsymbol{\aleph}_{0}$. O Jogador II possui estratégia vencedora no jogo $G_{1}(\mathscr{O}, \mathscr{H})$ em $\prod\left\{X_{\alpha}: \alpha<\kappa\right\}$ se $|\kappa|>\aleph_{0}$.

Curioso não? Podemos dizer que nem tanto, pois, como veremos a seguir, o coração dessa demonstração é o número total de rodadas. Deste modo, conseguimos montar facilmente uma estratégia para o Jogador I no produto enumerável juntando em passos finitos as demais estratégias. Porém, se o produto for não-enumerável, o próximo lema nos garantirá que tal feito realizado para o caso enumerável não se repetirá.

Lema 3.1.6. Seja $\left\{X_{\alpha}: \alpha<\kappa\right\}$ uma família de espaços topológicos tal que, para cada $\alpha<\kappa$, $\left|X_{\alpha}\right| \geq 2$ com $\kappa>\aleph_{0}$. Então, se $A \subset \prod\left\{X_{\alpha}: \alpha<\kappa\right\}$ é um subconjunto $G_{\delta}$ não vazio, temos que $|A| \geq 2$.

Demonstração. Seja $A$ um subconjunto $G_{\delta}$ não vazio de $\prod\left\{X_{\alpha}: \alpha<\kappa\right\}$ não vazio. Então $A=\bigcap\left\{A^{n}: n \in \omega\right\}$ em que cada $A^{n}$ é um aberto na topologia produto de $\prod\left\{X_{\alpha}: \alpha<\kappa\right\}$. Para 
cada $n \in \omega$ seja $V^{n} \subset A^{n}$ um aberto básico não vazio. Para cada $n \in \omega$ seja $\operatorname{supp}\left(V^{n}\right)=\{\alpha<$ $\left.\kappa: V_{\alpha}^{n} \neq X_{\alpha}\right\}, \operatorname{com} V^{n}=\prod_{\alpha<\kappa} V_{\alpha}^{n}$, onde cada $V_{\alpha}^{n}$ é aberto em $X_{\alpha}$. Isso implica que existe $\xi<\kappa$ tal que $\xi \notin \bigcup\left\{\operatorname{supp}\left(V^{n}\right): n \in \omega\right\}$. Tome $x=\left(x_{\alpha}: \alpha<\kappa\right) \in A$ seja $y=\left(y_{\alpha}: \alpha<\kappa\right)$ tal que $y_{\alpha}=x_{\alpha}$ se $\alpha \neq \xi$ e $y_{\xi} \neq x_{\xi}$ para algum $y_{\xi} \in X_{\xi}$. Note que $x \neq y$ e $y \in A$.

Demonstração da Proposição 3.1.5.

Para cada $\alpha<\kappa$ seja $\sigma_{X_{\alpha}}$ uma estratégia vencedora para o Jogador I em $X_{\alpha}$.

Afirmação 1:O Jogador I possui estratégia vencedora em $G_{1}(\mathscr{O}, \mathscr{H})$ em $\prod\left\{X_{n}: n \in \omega\right\}$.

Em $\prod\left\{X_{n}: n \in \omega\right\}$ a primeira jogada do Jogador I é

$$
\mathscr{C}_{0}=\left\{A^{0} \times X_{1} \times X_{2} \times \cdots: A^{0} \in \sigma_{X_{0}}(\emptyset)\right\} .
$$

Por sua vez o Jogador II escolhe um aberto $A_{0}^{0} \times X_{1} \times X_{2} \times \cdots \in \mathscr{C}_{0}$. Na próxima rodada o Jogador I joga

$$
\mathscr{C}_{1}=\left\{A^{0} \times A^{1} \times X_{2} \times \cdots: A^{0} \in \sigma_{X_{0}}\left(A_{0}^{0}\right), A^{1} \in \sigma_{X_{1}}(\emptyset)\right\}
$$

e o Jogador II escolhe $A_{1}^{0} \times A_{0}^{1} \times X_{2} \times \cdots \in \mathscr{C}_{1}$. Continuando esse processo, na n-ésima rodada, o Jogador I joga

$\mathscr{C}_{n}=\left\{A^{0} \times A^{1} \times \cdots \times A^{n} \times X_{n+1} \times \cdots: A^{0} \in \sigma_{X_{0}}\left(A_{0}^{0}, A_{1}^{0}, \ldots, A_{n-1}^{0}\right), A^{1} \in \sigma_{X_{1}}\left(A_{0}^{1}, \ldots, A_{n-2}^{1}\right), \ldots, A^{n} \in \sigma_{X_{n}}(\emptyset)\right\}$.

E assim, o Jogador II toma $A_{n}^{0} \times A_{n-1}^{1} \times \cdots \times A_{0}^{n} \times X_{n+1} \times \cdots$.

Note que $\left|\bigcap\left\{A_{n}^{0} \times A_{n-1}^{1} \times \cdots \times A_{0}^{n} \times X_{n+1} \times \cdots: n \in \omega\right\}\right| \leq 1$. De fato, suponha que isso não seja verdade. Em primeiro lugar, suponha que essa intersecção seja não vazia e seja $x=\left(x_{n}: n \in \omega\right)$ um elemento desta. Note que para cada $n \in \omega$ temos que $\left\{x_{n}\right\}=\bigcap\left\{A_{k}^{n}: k \in \omega\right\}$, pois, para cada $n \in \omega$ o Jogador I possui estratégia vencedora em $X_{n}$. Agora, suponha que exista $y=\left(y_{n}: n \in \omega\right)$ distinto de $x$, então existe $\ell \in \omega$ tal que $x_{\ell} \neq y_{\ell}$. Como o Jogador I possui estratégia vencedora em $X_{\ell}$ temos que existe $m \in \omega$ tal que $x_{\ell} \in A_{m}^{\ell}$ e $y_{\ell} \notin A_{m}^{\ell}$. Logo $y \notin \bigcap\left\{A_{n}^{0} \times A_{n-1}^{1} \times \cdots \times A_{0}^{n} \times X_{n+1} \times \cdots: n \in \omega\right\}$.

Afirmação 2: O Jogador II possui estratégia vencedora em $G_{1}(\mathscr{O}, \mathscr{H})$ em $\prod\left\{X_{\alpha}: \alpha<\kappa\right\}$ se $|\kappa|>\aleph_{0}$.

Fixe $x=\left(x_{\alpha}: \alpha<\kappa\right) \in \prod\left\{X_{\alpha}: \alpha<\kappa\right\}$. Na $n$-ésima rodada suponha que o Jogador I jogou $\mathscr{C}_{n}$. Basta que o Jogador II escolha um elemento $A^{n} \in \mathscr{C}_{n}$ que contenha o ponto $x$. Daí $\bigcap\left\{A^{n}: n \in \omega\right\}$ é um $G_{\delta}$ não vazio. Portanto segue do Lema 3.1.6 que $\left|\cap\left\{A^{n}: n \in \omega\right\}\right| \geq 2$.

\subsubsection{A equivalência para espaços de Lindelöf}

Até o momento temos as seguintes implicações: 


$$
\Delta \text { é } G_{\delta} \operatorname{em~} X^{2} \Leftrightarrow \neg S_{1}(\mathscr{O}, \mathscr{H}) \Rightarrow \mathrm{I} \uparrow G_{1}(\mathscr{O}, \mathscr{H}) \text {. }
$$

Quais condições o espaço $(X, \tau)$ tem que satisfazer para que possamos ter que $\mathrm{I} \uparrow G_{1}(\mathscr{O}, \mathscr{H})$ implica que $\Delta$ é $G_{\delta}$ em $X^{2}$ ? Como já foi revelado no início da seção, vamos mostrar agora que essa implicação vale para espaços de Lindeöf.

Proposição 3.1.7. Seja X Lindelöf. Se o Jogador I possuir estratégia vencedora em $G_{1}(\mathscr{O}, \mathscr{H})$ então $S_{1}(\mathscr{O}, \mathscr{H})$ não vale.

Demonstração. Antes de atacar a demonstração, note que podemos supor que o Jogador I joga coberturas enumeráveis em cada rodada. Para ver isso, seja $\sigma$ uma estratégia vencedora para o Jogador I. Na $n$-ésima rodada o Jogador I jogaria $\sigma\left(C_{0}, \ldots, C_{n-1}\right)$ conforme a sua estratégia. Seja $\mathscr{C}_{n} \subset \sigma\left(C_{0}, \ldots, C_{n-1}\right)$ uma subcobertura enumerável. Então o Jogador I joga $\mathscr{C}_{n}$ e por sua vez o Jogador II escolhe $C_{n} \subset \mathscr{C}_{n} \subset \sigma\left(C_{0}, \ldots, C_{n-1}\right)$. No fim das contas, o Jogador II acaba escolhendo abertos da estratégia traçada pelo Jogador I. Logo $\left|\bigcap\left\{C_{n}: n \in \omega\right\}\right| \leq 1$.

Considere a estratégia vencedora para o Jogador I dada pela seguinte coleção $\left\{\mathscr{C}_{\sigma}: \sigma \in\right.$ $\left.\omega^{<\omega}\right\}$ tal que $\mathscr{C}_{\sigma}=\left\{C_{\sigma^{\wedge} i}: i \in \omega\right\}, \bigcup\left\{C_{\sigma^{\wedge} n}: n \in \omega\right\}=X$ e $\left|\bigcap\left\{C_{f \nmid n}: n \in \omega\right\}\right| \leq 1$ para todo $f \in \omega^{\omega 2}$.

Agora, resta-nos verificar se a sequência de coberturas $\left\{\mathscr{C}_{\sigma}: \sigma \in \omega^{<\omega}\right\}$ satisfaz o Lema 3.1.2. Suponha que existam $x, y \in X \operatorname{com} x \neq y$ tais que, para todo $\sigma \in \omega^{<\omega}$, temos que $y \in \operatorname{St}\left(x, \mathscr{C}_{\sigma}\right)$. Então existe $g \in \omega^{\omega} \operatorname{com} x, y \in C_{g \nmid n}$ para todo $n \in \omega, \log 0\left|\cap\left\{C_{g \nmid n}: n \in \omega\right\}\right| \geq 2$ o que é um absurdo. Portanto, existe $\sigma \in \omega^{<\omega}$ tal que $y \notin S t\left(x, \mathscr{C}_{\sigma}\right)$.

Se o espaço não for Lindelöf ainda teremos esse resultado? A resposta é um enfático não! Como veremos a seguir, em $\omega_{1}$ o Jogador I possui estratégia vencedora em $G_{1}(\mathscr{O}, \mathscr{H})$, porém, o princípio $S_{1}(\mathscr{O}, \mathscr{H})$ é verdadeiro.

Proposição 3.1.8. Em $\omega_{1}$ o Jogador I possui estratégia vencedora em $G_{1}(\mathscr{O}, \mathscr{H})$.

Demonstração. Sejam $S=\left\{\alpha \in \omega_{1}\right.$ : existe $\beta \in \omega_{1}$ tal que $\left.\alpha=\beta+1\right\}$ e $L=\omega_{1} \backslash S$. Para cada $\gamma \in L$, tome $\left\{\alpha_{n}^{\gamma}: n \in \omega\right\} \subset \omega_{1}$ tal que $\alpha_{n}^{\gamma}<\alpha_{n+1}^{\gamma}<\gamma$ e $\sup \left\{\alpha_{n}^{\gamma}: n \in \omega\right\}=\gamma$. Para cada $n \in \omega$, defina $\left.\left.V_{n}^{\gamma}=\right] \alpha_{n}^{\gamma}, \gamma\right]$ e seja $A=\{\{\alpha\}: \alpha \in S\}$. Na primeira rodada o Jogador I joga $\mathscr{C}_{0}=A \cup\left\{V_{0}^{\gamma}: \gamma \in L\right\}$. Note que se o Jogador II escolher $\{\alpha\}$ para algum $\alpha \in S$, então o Jogador II perde! Logo, resta ao Jogador II escolher $V_{0}^{\gamma_{0}}$ para algum $\gamma_{0} \in L$. Na segunda rodada o Jogador I joga $\mathscr{C}_{1}=A \cup\{] \gamma_{0}, \omega_{1}[\} \cup\left\{V_{1}^{\gamma}: \gamma \in L\right.$ e $\left.\gamma \leq \gamma_{0}\right\}$. Suponha que o Jogador II escolheu $V_{1}^{\gamma_{1}}$ para algum $\gamma_{1} \in L$ tal que $\gamma_{1} \leq \gamma_{0}$. Note que se o jogador II jogar $\left.] \gamma_{0}, \omega_{1}\right]$ ele perde! Pois ]$\left.\gamma_{0}, \omega_{1}\right] \cap V_{0}^{\gamma_{0}}=\emptyset$. Daí o Jogador I joga $\mathscr{C}_{2}=A \cup\{] \gamma_{1}, \omega_{1}[\} \cup\left\{V_{2}^{\gamma}: \gamma \in L\right.$ e $\left.\gamma \leq \gamma_{1}\right\}$ e assim por diante.

2 Onde $\omega^{<\omega}=\bigcup_{n \in \omega} \omega^{n}$ e, portanto, é enumerável. Seja $\sigma \in \omega^{<\omega}$ então $\sigma: n \rightarrow \omega$ para algum $n$. Suponha, por exemplo, que tenhamos uma $\sigma: 2 \rightarrow \omega$ tal que $\sigma(0)=2$ e $\sigma(1)=7$, então $\left\{C_{\sigma^{\wedge} i}: i \in \omega\right\}=\left\{C_{27 i}: i \in \omega\right\}$. 
Note que $\left(\gamma_{n}: n \in \omega\right)$ forma uma sequência decrescente de ordinais, então existe $k \in \omega$ tal que $\gamma_{n}=\gamma_{k}$ para todo $n \geq k$. Então o Jogador II toma $V_{n}^{\gamma_{k}} \in \mathscr{C}_{n}$ para todo $n \geq k$. Logo, $\bigcap\left\{V_{n}^{\gamma_{n}}: n \in \omega\right\} \supset \bigcap\left\{V_{n}^{\gamma_{k}}: n \geq k\right\}=\left\{\gamma_{k}\right\}$, pois $\left\{V_{n}^{\gamma_{k}}: n \in \omega\right\}$ é um sistema fundamental de vizinhanças para $\gamma_{k}$.

Lema 3.1.9 ((CHABER, 1976)). ${ }^{3}$ Se X é enumeravelmente compacto e possui a propriedade da diagonal $G_{\delta}$ então $X$ é compacto.

Demonstração. Seja $\left(\mathscr{C}_{n}: n \in \omega\right) \subset \mathscr{O}$ tal que, para todo $x \in X$, temos que $\bigcap\left\{\operatorname{St}\left(x, \mathscr{C}_{n}\right): n \in\right.$ $\omega\}=\{x\}$. Suponha por absurdo que $X$ não é compacto. Note que isso é o mesmo que supor que exista uma cobertura $\mathscr{V}$ que não admita subcobertura enumerável ${ }^{4}$. Indutivamente, para cada $\alpha \in \omega_{1}$, tome $x_{\alpha} \in X$ e $m(\alpha) \in \omega$ com as seguintes propriedades:

1. $x_{\alpha} \in X \backslash \bigcup\left\{S t\left(x_{\beta}, \mathscr{C}_{m(\beta)}\right): \beta<\alpha\right\}$,

2. $\mathscr{V}$ não admite subcobertura enumerável para $X \backslash \bigcup\left\{S t\left(x_{\beta}, \mathscr{C}_{m(\beta)}\right): \beta \leq \alpha\right\}$

Para começar, escolha $x_{0} \in X$. Então, existe $m(0) \in \omega$ tal que não existe subcobertura enumerável de $\mathscr{V}$ que cubra $X \backslash S t\left(x_{0}, \mathscr{C}_{m(0)}\right)$. De fato, suponha que tal $m(0)$ não exista. Então, para cada $n \in \omega$, existe uma subcobetura enumerável $\mathscr{V}_{n} \subset \mathscr{V}$ que cobre $X \backslash S t\left(x_{0}, \mathscr{C}_{n}\right)$. Então $\bigcup\left\{\mathscr{V}_{n}: n \in \omega\right\}$ é uma subcobertura enumerável de $\mathscr{V}$ que cobre $\bigcup\left\{X \backslash S t\left(x_{0}, \mathscr{C}_{n}\right): n \in \omega\right\}=$ $X \backslash \bigcap\left\{\operatorname{St}\left(x_{0}, \mathscr{C}_{n}\right): n \in \omega\right\}=X \backslash\left\{x_{0}\right\}$. Portanto $\mathscr{V}$ admite subcobertura enumerável que cobre $X$ o que é um absurdo.

Suponha que $\left\{x_{\beta}: \beta<\alpha\right\}$ e $\{m(\beta): \beta<\alpha\}$ foram escolhidos tais que as condições 1 . e 2. sejam satisfeitas para cada $\beta<\alpha$.

Afirmação: Não existe subcobertura enumerável de $\mathscr{V}$ que cubra

$$
X \backslash \bigcup\left\{S t\left(x_{\beta}, \mathscr{C}_{m(\beta)}\right): \beta<\alpha\right\}
$$

Demonstração. Suponha que exista $\mathscr{W} \subset \mathscr{V}$ enumerável que cubra $X \backslash \bigcup\left\{S t\left(x_{\beta}, \mathscr{C}_{m(\beta)}\right): \beta<\alpha\right\}$. Então $\mathscr{S}=\left\{S t\left(x_{\beta}, \mathscr{C}_{m(\beta)}\right): \beta<\alpha\right\} \cup \mathscr{W}$ é uma cobertura enumerável para $X$. Seja $\mathscr{F} \subset \mathscr{S}$ uma subcobertura finita para $X$. Seja $\delta=\max \left\{\beta<\alpha: S t\left(x_{\beta}, \mathscr{C}_{m(\beta)}\right) \in \mathscr{F}\right\}$. Então $\mathscr{W}$ cobre $X \backslash \bigcup\left\{S t\left(x_{\beta}, \mathscr{C}_{m(\beta)}\right): \beta \leq \delta\right\}$ e isso viola a condição 2 . para o ordinal $\delta<\alpha$.

Agora, tome $x_{\alpha} \in X \backslash \bigcup\left\{S t\left(x_{\beta}, \mathscr{C}_{m(\beta)}\right): \beta<\alpha\right\}$. Então existe $m(\alpha) \in \omega$ tal que a condição 2. é satisfeita para $\alpha$. Se não, para cada $n \in \omega$ existe uma subcobertura enumerável $\mathscr{V}_{n} \subset \mathscr{V}$ que cobre

$$
\left(X \backslash \bigcup_{\beta<\alpha} S t\left(x_{\beta}, \mathscr{C}_{m(\beta)}\right)\right) \backslash S t\left(x_{\alpha}, \mathscr{C}_{n}\right) .
$$

3 Esse resultado encontra-se em (ENGELKING, 1989) enunciado como o exercício 3.12 .23 (e) na página 242.

4 Se $X$ for de Lindelöf acabou! 
Assim $\bigcup\left\{\mathscr{V}_{n}: n \in \omega\right\}$ é uma subcobertura enumerável de $\mathscr{V}$ que cobre

$$
\begin{aligned}
\bigcup_{n \in \omega}\left(\left(X \backslash \bigcup_{\beta<\alpha} S t\left(x_{\beta}, \mathscr{C}_{m(\beta)}\right)\right) \backslash S t\left(x_{\alpha}, \mathscr{C}_{n}\right)\right) & =\left(X \backslash \bigcup_{\beta<\alpha} S t\left(x_{\beta}, \mathscr{C}_{m(\beta)}\right)\right) \backslash \bigcap_{n \in \omega} S t\left(x_{\alpha}, \mathscr{C}_{n}\right)= \\
& =X \backslash\left(\bigcup_{\beta<\alpha} S t\left(x_{\beta}, \mathscr{C}_{m(\beta)}\right) \cup\left\{x_{\alpha}\right\}\right) .
\end{aligned}
$$

Isso contradiz o que foi feito na afirmação anterior.

Finalmente, pelo Princípio da Casa dos Pombos, existem $n \in \omega$ e $D \subset \omega_{1}$ não enumerável tais que, para todo $\alpha \in D$, temos que $m(\alpha)=n$. Seja $Y=\left\{x_{\alpha}: \alpha \in D\right\}$ e note que cada aberto de $\mathscr{C}_{n}$ contém no máximo um elemento de $Y$. De fato, seja $C \in \mathscr{C}_{n}$ tal que $x_{\alpha} \in C$ e suponha que exista $x_{\beta} \in Y$ tal que $x_{\beta} \in C$, então:

- Se $\alpha<\beta$ então $C \subset S t\left(x_{\alpha}, \mathscr{C}_{n}\right)$ e $x_{\beta} \notin S t\left(x_{\alpha}, \mathscr{C}_{n}\right)$ daí $x_{\beta} \notin C$.

- Se $\beta<\alpha$ então $C \subset S t\left(x_{\beta}, \mathscr{C}_{n}\right)$ e $x_{\alpha} \notin S t\left(x_{\beta}, \mathscr{C}_{n}\right)$ daí $x_{\alpha} \notin C$.

Mostremos que $Y$ é fechado. Suponha que exista $x \in \bar{Y} \backslash Y$, logo, existe $C \in \mathscr{C}_{n}$ tal que $x \in C$ e $C \cap Y \neq \emptyset$. Então $C \cap Y=\left\{x_{\alpha}\right\}$ para algum $\alpha \in D$. Portanto, $x \in C \backslash\left\{x_{\alpha}\right\}$ e $\left(C \backslash\left\{x_{\alpha}\right\}\right) \cap Y=\emptyset$ o que contradiz o fato de $x \in \bar{Y}$.

Seja $Z \subset Y$ enumerável, observe que $Z$ é discreto e fechado. Portanto $\mathscr{C}=\{\{z\}: z \in$ $Z\} \cup\{X \backslash Z\}$ é uma cobertura enumerável para $X$ que não admite subcobertura finita e isso implica que o espaço não é enumeravelmete compacto.

O próximo resultado é bem conhecido, mas o apresentaremos para conveniência do leitor.

Proposição 3.1.10. $\omega_{1}$ é enumeravelmente compacto.

Demonstração. Suponha que $\omega_{1}$ não seja enumeravelmente compacto. Então existe uma cobertura enumerável $\left\{A_{i}: i \in \omega\right\}$ tal que não conseguimos extrair uma subcobertura finita. Então, para cada $n \in \omega$, existe $x_{n} \notin \bigcup\left\{A_{i}: i \leq n\right\}$. Seja $x=\sup \left\{x_{n}: n \in \omega\right\}$, como $x<\omega_{1}$ temos que existe $k \in \omega$ tal que $x \in A_{k}$ e assim existe $k^{\prime} \in \omega$ tal que para todo $i \geq k^{\prime} x_{i} \in A_{k}$ e isso contraria a maneira que tomamos os $x_{i}$ 's.

Combinando o Lema 3.1.9 com a Proposição 3.1.10, concluímos que $\omega_{1}$ não possui a propriedade da diagonal $G_{\delta}$. O Professor Angelo Bella nos apontou que $\omega_{1}$ não é único conjunto privilegiado com tais peculiaridades, aliás, para todo cardinal não enumerável com confinalidade não enumerável conseguimos construir um conjunto que possui as mesmas propriedades:

Proposição 3.1.11. Seja $\alpha$ um cardinal não enumerável com confinalidade não enumerável. Então o Jogador I possui estratégia vencedora no jogo $G_{1}(\mathscr{O}, \mathscr{H})$ jogado em $A_{\alpha}=\{\beta<\alpha$ : cf $f(\beta)=\omega\}$ e o princípio seletivo $S_{1}(\mathscr{O}, \mathscr{H})$ não vale em tal espaço. 
Demonstração. Seja $\alpha$ um cardinal não enumerável com confinalidade não enumerável. Para cada $\gamma \in A_{\alpha}$, tome uma sequencia de ordinais $\left\{\beta_{n}^{\gamma}: n \in \omega\right\} \subset A_{\alpha}$ tal que $\beta_{n}^{\gamma}<\beta_{n+1}^{\gamma}<\gamma$ e $\sup \left\{\beta_{n}^{\gamma}\right.$ : $n \in \omega\}=\gamma$. Na primeira rodada, o Jogador I joga $\mathscr{C}_{0}=\left\{V_{0}^{\gamma}: \gamma \in A_{\alpha}\right\}$. Então, o Jogador II escolhe $V_{0}^{\gamma_{0}}$ para algum $\gamma_{0} \in A_{\alpha}$. Na segunda rodada o Jogador I joga $\mathscr{C}_{1}=\{] \gamma_{0}, \omega_{1}[\} \cup\left\{V_{1}^{\gamma}: \gamma \in A_{\alpha} \mathrm{e}\right.$ $\left.\gamma \leq \gamma_{0}\right\}$ e o Jogador II responde com $V_{1}^{\gamma_{1}}$ para algum $\gamma_{1} \in A_{\alpha}$ tal que $\gamma_{1} \leq \gamma_{0}$. Para terminar a demonstração basta repetir o que foi feito para o espaço $\omega_{1}$.

Suponha que $A_{\alpha}$ não seja enumeravelmente compacto. Então, existe uma cobertura enumerável $\left\{A_{i}: i \in \omega\right\}$ tal que não conseguimos extrair uma subcobertura finita. Então para cada $n \in \omega$ existe $x_{n} \notin \bigcup\left\{A_{i}: i \leq n\right\}$. Seja $x=\sup \left\{x_{n}: n \in \omega\right\}$, note que $x<\alpha$, caso contrário, $\alpha=x$ e então defina $f: \omega \rightarrow \alpha$ como $f(n)=x_{n}$ e assim $c f(\alpha)=\omega$ o que é um absurdo. O resto da demonstração segue igual a da Proposição 3.1.10. Por $A_{\alpha}$ não ser compacto e aplicando o Lema 3.1.9 concluímos que não vale $S_{1}(\mathscr{O}, \mathscr{H})$.

\subsection{A equivalência para espaços hereditariamente meta- compactos}

Será que a classe dos espaços de Lindelöf é a única que conseguimos para termos que o Jogador I possui estratégia vencedora em $G_{1}(\mathscr{O}, \mathscr{H})$ implica que não vale $S_{1}(\mathscr{O}, \mathscr{H})$ ? O objetivo dessa seção é exibir outra classe de espaços em que essa afirmação ainda valha. Conseguimos o mesmo resultado para a classe de espaços hereditariamente metacompactos, que por sua vez, é diferente da classe de espaços de Lidelöf. Um exemplo fácil que ilustra isso é tomar $D$ um conjunto não enumerável com a topologia discreta. Infelizmente a classe de espaços metacompactos não contém a classe de espaços de Lindelöf, pois, o "Dieudonné plank" é um exemplo de um espaço de Lindelöf que não é paracompacto (veja em (STEEN; SEEBACH, 1995)) e portanto não é metacompacto.

Para início de conversa, afinal, o que é um espaço metacompacto?

Definição 3.2.1. Dizemos que a cobertura $\mathscr{A} \in \mathscr{O}$ é uma cobertura ponto-finita se, para todo $x \in X$, o conjunto $\{A \in \mathscr{A}: x \in A\}$ for finito. Dizemos que o espaço $(X, \tau)$ é um espaço metacompacto se toda cobertura aberta possui um refinamento aberto ponto-finito. Dizemos que um espaço é hereditariamente metacompacto se todo subespaço deste for metacompacto.

Como foi dito anteriormente o foco dessa seção é provar a Proposição 3.2.8. Para tanto, introduziremos um jogo auxiliar.

Definição 3.2.2. Seja $A \subset X$ e $\mathscr{O}(A)$ o conjunto das coberturas abertas para A. Considere $o$ seguinte jogo $P(X):$ Na 0 -ésima rodada o Jogador I joga $\mathscr{C}_{0} \in \mathscr{O}$ e o Jogador II toma $C_{0} \in \mathscr{C}_{0}$. 
Na rodada seguinte o Jogador I joga $\mathscr{C}_{1} \in \mathscr{O}\left(C_{0}\right)$ e, por sua vez, o Jogador II escolhe $C_{1} \in \mathscr{C}_{1}$. Na n-ésima rodada o Jogador I joga $\mathscr{C}_{n} \in \mathscr{O}\left(C_{n-1}\right)$ onde $C_{n-1} \in \mathscr{C}_{n-1}$ e o Jogador II toma $C_{n} \in \mathscr{C}_{n}$. O jogador II vence se $\left|\bigcap\left\{C_{n}: n \in \omega\right\}\right| \geq 2$.

Note que, enquanto no jogo $G_{1}(\mathscr{O}, \mathscr{H})$, o Jogador I joga coberturas para o espaço todo em todas as rodadas, em $P(X)$ o Jogador I joga coberturas para abertos escolhidos pelo Jogador II na rodada anterior.

Proposição 3.2.3. Se o Jogador I possui estratégia vencedora em $G_{1}(\mathscr{O}, \mathscr{H})$ então o Jogador I possui estratégia vencedora em $P(X)$.

Demonstração. Seja $\sigma$ estratégia vencedora para o Jogador I em $G_{1}(\mathscr{O}, \mathscr{H})$. Na primeira rodada em $P(X)$ o Jogador I joga $\sigma(\emptyset)$ e o Jogador II escolhe $A_{0} \in \sigma(\emptyset)$. Então, na segunda rodada em $P(X)$ o Jogador I joga $\mathscr{C}_{1}=\left\{A_{0} \cap A: A \in \sigma\left(A_{0}\right)\right\}$ e o Jogador II escolhe $C_{1} \in \mathscr{C}_{1}$. Note que $C_{1}=A_{0} \cap A_{1}$ para algum $A_{1} \in \sigma\left(A_{0}\right)$. Então, na $n$-ésima rodada do jogo $P(X)$, o Jogador I joga $\mathscr{C}_{n}=\left\{A_{0} \cap A_{1} \cap \cdots \cap A_{n-1} \cap C: C \in \sigma\left(A_{0}, \ldots, A_{n-1}\right)\right\}$ e o Jogador II escolhe $C_{n} \in \mathscr{C}_{n}$, com $C_{n}=A_{0} \cap A_{1} \cap \cdots \cap A_{n}$ para algum $A_{n} \in \sigma\left(A_{0} \cap A_{1} \cap \cdots \cap A_{n-1}\right)$. Portanto $\left|\cap\left\{C_{n}: n \in \omega\right\}\right|=$ $\left|\cap\left\{A_{n}: n \in \omega\right\}\right| \leq 1$, onde $A_{0}=C_{0}$.

Visto essa proposição, podemos nos perguntar se vale a implicação contrária. Para os leitores mais afoitos já adiantaremos a resposta e, de fato, a implicação contrária vale se tivermos um espaço regular (Corolário 4.2.6).

Na seção anterior, $\omega_{1}$ nos foi muito útil para mostrar que a propriedade de Lindelöf é necessária. Mostraremos agora que $\omega_{1}$ também não é metacompacto, quem dirá hereditariamente metacompacto. Para realizar tal feito usaremos o Lema do "Pressing Down".

Definição 3.2.4. Seja $C \subset \omega_{1}$. Dizemos que $C$ é um club se é fechado em $\omega_{1}$ (com relação à topologia) e ilimitado. Seja $S \subset \omega_{1}$. Dizemos que $S$ é estacionário se intercepta todos os club's de $\omega_{1}$. Seja $f: S \rightarrow \omega_{1}$. Dizemos que $f$ é regressiva se para todo $\gamma \in S$ temos que $f(\gamma)<\gamma$.

Lema 3.2.5 (Lema do "Pressing Down"). Seja $S$ um subconjunto estacionário de $\omega_{1}$ e $f: S \rightarrow \omega_{1}$ regressiva. Então existe $\alpha<\omega_{1}$ tal que $f^{-1}\{\alpha\}$ é estacionário.

Demonstração. No Lema III 6.14 de (KUNEN, 2011) existe uma prova para um caso mais geral.

Proposição 3.2.6. O espaço $\omega_{1}$ não é metacompacto.

Demonstração. Seja $\mathscr{C}=\left\{\left[0, \alpha+1\left[: \alpha \in \omega_{1}\right\}\right.\right.$ cobertura aberta de $\omega_{1}$. Seja $\mathscr{R}$ um refinamento aberto de $\mathscr{C}$. Seja $L$ o conjunto dos ordinais limites de $\omega_{1}$. Note que cada $\gamma \in L$ está em algum $U_{\gamma} \in \mathscr{R}$. Seja $g: L \rightarrow \omega_{1}$, tal que

$$
\gamma \in] g(\gamma), \gamma] \subset U_{\gamma}
$$


Como $g$ é uma função regressiva e $L$ é estacionário ${ }^{5}$, pelo Lema do Pressing Down, existe $\beta \in \omega_{1}$ tal que $g^{-1}[\{\beta\}] \subset L$ é estacionário. Em particular tal conjunto é ilimitado. Note que para cada $\xi \in g^{-1}[\{\beta\}]$ temos que $\left.\left.\left.] \beta, \xi\right]=\right] g(\xi), \xi\right] \subset U_{\xi}$. Portanto, $\beta+1$ está em uma quantidade infinita de elementos de $\mathscr{R}$.

Enfim, chegamos ao ápice dessa seção. A fim de deixar a demonstração da Proposição 3.2.8 mais limpa faremos um lema técnico antes.

Lema 3.2.7. Seja $X$ hereditariamente metacompacto. Se o Jogador I possui estratégia vencedora em $P(X)$, então existe uma estratégia vencedora para o Jogador I em $P(X)$ tal que o mesmo joga apenas coberturas abertas ponto-finitas.

Demonstração. Seja $\sigma$ uma estratégia vencedora para o jogador I em $P(X)$. Seja $\sigma(\emptyset)$ o primeiro movimento do Jogador I e seja $\mathscr{C}_{0}=\sigma^{*}(\emptyset)$ um refinamento ponto-finito de $\sigma(\emptyset)$. Se o Jogador II escolhe $A_{0}^{*} \in \mathscr{C}_{0}$, então existe um elemento $A_{0} \in \sigma(\emptyset)$ tal que $A_{0}^{*} \subset A_{0}$. Seja $\sigma^{*}\left(A_{0}\right)$ um refinamento ponto-finito de $\sigma\left(A_{0}\right)$. Seja $\mathscr{C}_{1}=\left\{B^{*} \cap A_{0}^{*}: B^{*} \in \sigma^{*}\left(A_{0}\right)\right\}$ a jogada feita pelo Jogador I. Note que $\mathscr{C}_{1}$ é uma cobertura ponto-finita para $A_{0}^{*}$. Então o Jogador II escolhe $A_{1}^{*} \in \mathscr{C}_{1}$ tal que $A_{1}^{*}=B_{1}^{*} \cap A_{0}^{*} \operatorname{com} B_{1}^{*} \in \sigma^{*}\left(A_{0}\right)$. Assim, existe um aberto $A_{1} \in \sigma\left(A_{0}\right)$ tal que $B_{1}^{*} \subset A_{1}$. Seja $\sigma^{*}\left(A_{0}, A_{1}\right)$ um refinamento pointo-finito de $\sigma\left(A_{0}, A_{1}\right)$ e o Jogador I responde $\mathscr{C}_{2}=\left\{B^{*} \cap A_{1}^{*}: B^{*} \in \sigma^{*}\left(A_{0}, A_{1}\right)\right\}$. Novamente, observe que $\mathscr{C}_{2}$ é uma cobertura ponto-finita para $A_{1}^{*}$. Então o Jogador II escolhe $A_{2}^{*} \in \mathscr{C}_{2}, A_{2}^{*}=B_{2}^{*} \cap A_{1}^{*} \operatorname{com} B_{2}^{*} \in \sigma^{*}\left(A_{0}, A_{1}\right)$. Assim, existe um $A_{2} \in \sigma\left(A_{0}, A_{1}\right)$ tal que $B_{2}^{*} \subset A_{2}$.

Procedendo dessa maneira, na $n$-ésima rodada o Jogador I joga $\mathscr{C}_{n}=\left\{B^{*} \cap A_{n-1}^{*}: B^{*} \in\right.$ $\left.\sigma^{*}\left(A_{0}, \ldots, A_{n-1}\right)\right\}$ e o Jogador II toma $A_{n}^{*} \in \mathscr{C}_{n}$. Note que para cada $n \in \omega$ temos que $A_{n}^{*} \subset A_{n}$. Portanto,

$$
\left|\bigcap_{n \in \omega} A_{n}^{*}\right| \leq\left|\bigcap_{n \in \omega} A_{n}\right| \leq 1
$$

Proposição 3.2.8. Seja $(X, \tau)$ um espaço hereditariamente metacompacto. Se o Jogador I possui estratégia vencedora em $P(X)$ então o princípio $S_{1}(\mathscr{O}, \mathscr{H})$ não é satisfeito.

Demonstração. Como foi visto no lema anterior, podemos supor que o Jogador I só joga coberturas ponto-finitas. Seja $\sigma$ uma estratégia vencedora para o Jogador I em $P(X)$. Para cada $x \in X$, seja $S(x, \emptyset)=\{C \in \sigma(\emptyset): x \in C\}$ e $S\left(x, C_{0}, \ldots, C_{n}\right)=\left\{C \in \sigma\left(C_{0}, \ldots, C_{n}\right): C_{n} \in\right.$ $S\left(x, C_{0}, \ldots, C_{n-1}\right), \ldots, C_{0} \in S(x, \emptyset)$ e $\left.x \in C\right\}$. Note que $S(x, \emptyset)$ e $S\left(x, C_{0}, \ldots, C_{n}\right)$ são conjuntos finitos. Para cada $x \in X$, seja $V_{0}^{x}=\bigcap S(x, \emptyset)$ e $V_{n}^{x}=\bigcap\left\{\bigcap S\left(x, C_{0}, \ldots, C_{n}\right): C_{n} \in S\left(x, C_{0}, \ldots, C_{n-1}\right), \ldots, C_{0} \in\right.$ $S(x, \emptyset)\}$.

5 Para tanto, seja $C \subset \omega_{1}$ um club, por $C$ ser ilimitado conseguimos exibir uma sequência crescente $\left(x_{n}: n \in \omega\right) \subset C$. Note que $x=\sup \left\{x_{n}: n \in \omega\right\}$ é um ordinal limite e por $C$ ser fechado temos que $x \in C$. 
Para cada $n \in \omega$ vamos definir $\mathscr{C}_{n}=\left\{V_{n}^{z}: z \in X\right\}$. Iremos mostrar que para cada $x \in X$ teremos que $\bigcap\left\{S t\left(x, \mathscr{C}_{n}\right): n \in \omega\right\}=\{x\}$. Suponha que isso não aconteça, então existem $x, y \in X$ $\operatorname{com} x \neq y$ tais que $y \in \bigcap\left\{\operatorname{St}\left(x, \mathscr{C}_{n}\right): n \in \omega\right\}$. Note que se $S t\left(x, \mathscr{C}_{n}\right)=\bigcup\left\{V_{n}^{z}: z \in X\right.$ e $\left.x \in V_{n}^{z}\right\}$ então para cada $n \in \omega$ existe um $z_{n} \in X$ tal que $x, y \in V_{n}^{z_{n}}$. Seja $\operatorname{Lev}_{n}(T)=\bigcup\left\{S\left(x, C_{0}, \ldots, C_{n}\right)\right.$ : $\left.C_{n} \in S\left(x, C_{0}, \ldots, C_{n-1}\right), \ldots, C_{0} \in S(x, \emptyset)\right\}$ e seja $T=\bigcup\left\{\operatorname{Lev}_{n}(T): n \in \omega\right\}$. Temos que $(T, \leq)$ é uma árvore cujo a ordem é dada por " $\supseteq$ ”. Observe que $V_{n}^{z_{n}} \in \operatorname{Lev}_{n}(T)$ para cada $n \in \omega$.

Afirmação: Existe um ramo $R$ de $(T, \leq)$ tal que $x, y \in \bigcap R$.

Demonstração. Cada nível da árvore $(T, \leq)$ possui uma quantidade finita de elementos e estes se ramificam em outros finitos elementos no próximo nível. Observe que para cada $n \in \omega$ temos que $x, y \in V_{n}^{z_{n}}$ e isso implica que $x, y \in A_{n}$ para algum $A_{n} \in S\left(z_{n}, A_{0}, \ldots, A_{n-1}\right) \subset S\left(x, A_{0}, \ldots, A_{n-1}\right)$, para algum $A_{n-1} \in S\left(z_{n}, A_{0}, \ldots, A_{n-2}\right) \subset S\left(x, A_{0}, \ldots, A_{n-2}\right)^{6}, \ldots$, para algum $A_{0} \in S\left(z_{n}, \emptyset\right) \subset S(x, \emptyset)$. Além disso, $x, y \in A_{0} \cap \cdots \cap A_{n}$ e $A_{0} \leq \cdots \leq A_{n}$.

Então existe $C_{0} \in \operatorname{Lev}_{0}(T) \operatorname{com} x, y \in C_{0}$, e existe $\mathscr{A}_{0} \subset T$ com $\left|\mathscr{A}_{0}\right|=\omega$ tal que, para todo $A \in \mathscr{A}_{0}$, temos que $x, y \in A$ e $C_{0} \leq A$. Novamente, existe $C_{1} \in \operatorname{Lev}_{1}(T) \operatorname{com} x, y \in C_{1} \mathrm{e}$ existe $\mathscr{A}_{1} \subset \mathscr{A}_{0}$ com $\left|\mathscr{A}_{1}\right|=\omega$ tal que, para todo $A \in \mathscr{A}_{1}$, temos que $x, y \in A, C_{1} \leq A$ e $C_{0} \leq C_{1}$.

Procedendo dessa maneira, podemos encontrar para todo $n$ um elemento $C_{n} \in \operatorname{Lev}_{n}(T)$ tal que $C_{0} \leq C_{1} \leq \cdots \leq C_{n}$ e um subconjunto $\mathscr{A}_{n} \subset \mathscr{A}_{n-1}$ tal que $\left|\mathscr{A}_{n}\right|=\omega$ e, para cada $A \in \mathscr{A}_{n}$ tenhamos que $C_{n} \leq A$. Logo, $R=\left(C_{n}: n \in \omega\right)$ é o ramo desejado e $x, y \in C_{n}$ para cada $n \in \omega$.

Portanto, o Jogador II vence, o que é uma contradição. $\log o, \bigcap\left\{S t\left(x, \mathscr{C}_{n}\right): n \in \omega\right\}=\{x\}$ para cada $x \in X$.

Corolário 3.2.9. Seja $(X, \tau)$ um espaço hereditariamente metacompacto. Se o Jogador I possui estratégia vencedora em $G_{1}(\mathscr{O}, \mathscr{H})$, então o princípio $S_{1}(\mathscr{O}, \mathscr{H})$ não é satisfeito.

6 Na verdade $x, y \in A_{n}$ para TODO $A_{n} \in S\left(z_{n}, A_{0}, \ldots, A_{n-1}\right) \subset S\left(x, A_{0}, \ldots, A_{n-1}\right)$, mas para a observação precisamos que $x, y$ esteja contido e um único elemento apenas. 



\section{OUTROS JOGOS E ALGUMAS RELAÇÕES}

Neste capítulo, vamos definir outros jogos e estudar quais relações existem entre esses jogos e quais relações eles possuem com o jogo $G_{1}(\mathscr{O}, \mathscr{H})$. Posteriormente mostraremos que, se o espaço topológico for regular, o jogo $G_{1}(\mathscr{O}, \mathscr{H})$ será equivalente ao jogo $P(X)$. Para realizar tal feito, definiremos outros jogos novos que serão duais aos jogos $G_{1}(\mathscr{O}, \mathscr{H})$ e ao jogo $P(X)$. No final do capítulo, motivados pelos espaços de Moore, definiremos um novo princípio seletivo $S_{1}(\mathscr{O}, \mathscr{K})$ e analisaremos quais relações existem entre os jogos $G_{1}(\mathscr{O}, \mathscr{H})$ e $G_{1}(\mathscr{O}, \mathscr{K})$. Então, caro leitor, certifique-se de estar bem confortável quando fizer essa leitura, pois esse capítulo será bem técnico.

\subsection{Os jogos $G(X)$ e $P^{\prime}(X)$}

Agora introduziremos um jogo novo $G(X)$ que como veremos no próximo capítulo, terá relação com propriedades relacionadas a metrizabilidade. Além disso, mostraremos quais relações ele possui com o jogo $G_{1}(\mathscr{O}, \mathscr{H})$.

Definição 4.1.1. Seja $G(X)$ definido da seguinte forma: Na 0-ésima rodada o Jogador I joga $\mathscr{C}_{0} \in \mathscr{O}$ e o Jogador II escolhe $A_{0} \in \mathscr{C}_{0}$. Na próxima rodada, o Jogador I joga $\mathscr{C}_{1} \in \mathscr{O}\left(A_{0}\right)$ e, o Jogador I toma $A_{1} \in \mathscr{C}_{1}$. Na n-ésima rodada o Jogador I joga $\mathscr{C}_{n} \in \mathscr{O}\left(A_{n-1}\right)$ o Jogador II por sua vez toma $A_{n} \in \mathscr{C}_{n}$. Dizemos que o Jogador I vence se, dada uma cobertura arbitrária $\mathscr{C} \in \mathscr{O}$ para o espaço X e para qualquer sequência $\left(x_{n}: n \in \omega\right)$ com $x_{n} \in A_{n}$ para cada $n \in \omega$, existe $C \in \mathscr{C}$ e existe $m \in \omega$ tal que $x_{n} \in C$ para todo $n \geq m$.

Observação 4.1.2. Seja $(X, \tau)$ um espaço topológico. Note que podemos trocar o critério de vitória do Jogador I em $G(X)$ por: qualquer sequência $\left(x_{n}: n \in \omega\right)$ com $x_{n} \in A_{n}$ é convergente, onde $A_{n}$ é a escolha que o Jogador II faz na n-ésima rodada.

De fato, seja $\left(x_{n}: n \in \omega\right)$ uma sequência com $x_{n} \in A_{n}$ e suponha que convirja para $x$. Seja $\mathscr{C} \in \mathscr{O}$ uma cobertura aberta arbitrária, então existe $C \in \mathscr{C}$ e existe $m \in \omega$ com $x_{n} \in C$ para 
$n \geq m$. Seja $\left(x_{n}: n \in \omega\right)$ uma sequência com $x_{n} \in A_{n}$ e suponha que esta não seja convergente. Então para cada $x \in X$ existe um aberto $V_{x} \in \tau$ contendo $x$ tal que $\left(V_{x} \backslash\{x\}\right) \cap\left\{x_{n}: n \in \omega\right\}$ é no máximo finito. Logo, a cobertura $\left\{V_{x}: x \in X\right\}$ contrazir o fato do Jogador I possuir estratégia vencedora em $G(X)$.

Porém, ao longo do texto usaremos o critério de vitória para o Jogador I em $G(X)$ dado pela Definição 4.1.1.

Proposição 4.1.3. Se o Jogador I possui estratégia vencedora em $G(X)$ então o Jogador I possui estratégia vencedora em $P(X)$.

Demonstração. Seja $\sigma$ estratégia vencedora para o Jogador I em $G(X)$. Em $P(X)$, suponha, por absurdo, que o Jogador I não possua estratégia vencedora. $\operatorname{Em} P(X)$, na primeira rodada, suponha que o Jogador I jogue $\sigma(\emptyset)$ e o Jogador II escolhe $C_{0} \in \sigma(\emptyset)$ de forma que lhe garanta a vitória no final do jogo. Na $n$-ésima rodada o Jogador I joga $\sigma\left(C_{0}, \ldots, C_{n-1}\right) \in \mathscr{O}\left(C_{n-1}\right)$, então o Jogador II toma $C_{n} \in \sigma\left(C_{0}, \ldots, C_{n-1}\right)$ tal que no final do jogo $\left|\bigcap\left\{C_{n}: n \in \omega\right\}\right| \geq 2$. Sejam $x, y \in \bigcap\left\{C_{n}: n \in \omega\right\}$. Considere $\mathscr{C} \in \mathscr{O}$ tal que $\mathscr{C}=\{X \backslash\{x\}, X \backslash\{y\}\}$ e seja $\left(z_{n}: n \in \omega\right)$ com $z_{n}=x$ se $n$ for par e $z_{n}=y$ se $n$ ímpar. Portanto, não existe $m \in \omega$ tal que exista $C \in \mathscr{C}$ com $x_{n} \in C$ para $n \geq m$, o que contradiz o Jogador I possuir estratégia vencedora em $G(X)$.

Será que a implicação contrária da proposição anterior vale? Infelizmente, ou felizmente, não. Vamos mostrar que não é verdade que o Jogador I possuir estratégia vencedora no jogo $P(X)$ acarretará que o Jogador I possuirá estratégia vencedora em $G(X)$.

Exemplo 4.1.4. O jogador I possui estratégia vencedora em $P\left(\mathbb{R}_{S}\right)$.

De fato, na 0-ésima rodada o Jogador I joga $\sigma(\emptyset)=\{[z, z+1[: z \in \mathbb{Z}\}$ e o Jogador II escolhe $\left[z_{0}, z_{0}+1\left[\right.\right.$ para algum $z_{0} \in \mathbb{Z}$. Então, na próxima rodada, o Jogador I responde com $\sigma\left(\left[z_{0}, z_{0}+1[)=\left\{\left[z_{0}, z_{0}+1 / 2\left[,\left[z_{0}+1 / 2, z_{0}+1[\}\right.\right.\right.\right.\right.\right.$ e o Jogador II toma $\left[z_{0}+k_{0} / 2, z_{0}+\left(k_{0}+1\right) / 2[\right.$ para algum $k \in\{0,1\}$. Na n-ésima rodada o Jogador I joga

$$
\begin{aligned}
& \sigma\left(\left[z_{0}, z_{0}+1\left[, \ldots,\left[z_{0}+\sum_{i=0}^{n-2} \frac{k_{i}}{2^{i+1}}+\frac{k_{n-1}}{2^{n}}, z_{0}+\sum_{i=0}^{n-2} \frac{k_{i}}{2^{i+1}}+\frac{k_{n-1}+1}{2^{n}}\right]\right)=\right.\right. \\
& =\left\{\left[z_{0}+\sum_{i=0}^{n-1} \frac{k_{i}}{2^{i+1}}, z_{0}+\sum_{i=0}^{n-1} \frac{k_{i}}{2^{i+1}}+\frac{1}{2^{n+1}}\left[,\left[z_{0}+\sum_{i=0}^{n-1} \frac{k_{i}}{2^{i+1}}+\frac{1}{2^{n+1}}, z_{0}+\sum_{i=0}^{n-1} \frac{k_{i}}{2^{i+1}}+\frac{1}{2^{n}}[\}\right.\right.\right.\right.
\end{aligned}
$$

onde $k_{0}, \ldots, k_{n-1} \in\{0,1\}$.

Então o Jogador II escolhe

$$
\left[z_{0}+\sum_{i=0}^{n-1} \frac{k_{i}}{2^{i+1}}+\frac{k_{n}}{2^{n+1}}, z_{0}+\sum_{i=0}^{n-1} \frac{k_{i}}{2^{i+1}}+\frac{k_{n}+1}{2^{n+1}}[\right.
$$


para algum $k_{n} \in\{0,1\}$. Logo,

$$
\mid \bigcap_{n \in \omega}\left[z_{0}+\sum_{i=0}^{n-1} \frac{k_{i}}{2^{i+1}}+\frac{k_{n}}{2^{n+1}}, z_{0}+\sum_{i=0}^{n-1} \frac{k_{i}}{2^{i+1}}+\frac{k_{n}+1}{2^{n+1}}[\mid \leq 1 .\right.
$$

Note que os intervalos escolhidos pelo Jogador II na n-ésima rodada possuem comprimento $1 / 2^{n+1}$. Na pior das hipóteses essa intersecção possui um único elemento.

Para o próximo exemplo veremos uma versão do Teorema dos Intervalos Encaixantes para a reta de Sorgenfrey.

Observação 4.1.5. Sejam $\left\{\left[a_{n}, b_{n}[: n \in \omega\}\right.\right.$ não vazios tais que para todo $n \in \omega$ temos que $a_{n}<a_{n+1}$ e $b_{n+1}<b_{n}$. Além disso queremos que, dado $\varepsilon>0$, existe $n \in \omega$ tal que $b_{n}-a_{n}<\varepsilon$. Note que $a_{m}<b_{n}$ para todos $m, n \in \omega$. Logo, existe $c \in \mathbb{R}$ tal que $a_{n}<c<b_{n}$ para todo $n \in \omega$. Suponha que exista $d \in \mathbb{R}$ com $d \neq c$ tal que $a_{n}<d<b_{n}$ para todo $n \in \omega$, então $|c-d|<b_{n}-a_{n}$ para todo $n \in \omega$. Portanto $c=d$.

Exemplo 4.1.6. O Jogador II possui estratégia vencedora em $G\left(\mathbb{R}_{S}\right)$.

Na 0-ésima rodada o Jogador I joga $\mathscr{C}_{0} \in \mathscr{O}$. Por sua vez, o Jogador II escolhe $A_{0} \in \mathscr{C}_{0}$ e toma $a_{0}, b_{0} \in A_{0}$ tal que $\left[a_{0}, b_{0}\left[\subset A_{0}\right.\right.$. Na próxima rodada, o Jogador I joga $\mathscr{C}_{1} \in \mathscr{O}\left(A_{0}\right)$. Então, o Jogador II toma $A_{1} \in \mathscr{C}_{1}$ tal que $a_{0} \in A_{1}$. Então, existe $b_{1} \in A_{1}$ tal que $\left[a_{0}, b_{1}\left[\subset A_{1}\right.\right.$ e $\left|b_{1}-a_{0}\right|<1 / 2$. Tome $a_{1}=\left(a_{0}+b_{1}\right) / 2$, daí $\left[a_{1}, b_{1}\left[\subset A_{1}\right.\right.$. Na n-ésima rodada, o jogador I joga $\mathscr{C}_{n} \in \mathscr{O}\left(A_{n-1}\right)$ e o Jogador II escolhe $A_{n} \in \mathscr{C}_{n}$ tal que $a_{n-1} \in A_{n}$ e assim, existe $b_{n} \in A_{n}$ tal que $\left[a_{n-1}, b_{n}\left[\subset A_{n}\right.\right.$ e $\left|b_{n}-a_{n-1}\right|<1 / 2^{n}$. Então, seja $a_{n}=\left(a_{n-1}+b_{n}\right) / 2$, logo, $\left[a_{n}, b_{n}\left[\subset A_{n}\right.\right.$. Pela Observação 4.1.5, existe $c \in \mathbb{R}$ tal que $\{c\}=\bigcap_{n \in \omega}\left[a_{n}, b_{n}[\right.$. Tome a seguinte cobertura $\mathscr{C}=\{]-\infty, a_{0}[\} \cup\left\{\left[c,+\infty[\} \cup\left\{\left[a_{n}, a_{n-1}[: n \in \omega\}\right.\right.\right.\right.$. Logo, se tomarmos a sequência $\left(a_{n}: n \in \omega\right)$ temos que, para cada $n \in \omega, a_{n} \in A_{n}$ e não existe $C \in \mathscr{C}$ tal que exista $k \in \omega$ satisfazendo $a_{n} \in C$ para todo $n \geq k$.

Faremos agora uma modificação no jogo $P(X)$ que nos trará alguns resultados interessantes

Definição 4.1.7. Considere o seguinte jogo $P^{\prime}(X): N a$-ésima rodada o Jogador I joga $\mathscr{C}_{0} \in \mathscr{O}$ e o Jogador II toma $C_{0} \in \mathscr{C}_{0}$. Na rodada seguinte o Jogador I joga $\mathscr{C}_{1} \in \mathscr{O}\left(C_{0}\right)$ e, por sua vez, o Jogador II escolhe $C_{1} \in \mathscr{C}_{1}$. Na n-ésima rodada o Jogador I joga $\mathscr{C}_{n} \in \mathscr{O}\left(C_{n-1}\right)$ onde $C_{n-1} \in \mathscr{C}_{n-1}$ e o Jogador II toma $C_{n} \in \mathscr{C}_{n}$. O jogador II vence se $\left|\cap\left\{C_{n}: n \in \omega\right\}\right|=1$.

Naturalmente, temos que se o Jogador I possui estratégia vencedora em $P^{\prime}(X)$, então o Jogador I possui estratégia vencedora em $P(X)$.

Respondendo à pergunta mais natural possível, será que conseguimos o mesmo resultado obtido pela Proposição 4.1.3 trocando o jogo $P(X)$ pelo jogo $P^{\prime}(X)$. A resposta é sim. Porém, precisamos que o espaço seja regular. Antes de mostrar isso de fato, precisamos do seguinte lema auxiliar: 
Lema 4.1.8. Seja $X$ regular. Suponha que o Jogador I possua estratégia vencedora em $G(X)$. Então existe uma estratégia vencedora $\delta$ para o Jogador I tal que para todo $C \in \delta\left(C_{0}, \ldots, C_{n-1}\right)$ temos que $\bar{C} \varsubsetneqq C_{n-1}$.

Antes de fazer a demonstração do Lema considere a seguinte observação que também será útil no próximo capítulo.

Observação 4.1.9. Seja $U$ aberto não vazio sem pontos isolados e seja $x \in U$. Então existe um aberto não vazio $V \subset U$ tal que $x \in U \backslash \bar{V}$. De fato, seja $y \in U$ com $x \neq y$. Como $U$ é de Hausdorff, então existem $A, B \in \tau$ tal que $x \in A, y \in B$ e $A \cap B=\emptyset$. Logo, existe $V \in \tau$ tal que $y \in V \subset \bar{V} \subset B \cap U$. Assim, $x \in U \backslash \bar{V}$.

Demonstração do Lema 4.1.8. Seja $\sigma$ estratégia vencedora para o Jogador I em $G(X)$. Defina $\delta(\emptyset)=\sigma(\emptyset)$ e $\delta\left(C_{0}\right)=\left\{C_{x}: x \in C_{0}\right.$ e $\left.x \in C_{x} \subset \overline{C_{x}} \varsubsetneqq C_{0}\right\}$. Suponha que o Jogador II escolha $C_{x_{1}} \in \delta\left(C_{0}\right)$ então teremos que $\delta\left(C_{0}, C_{x_{1}}\right)=\left\{C_{y}: y \in C_{y} \subset \overline{C_{y}} \varsubsetneqq C_{x_{1}} \cap C_{1}\right.$ onde $C_{1} \in \sigma\left(C_{0}\right)$ tal que $\left.C_{x_{1}} \cap C_{1} \neq \emptyset\right\}$. Na $n$-ésima rodada temos que $\delta\left(C_{0}, \ldots, C_{x_{n}}\right)=\left\{C_{y}: y \in C_{y} \subset \overline{C_{y}} \varsubsetneqq C_{x_{n}} \cap C_{n}\right.$ onde $C_{n} \in \sigma\left(C_{0}, \ldots, C_{n-1}\right)$ tal que $\left.C_{x_{n}} \cap C_{n} \neq \emptyset\right\}$.

Agora, seja $\left(x_{n}: n \in \omega\right)$ tal que $x_{n} \in C_{x_{n}}$ e seja $\mathscr{C} \in \mathscr{O}$ arbitrário. Note que para cada $n \in \omega$ temos que existe $x_{n} \in C_{n}$ então por $\sigma$ ser vencedora para o Jogador I em $G(X)$ implica que existe $C \in \mathscr{C}$ tal que existe $m \in \omega$ tal que $x_{n} \in C$ para $n \geq m$.

Proposição 4.1.10. Seja X regular. Se o Jogador I possui estratégia vencedora em $G(X)$ então o Jogador I possui estratégia vencedora em $P^{\prime}(X)$.

Demonstração. Seja $\sigma$ estratégia vencedora para o Jogador I em $G(X)$ que satisfaça o lema anterior. Suponha que o Jogador I não possua estratégia vencedora em $P^{\prime}(X)$. Neste mesmo jogo, na $n$-ésima rodada o Jogador I joga $\sigma\left(C_{0}, \ldots, C_{n-1}\right) \in \mathscr{O}\left(C_{n-1}\right)$ tal que para todo $C \in$ $\sigma\left(C_{0}, \ldots, C_{n-1}\right)$ temos que $\bar{C} \subset C_{n-1}$. Então $\left|\bigcap\left\{C_{n}: n \in \omega\right\}\right| \neq 1$. Se $\left|\bigcap\left\{C_{n}: n \in \omega\right\}\right| \geq 2$ temos um absurdo! (Basta ver a Proposição 4.1.3). Se $\left|\cap\left\{C_{n}: n \in \omega\right\}\right|=\emptyset$ seja $\mathscr{C}=\left\{X \backslash \overline{C_{1}}\right\} \cup\left\{C_{n} \backslash\right.$ $\left.\overline{C_{n+2}}: n \in \omega\right\} \in \mathscr{O}$. Seja $\left(x_{n}: n \in \omega\right)$ tal que $x_{n} \in C_{n} \backslash \overline{C_{n+1}}$. Pois, para cada $n \in \omega$ temos que $C_{n} \backslash \overline{C_{n+1}} \neq \emptyset$ devido à Observação 4.1.9. Note que, para cada $n \in \omega$, temos que $x_{n+1} \in C_{n} \backslash \overline{C_{n+2}}$ e $x_{k} \notin C_{n} \backslash \overline{C_{n+2}}$ para $k \geq n+1$, o que é um absurdo. Sendo assim, o Jogador I possui estratégia vencedora em $P^{\prime}(X)$.

\subsection{Jogos duais aos jogos $G_{1}(\mathscr{O}, \mathscr{H})$ e $P(X)$}

Existe um jogo chamado ponto-aberto. Esse jogo, como o próprio nome revela, na $n$ ésima rodada consiste em o Jogador I escolher um ponto e o Jogador II escolher um aberto que contenha esse ponto. No final, o Jogador I vence se a união de todos os abertos que o Jogador II escolheu é o espaço todo. Em (GALVIN, 1978) vemos que o Jogador I possuir estratégia 
vencedora no jogo de Rothberger é o mesmo que dizer que no jogo ponto-aberto o Jogador II possui estratégia vencedora. Além disso, foi mostrado também que o Jogador II possuir estratégia vencedora no jogo de Rothberger é equivalente ao Jogador I possuir estratégia vencedora no jogo ponto-aberto. Numa situação como essa, diremos que um jogo é dual ao outro. Encontrar jogos duais muitas vezes ajuda a mostrar resultados para os jogos originais, como veremos mais tarde nessa seção. Definiremos agora um jogo que é dual a $G_{1}(\mathscr{O}, \mathscr{H})$.

Definição 4.2.1. Considere $P A(X)$ o seguinte jogo: Na n-ésima rodada o Jogador I joga um ponto $x_{n} \in X$ e o Jogador II joga $A_{n} \in \tau$ tal que $x_{n} \in A_{n}$. O Jogador I vence se $\left|\bigcap\left\{A_{n}: n \in \omega\right\}\right| \geq 2$.

Proposição 4.2.2. O jogo $P A(X)$ é dual ao jogo $G_{1}(\mathscr{O}, \mathscr{H})$

\section{Demonstração.}

Afirmação 1: I $\uparrow P A(X) \Rightarrow \mathrm{II} \uparrow G_{1}(\mathscr{O}, \mathscr{H})$.

Seja $\sigma$ uma estratégia vencedora para o Jogador I em $P A(X)$. Em $G_{1}(\mathscr{O}, \mathscr{H})$, seja $\mathscr{C}_{0} \in \mathscr{O}$ a primeira jogada do Jogador I em $G_{1}(\mathscr{O}, \mathscr{H})$. Então o Jogador II toma $A_{0} \in \mathscr{C}_{0}$ tal que $x_{0}=\sigma(\emptyset) \in A_{0}$. Na próxima rodada o Jogador I joga $\mathscr{C}_{1} \in \mathscr{O}$ e o Jogador II toma $A_{1} \in \mathscr{C}_{1}$ tal que $x_{1}=\sigma\left(A_{0}\right) \in \mathscr{C}_{1}$, e assim por diante. Temos que $\left(x_{0}, A_{0}, x_{1}, A_{1}, \ldots\right)$ forma uma partida em $P A(X)$ em que o Jogador I vence, logo

$$
\left|\bigcap\left\{A_{n}: n \in \omega\right\}\right| \geq 2 .
$$

Portanto, em $G_{1}(\mathscr{O}, \mathscr{H})$, o Jogador II vence .

Afirmação 2: I $\uparrow G_{1}(\mathscr{O}, \mathscr{H}) \Rightarrow \mathrm{II} \uparrow P A(X)$.

Seja $\sigma$ estratégia vencedora para o Jogador I em $G_{1}(\mathscr{O}, \mathscr{H})$. Em $P A(X)$ seja $x_{0} \in X$ a primeira jogada do Jogador I em $P A(X)$. Então o Jogador II toma $A_{0} \in \sigma(\emptyset)$ tal que $x_{0} \in A_{0}$. Na próxima rodada, o Jogador I joga $x_{1} \in X$ e o Jogador II toma $A_{1} \in \sigma\left(A_{0}\right)$ tal que $x_{1} \in A_{1}$. E assim por diante. Temos que $\left(A_{0}, \mathscr{C}_{0}, A_{1}, \mathscr{C}_{1}, \ldots\right)$ forma uma partida em $G_{1}(\mathscr{O}, \mathscr{H})$ em que o Jogador I vence, logo

$$
\left|\bigcap\left\{A_{n}: n \in \omega\right\}\right| \leq 1 .
$$

Portanto, em $P A(X)$, o Jogador II vence .

Seja $\sigma$ estratégia vencedora para o Jogador II em $P A(X)$. Então $\{\sigma(x): x \in X\}$ é uma cobertura aberta para $X$. Para ver isso, basta notar que para cada $x \in X$ temos que $x \in \sigma(x) \in \tau$. Note também que $\left\{\sigma\left(x_{0}, \ldots, x_{n}, x\right): x \in X\right\}$ é uma cobertura aberta para $X$. 
Afirmação 3: II $\uparrow P A(X) \Rightarrow \mathrm{I} \uparrow G_{1}(\mathscr{O}, \mathscr{H})$.

Seja $\sigma$ estratégia vencedora para o Jogador II em $P A(X)$. Em $G_{1}(\mathscr{O}, \mathscr{H})$ o Jogador I joga $\mathscr{C}_{0}=\{\sigma(x): x \in X\}$ e o Jogador II toma $\sigma\left(x_{0}\right)$ para algum $x_{0} \in X$. Na próxima rodada, o Jogador I joga $\mathscr{C}_{1}=\left\{\sigma\left(x_{0}, x\right): x \in X\right\}$ e o Jogador II toma $\sigma\left(x_{0}, x_{1}\right)$ para algum $x_{1} \in X$. E assim por diante. Temos que $\left(x_{0}, \sigma\left(x_{0}\right), x_{1}, \sigma\left(x_{0}, x_{1}\right), \ldots\right)$ forma uma partida em $P A(X)$ em que o Jogador II vence, $\log 0$

$$
\left|\bigcap\left\{\sigma\left(x_{0}, \ldots, x_{n-1}, x_{n}\right): n \in \omega\right\}\right| \leq 1 .
$$

Portanto, em $G_{1}(\mathscr{O}, \mathscr{H})$, o Jogador I vence .

Seja $\sigma$ estratégia vencedora para II em $G_{1}(\mathscr{O}, \mathscr{H})$. Note que existe um ponto $y \in X$ tal que, se $A$ é um aberto qualquer que contém $y$, existe $\mathscr{C} \in \mathscr{O}$ tal que $\sigma(\mathscr{C})=A$. Suponha que isso não ocorra. Ou seja, para todo $x \in X$ existe $A_{x} \in \tau$ tal que $x \in A_{x}$ e, para todo $\mathscr{C} \in \mathscr{O}$ temos que $\sigma(\mathscr{C}) \neq A_{x}$. Observe que $\mathscr{A}=\left\{A_{x}: x \in X\right\} \in \mathscr{O}$ e $\sigma(\mathscr{A})=A_{x}$ para algum $x \in X$, o que é uma contradição.

Afirmação 4: II $\uparrow G_{1}(\mathscr{O}, \mathscr{H}) \Rightarrow \mathrm{I} \uparrow P A(X)$.

Seja $\sigma$ estratégia vencedora para o Jogador II em $G_{1}(\mathscr{O}, \mathscr{H})$. Em $P A(X)$ o Jogador I joga $x_{0} \in X$ seguindo as condições acima e o Jogador II toma $A_{0} \in \tau$ tal que $x_{0} \in A_{0}$. Logo, existe $\mathscr{C}_{0} \in \mathscr{O}$ tal que $\sigma\left(\mathscr{C}_{0}\right)=A_{0}$. Na próxima rodada, o Jogador I joga $x_{1} \in X$, novamente, seguindo as condições acima e o Jogador II toma $A_{1} \in \tau$ tal que $x_{1} \in A_{1}$, logo existe $\mathscr{C}_{1} \in \mathscr{O}$ tal que $\sigma\left(\mathscr{C}_{1}\right)=A_{1}$. E assim por diante.

Logo, $\left|\bigcap\left\{A_{n}: n \in \omega\right\}\right|=\left|\bigcap\left\{\sigma\left(\mathscr{C}_{n}\right): n \in \omega\right\}\right| \geq 2$.

De maneira parecida com o que foi feito acima, conseguimos exibir um jogo que é dual ao jogo $P(X)$.

Definição 4.2.3. Considere $P A^{\prime}(X)$ o seguinte jogo: Na 0-ésima rodada o Jogador I joga um ponto $x_{0} \in X$ e o Jogador II joga um aberto $A_{0}$ tal que $x_{0} \in A_{0}$. Na proxima rodada o Jogador I joga $x_{1} \in A_{0}$ e o Jogador II joga um aberto $A_{1} \subset A_{0}$ tal que $x_{1} \in A_{1}$. Na n-ésima rodada o Jogador I joga um ponto $x_{n} \in A_{n-1}$ e o Jogador II joga $A_{n} \subset A_{n-1}$ tal que $x_{n} \in A_{n}$. O Jogador I vence se $\left|\bigcap\left\{A_{n}: n \in \omega\right\}\right| \geq 2$.

Proposição 4.2.4. O jogo $P A^{\prime}(X)$ é dual ao jogo $P(X)$.

Demonstração. Basta repetir o que foi feito na demonstração da Proposição 4.2.2 tomando os devidos cuidados com respeito aos jogos $P A^{\prime}(X)$ e $P(X)$. 
O próximo resultado mostra que num espaço topológico regular, se o Jogador I tiver estratégia vencedora em $P(X)$, então o Jogador I terá estratégia vencedora em $\uparrow G_{1}(\mathscr{O}, \mathscr{H})$.

Proposição 4.2.5. Seja X regular. O Jogador I possuir estratégia vencedora em $P A^{\prime}(X)$ é equivalente ao Jogador I posuir estratégia vencedora em $P A(X)$. Além disso, o Jogador II possuir estratégia vencedora em $P A^{\prime}(X)$ é equivalente ao Jogador II possuir estratégia vencedora em $P A(X)$.

\section{Demonstração.}

$\mathrm{I} \uparrow P A^{\prime}(X) \Rightarrow \mathrm{I} \uparrow P A(X)$.

Seja $\sigma$ estratégia vencedora para o Jogador I em $P A^{\prime}(X)$. Em $P A(X)$, o Jogador I joga $\sigma(\emptyset)$ e o Jogador II toma $A_{0} \in \tau$ tal que $\sigma(\emptyset) \in A_{0}$. Na próxima rodada o Jogador I joga $\sigma\left(A_{0}\right) \in A_{0}$ e o Jogador II toma $A_{1} \in \tau$ tal que $\sigma\left(A_{0}\right) \in A_{1}$. Seja $B_{1}=A_{1} \cap A_{0}$ (note que $B_{1} \neq \emptyset$, pois $\left.\sigma\left(A_{0}\right) \in B_{1}\right)$. Defina $B_{0}=A_{0}$. Na próxima rodada o Jogador I joga $\sigma\left(B_{0}, B_{1}\right) \in B_{1}$ e o Jogador II joga $A_{2} \in \tau$ tal que $\sigma\left(B_{0}, B_{1}\right) \in A_{2}$. Seja $B_{2}=A_{2} \cap B_{1}$. Na $n$-ésima rodada o Jogador I joga $\sigma\left(B_{0}, \ldots, B_{n-1}\right) \in B_{n-1}$ e o Jogador II toma $A_{n} \in \tau$ tal que $\sigma\left(B_{0}, \ldots, B_{n-1}\right) \in A_{n}$. Seja $B_{n}=A_{n} \cap B_{n-1}$. Note que $B_{n+1} \subset B_{n}$ e $B_{n} \subset A_{n}$ para todo $n \in \omega$. Como o Jogador I possui estratégia vencedora em $P A^{\prime}(X)$ temos que

$$
2 \leq\left|\bigcap\left\{B_{n}: n \in \omega\right\}\right| \leq\left|\bigcap\left\{A_{n}: n \in \omega\right\}\right|
$$

e portanto o Jogador I possui estratégia vencedora em $P A(X)$.

$\mathrm{I} \uparrow P A(X) \Rightarrow \mathrm{I} \uparrow P A^{\prime}(X)$

Aqui usaremos a regularidade do espaço para evitar que em $P A(X)$ a estratégia vencedora para o Jogador I permita que exista uma rodada em que ele jogue um ponto na fronteira do aberto jogado pelo Jogador II na rodada anterior.

Seja $\sigma$ estratégia vencedora para o Jogador I em $P A(X)$. Em $P A^{\prime}(X)$ o Jogador I joga $\sigma(\emptyset)$ e o Jogador II joga $A_{0} \in \tau$ tal que $\sigma(\emptyset) \in A_{0}$. Seja $B_{0} \in \tau$ tal que $\sigma(\emptyset) \in B_{0} \subset \overline{B_{0}} \subset A_{0}$. Em $P A(X)$ o Jogador I "pensa" que, ao invés de $A_{0}$, o Jogador II jogou $B_{0}$ e, assim, o Jogador I responde com $\sigma\left(B_{0}\right)$. Note que $\sigma\left(B_{0}\right) \in \overline{B_{0}}$, pois, caso contrário, o Jogador II poderia escolher $V \ni \sigma\left(B_{0}\right)$ aberto tal que $V \cap B_{0}=\emptyset$. Voltando para o jogo $P A^{\prime}(X)$ o Jogador I joga $\sigma\left(B_{0}\right) \in A_{0}$ e o Jogador II escolhe $A_{1} \subset A_{0}$ tal que $\sigma\left(B_{0}\right) \in A_{1}$. Novamente, seja $B_{1} \in \tau$ tal que $\sigma\left(B_{0}\right) \in$ $B_{1} \subset \overline{B_{1}} \subset A_{1}$. Em $P A(X)$ o Jogador I "pensa" que, ao invés de $A_{1}$, o Jogador II jogou $B_{1}$ e, então, o Jogador I responde com $\sigma\left(B_{0}, B_{1}\right) \in \overline{B_{1}} \subset A_{1}$. Voltando para o Jogo $P A^{\prime}(X)$ o Jogador I joga $\sigma\left(B_{0}, B_{1}\right) \subset A_{1}$ e o Jogador II responde tomando $A_{2} \subset A_{1}$ tal que $\sigma\left(B_{0}, B_{1}\right) \in A_{2}$ e assim por diante. 
Note que, para todo $n \in \omega$, temos que $B_{n} \subset A_{n}$ e, pelo fato do Jogador I possuir estratégia vencedora em $P A$, temos

$$
2 \leq\left|\bigcap\left\{B_{n}: n \in \omega\right\}\right| \leq\left|\bigcap\left\{A_{n}: n \in \omega\right\}\right| .
$$

II $\uparrow P A(X) \Rightarrow$ II $\uparrow P A^{\prime}(X)$.

Seja $\sigma$ estratégia vencedora para o Jogador II em $P A(X)$. Seja $x_{0} \in X$ a primeira jogada do Jogador I. O Jogador II responde com $A_{0}=\sigma\left(x_{0}\right)$. Na próxima rodada I toma $x_{1} \in A_{0}$ e o Jogador II toma $A_{1}=\sigma\left(x_{0}, x_{1}\right) \cap A_{0}$. O Jogador I joga $x_{2} \in A_{1}$ e o Jogador II responde com $A_{2}=\sigma\left(x_{0}, x_{1}, x_{2}\right) \cap A_{1}$. E assim por diante. Observe que, para cada $n \in \omega$, temos que $A_{n} \subset \sigma\left(x_{0}, \ldots, x_{n}\right)$. Logo

$$
\left|\bigcap\left\{A_{n}: n \in \omega\right\}\right| \leq\left|\bigcap\left\{\sigma\left(x_{0}, \ldots, x_{n}\right): n \in \omega\right\}\right| \leq 1 .
$$

$\mathrm{II} \uparrow P A^{\prime}(X) \Rightarrow \mathrm{II} \uparrow P A(X)$.

Aqui usaremos a regularidade para permitir que, em $P A(X)$, em qualquer rodada, mesmo que o Jogador I escolha pontos na fronteira de abertos jogados pelo Jogador II na rodada anterior no final do jogo o Jogador II vencerá.

Seja $\sigma$ estratégia vencedora para o Jogador II em $P A^{\prime}(X)$. Em $P A(X)$, seja $x_{0} \in X$ a primeira jogada do Jogador I. Seja $V_{0} \in \tau$ tal que $x_{0} \in V_{0} \subset \overline{V_{0}} \subset \sigma\left(x_{0}\right)$. O Jogador II joga $V_{0}$. Note que, se o Jogador I jogar em $X \backslash \overline{V_{0}}$, ele perde. Sendo assim, o Jogador I joga $x_{1} \in \overline{V_{0}} \subset \sigma\left(x_{0}\right)$. Então $\sigma\left(x_{0}, x_{1}\right) \subset \sigma\left(x_{0}\right)$ é tal que $x_{1} \in \sigma\left(x_{0}, x_{1}\right)$. Seja $V_{1} \in \tau$ tal que $x_{1} \in V_{1} \subset \overline{V_{1}} \subset \sigma\left(x_{0}, x_{1}\right)$, Logo, o Jogador II joga $V_{1}$, e assim por diante.

Então

$$
\left|\bigcap\left\{V_{n}: n \in \omega\right\}\right| \leq\left|\bigcap\left\{\sigma\left(x_{0}, \ldots, x_{n}\right): n \in \omega\right\}\right| \leq 1
$$

Corolário 4.2.6. Seja X um espaço topológico regular. O Jogador I possui estratégia vencedora em $G_{1}(\mathscr{O}, \mathscr{H})$ se, e somente se, o Jogador I possui estratégia vencedora em $P(X)$.

Demonstração. Basta combinar as Proposições 4.2.2, 4.2.4 e 4.2.5.

\subsection{0 jogo $G_{1}(\mathscr{O}, \mathscr{K})$}

Através do jogo $G_{1}(\mathscr{O}, \mathscr{H})$ conseguimos generalizar a propriedade da diagonal $G_{\delta} \mathrm{e}$ esta última propriedade, como já foi dito, se faz muito importante em teoremas de metrizabilidade. Um resultado muito importante sobre metrizabilidade é o Teorema Metrizabilidade de 
Moore. Mas antes de enunciá-lo precisamos entender o que é um espaço topológico possuir um desenvolvimento forte.

Definição 4.3.1. Seja $X$ um espaço topológico. Uma sequência de coberturas abertas $\left(\mathscr{C}_{n}: n \in\right.$ $\omega)$ é um desenvolvimento para $X$ se, para todo $x \in X$ e para toda $U$ vizinhança de $x$, existe $n \in \omega$ tal que $S t\left(V, \mathscr{C}_{n}\right) \subset U$. Um espaço $X$ é dito ser de Moore se existe uma sequência enumerável de coberturas abertas que é um desenvolvimento para $X$.

Será que existe alguma relação entre espaços de Moore e o jogo $G_{1}(\mathscr{O}, \mathscr{H})$ ? Ou entre os demais jogos? Para enxergarmos quais são essas relações definiremos um novo jogo. Seja $\mathscr{K}=\left\{R \in(\tau \backslash\{\emptyset\})^{\omega}:|\bigcap R| \geq 2 \text { ou } R \text { não é base para qualquer } y \in \bigcap R\right\}^{1}$ e considere o jogo $G_{1}(\mathscr{O}, \mathscr{K})$. Note que

Proposição 4.3.2. Se o Jogador I possuir estratégia vencedora em $G_{1}(\mathscr{O}, \mathscr{K})$ então o Jogador I possui estratégia vencedora em $G_{1}(\mathscr{O}, \mathscr{H})$. Porém a recíproca não é verdadeira.

Antes de começar a demonstração enunciaremos e daremos alguns resultados sobre familías dominantes e famílias ilimitadas. Existem muitos resultados e aplicações relacionados à esses objetos. Para ver mais resultados sobre esse tema veja (JECH, 2003) e (KUNEN, 2011).

Definição 4.3.3. Sejam $f, g \in \omega^{\omega}$. Dizemos que $f \leq^{*} g$ se $\{n \in \omega: f(n)>g(n)\}$ é finito. Em outras palavras, $f \leq^{*}$ g se existe $k \in \omega$ tal que $f(n) \leq g(n)$ para todo $n>k$.

Mostremos que $\leq^{*}$ é uma pré-ordem (isto é, igual a ordem parcial mas sem a hipótese de que $a \leq b$ e $b \leq a$ implica $a=b$ ).

1. Seja $f \in \omega^{\omega}$. Como $\{n \in \omega: f(n)>f(n)\}=\emptyset$ então $f \leq^{*} f$ para todo $f \in \omega^{\omega}$.

2. Sejam $f, g, h \in \omega^{\omega}$ tais que $f \leq^{*} g$ e $g \leq^{*} h$. Então os conjuntos $A=\{n \in \omega: f(n)>g(n)\}$ e $B=\{n \in \omega: g(n)>h(n)\}$ são finitos. Suponha que exista $k \in\{n \in \omega: f(n)>h(n)\}$ tal que $k \notin A$ e $k \notin B$. Então $f(k) \leq g(k)$ e $g(k) \leq h(k)$ que implica $f(k) \leq h(k)$ o que é um absurdo. Logo $\{n \in \omega: f(n)>h(n)\} \subset A \cup B$ que é finito. Portanto $f \leq^{*} h$.

Definição 4.3.4. Dizemos que uma família $A \subset \omega^{\omega}$ é ilimitada se não existe $g \in \omega^{\omega}$ tal que, para todo $f \in A, f \leq^{*} g$. Dizemos que uma família $A \subset \omega^{\omega}$ é dominante se para todo $g \in \omega^{\omega}$, existe $f \in A$ tal que $g \leq^{*} f$.

Com isso temos:

$\overline{1}$ Note que se o espaço $X$ for $T_{1}$ então $\mathscr{K}=\left\{R \in(\tau \backslash\{\emptyset\})^{\omega}: R\right.$ não é base para qualquer $\left.y \in \bigcap R\right\}$. Suponha que $|\cap A| \geq 2$ para $A \in(\tau \backslash\{\emptyset\})^{\omega}$. Vamos mostrar que $A$ não é base para qualquer $x \in \bigcap A$. Sejam $x$ e $y$ distintos tais que $x, y \in \bigcap A$, como $X$ é $T_{1}$ existe $U \in \tau$ tal que $x \in U$ e $y \notin U$, porém, não existe $A_{n} \in A$ tal que $A_{n} \subset U$. 
Proposição 4.3.5. Toda família dominante é ilimitada.

Demonstração. Suponha por absurdo que $A$ seja uma família dominante e limitada, isto é, existe $g \in \omega^{\omega}$ tal que $f \leq^{*} g$ para toda $f \in A$. Defina $\tilde{g}$ como $\tilde{g}(n)=g(n)+1$. Como $A$ é dominante, existe $h \in A$ tal que $\tilde{g} \leq^{*} h$. Como $h \leq^{*} g$ e $\tilde{g} \leq^{*} h$, existe $a \in \omega$ tal que $h(a) \leq g(a)$ e $\tilde{g}(a) \leq h(a)$ 2. Mas note que, para todo $n \in \omega$, temos que $g(n)<\tilde{g}(n)$. Portanto $h(a)<h(a)$ o que é um absurdo.

Com a próxima proposição, podemos concluir que toda família dominante é não enumerável.

Proposição 4.3.6. Não existe uma família ilimitada que seja enumerável.

Demonstração. Suponha que exista uma família ilimitada que seja enumerável. Seja $A=\left\{f_{i}\right.$ : $i \in \omega\}$ tal família. Defina $f$ como:

$$
\begin{aligned}
& f(0)=1+f_{0}(0) \\
& f(1)=1+f_{0}(1)+f_{1}(1) \\
& f(2)=1+f_{0}(2)+f_{1}(2)+f_{2}(2) \\
& \quad \vdots \\
& f(n)=1+1+f_{0}(2)+f_{1}(2)+\cdots+f_{n}(n) .
\end{aligned}
$$

Note que até pode ocorrer que $f_{1}(0)>f(0)$, mas $f_{1}(n)<f(n)$ para todo $n \geq 1$. Logo $\mid\{n \in$ $\left.\omega: f_{1}(n)>f(n)\right\} \mid \leq 1$. Assim como pode ocorrer que $f_{2}(0)>f(0)$ e $f_{2}(1)>f(1)$, porém $f_{2}(n)<f(n)$ para $n \geq 2$. Então $\left|\left\{n \in \omega: f_{2}(n)>f(n)\right\}\right| \leq 2$. Assim, para $k \in \omega$ :

$$
\left|\left\{n \in \omega: f_{k}(n)>f(n)\right\}\right| \leq k
$$

Logo $f_{k} \leq^{*} f$. Portanto $A$ é limitada.

Demonstração da Proposição 4.3.2. É fácil ver que se o Jogador I possuir estratégia vencedora em $G_{1}(\mathscr{O}, \mathscr{K})$ então o Jogador I possui estratégia vencedora em $G_{1}(\mathscr{O}, \mathscr{H})$.

Agora, daremos um exemplo que mostrará que a recíproca não é verdadeira. Seja $A_{n}=\left\{a_{k}^{n}: k \in \omega\right\}$ e seja $X=\bigcup\left\{A_{n}: n \in \omega\right\} \cup\{a\}$. Agora, definamos uma topologia para esse espaço. Declaramos que $\left\{a_{k}^{n}\right\}$ é uma vizinhança para o ponto $a_{k}^{n}$. Uma vizinhaça para o ponto $a$ é da seguinte forma $V_{f}=\left\{a_{k}^{n}: k \geq f(n)\right\}$ onde $f \in \omega^{\omega}$. Note que para cada $f \in \omega^{\omega}$ temos que $V_{f}$ é uma vizinhança de $X$. Este espaço é conhecido como Fan Space.

$\mathrm{I} \uparrow G_{1}(\mathscr{O}, \mathscr{H}):$

2 Isso se dá pela definição de $\leq^{*}$. 
Para cada $k \in \omega$ seja $\mathscr{C}_{k}=\left\{V_{k}\right\} \cup\left\{\{b\}: b \in X \backslash V_{k}\right\}$ onde $V_{k}=V_{f}$ para $f$ constante igual à $k$. Na $k$-ésima rodada, o Jogador I joga $\mathscr{C}_{k}$. Se o Jogador II escolher $\{b\}$ para algum $b \in X \backslash V_{k}$ temos que o Jogador I vence. Caso contrário, observe que $\{a\}=\bigcap\left\{V_{k}: k \in \omega\right\}$. Portanto o Jogador I vence.

$\mathrm{I} \bigvee G_{1}(\mathscr{O}, \mathscr{K})$ :

Seja $\sigma$ uma estratégia para o Jogador I. Na $k$-ésima rodada o Jogador I joga $\sigma\left(V_{f_{0}}, \ldots, V_{f_{k-1}}\right)$ então o Jogador II escolhe $V_{f_{k}} \in \sigma\left(V_{f_{0}}, \ldots, V_{f_{k-1}}\right)$, onde $V_{f_{k}}$ é alguma vizinhança de $a$. Observe que $\left\{V_{f_{k}}: k \in \omega\right\}$ não forma uma base para o ponto $a$. De fato, se isso ocorresse, teríamos que para todo $f \in \omega^{\omega}$ existiria $k \in \omega$ tal que $V_{f_{k}} \subset V_{f}$. Mas isso é o mesmo que dizer que $f_{k}(n)>f(n)$ para todo $n \in \omega$ e isso implicaria que $\left\{f_{k}: k \in \omega\right\}$ seria uma família dominante em $\omega^{\omega}$ o que é uma contradição, pois uma família dominante é uma família ilimitada e não existem famílias ilimitadas enumeráveis. Logo, existe $g \in \omega^{\omega}$ tal que $V_{f_{k}} \nsubseteq V_{g}$ e portanto o Jogador II vence.

Proposição 4.3.7. Seja $X$ um espaço de Moore e $T_{1}$. Então não vale $S_{1}(\mathscr{O}, \mathscr{K})$.

Demonstração. Observe que $\neg S_{1}(\mathscr{O}, \mathscr{K})$ é dado por: Existe $\left(\mathscr{C}_{n}: n \in \omega\right) \subset \mathscr{O}$ tal que, para cada $n \in \omega$ e para qualquer $C_{n} \in \mathscr{C}_{n}$, temos que $\left(C_{n}: n \in \omega\right) \notin \mathscr{K}$.

Seja $\left(\mathscr{C}_{n}: n \in \omega\right)$ um desenvolvimento para o espaço $X$. Vamos mostrar que, para cada $n \in \omega$ e para qualquer $C_{n} \in \mathscr{C}_{n}$, temos que $\left|\bigcap\left\{C_{n}: n \in \omega\right\}\right| \leq 1$. Seja $\left(A_{n}: n \in \omega\right)$ onde $A_{n} \in \mathscr{C}_{n}$ para cada $n \in \omega$ e suponha que existam $x$ e $y$ distintos tais que $x, y \in \bigcap\left\{A_{n}: n \in \omega\right\}$. Note que $X \backslash\{y\}$ é um aberto que contém $x$, logo, existe $k \in \omega$ e existe $V$ vizinhança de $x$ tal que $S t\left(V, \mathscr{C}_{k}\right) \subset X \backslash\{y\}$. Em particular, $\operatorname{St}\left(x, \mathscr{C}_{k}\right) \subset X \backslash\{y\} . \operatorname{Logo}, A_{k} \subset \operatorname{St}\left(x, \mathscr{C}_{k}\right) \subset X \backslash\{y\}$ o que é um absurdo!

Além disso, é fácil ver que $\left(A_{n}: n \in \omega\right)$ é base para o ponto $x$.

Proposição 4.3.8. Seja X um espaço de Moore. Então o espaço X possui a propriedade da diagonal $G_{\delta}$.

Demonstração. Seja $\left(\mathscr{C}_{n}: n \in \omega\right)$ um desenvolvimento para o espaço $X$. Vamos mostrar que para cada $x \in X$ temos que $\bigcap\left\{S t\left(x, \mathscr{C}_{n}\right): n \in \omega\right\}=\{x\}$. Dado $x \in X$, suponha que exista $y \neq x$ tal que $y \in \bigcap\left\{S t\left(x, \mathscr{C}_{n}\right): n \in \omega\right\}$. Note que $X \backslash\{y\}$ é uma vizinhança do ponto $x$, então existe $V$ vizinhança de $x$ e, existe $k \in \omega$ tais que $S t\left(x, \mathscr{C}_{k}\right) \subset X \backslash\{y\}$, o que é um absurdo. Portanto, pelo Lema 3.1.2, o espaço $X$ possui a propriedade da diagonal $G_{\delta}$.

Note que as próximas duas observações servem para mostrar que não valem as implicações contrárias das Proposições 4.3.7 e 4.3.8.

Antes disso daremos alguns resultados auxiliares: 
Definição 4.3.9. Uma família de subconjuntos de um espaço topológico é dito ser $\sigma$-localmente finita se pode ser representado por uma união enumerável de famílias localmente finitas.

Teorema 4.3.10 (de metrização de Nagata-Smirnov). Um espaço topológico é metrizável se, e somente se, é regular e possui uma base $\sigma$-localmente finita.

Demonstração. Veja em (ENGELKING, 1989) a demonstração do Teorema 4.4.7 na página 282.

Observação 4.3.11. Seja $\mathbb{R}_{S}$ a reta de Sorgenfrey. Note que $\mathbb{R}_{S}$ não é de Moore. De fato, suponha $\mathbb{R}_{S}$ seja de Moore e seja $\left(\mathscr{C}_{n}: n \in \omega\right)$ um desenvolvimento para este espaço. Observe que $\{S(x, \mathscr{C}): x \in X$ e $n \in \omega\}$ é uma base para $\mathbb{R}_{S}$ e como consequência disso temos que $\bigcup\left\{\mathscr{C}_{n}: n \in \omega\right\}$ é uma base para $\mathbb{R}_{S}$. De fato, seja $x \in \mathbb{R}_{S}$ e U uma vizinhança de $x$, por $\left(\mathscr{C}_{n}: n \in \omega\right)$ ser um desenvolvimento segue que existe $n \in \omega$ tal que $x \in \operatorname{St}\left(x, \mathscr{C}_{n}\right) \subset U$. Como $\operatorname{St}\left(x, \mathscr{C}_{n}\right)=\bigcup\left\{C \in \mathscr{C}_{n}: x \in C\right\}$ basta tomar algum $C \in\left\{C \in \mathscr{C}_{n}: x \in C\right\}$. Portanto $x \in C \subset U$.

Como $\mathbb{R}_{S}$ é regular e Lindelöf ${ }^{3}$ então pelo Teorema 2.5 .20 segue que $\mathbb{R}_{S}$ é paracompacto. Para cada $n \in \omega$ seja $\mathscr{C}_{n}^{\prime}$ um refinamento localmente finito de $\mathscr{C}_{n}$. Então $\bigcup\left\{\mathscr{C}_{n}^{\prime}: n \in \omega\right\}$ é uma base $\sigma$-localmente finita para $\mathbb{R}_{S}$. Pelo Teorema de metrização de Nagata-Smirnov como $\mathbb{R}_{S}$ não é metrizável implica que o mesmo não possui uma base $\sigma$-localmente finita e portanto $\mathbb{R}_{S}$ não é de Moore.

Observação 4.3.12. Em $\mathbb{R}_{S}$ não vale $S_{1}(\mathscr{O}, \mathscr{K})$. Tome $\mathscr{C}_{n}=\left\{\left[x, x+\frac{1}{n+1}\left[: x \in \mathbb{R}_{S}\right\}\right.\right.$ e suponha que para cada $n \in \omega$ exista $\left[x_{n}, x_{n}+\frac{1}{n+1}\left[\in \mathscr{C}_{n}\right.\right.$ tal que $\mid \bigcap\left\{\left[x_{n}, x_{n}+\frac{1}{n+1}[: n \in\right.\right.$ $\omega\} \mid \geq 2$. Sejam $x, y$ elementos distintos nessa intersecção e seja $m \in \omega$ tal que $\frac{1}{m+1}<$ $\frac{1}{2}|x-y|$ então ou $x \in\left\{\left[x_{m}, x_{m}+\frac{1}{n+1}\left[\right.\right.\right.$ e $y \notin\left\{\left[x_{m}, x_{m}+\frac{1}{n+1}\left[\right.\right.\right.$ ou $x \notin\left\{\left[x_{m}, x_{m}+\frac{1}{n+1}[e\right.\right.$ $y \in\left\{\left[x_{m}, x_{m}+\frac{1}{n+1}[\right.\right.$. Portanto, a intersecção ou é um ponto ou é vazia.

Finalmente, vemos que um espaço ser de Moore é pedir muito. 
Nesse capítulo mostraremos algumas aplicações do jogo $G_{1}(\mathscr{O}, \mathscr{H})$ e demais jogos vistos no Capítulo 4.

\subsection{Aplicações de $G_{1}(\mathscr{O}, \mathscr{H})$}

No trabalho de (BUZYAKOVA, 2006) foi mostrado que todo espaço topológico c.c.c. ${ }^{1}$ satisfazendo a propriedade da diagonal $G_{\delta}$ regular $^{2}$ tem tamanho no máximo $2^{\omega}$. Nessa seção vamos mostrar um resultado similar envolvendo o jogo $G_{1}(\mathscr{O}, \mathscr{H})$. Além disso, veremos outras aplicações do jogo $G_{1}(\mathscr{O}, \mathscr{H})$.

Em (AURICHI; LARA, 2016) obtemos um resultado inspirado no trabalho da Buzyakova substituindo a propriedade c.c.c. e a regularidade pelo espaço ser metacompacto, separável, possui a propriedade da diagonal $G_{\delta}$ e o Jogador I possuir estratégia vencedora em $G_{1}(\mathscr{O}, \mathscr{H})$.

Proposição 5.1.1. Seja $(X, \tau)$ um espaço metacompacto e separável. Se o Jogador I possui estratégia vencedora em $G_{1}(\mathscr{O}, \mathscr{H})$ então $|X| \leq 2^{\omega}$.

A idéia para essa demonstração é construir um espaço métrico com base enumerável $\mathscr{U}$ e uma função $f: \mathscr{U} \rightarrow X$ sobrejetora. Note que um espaço métrico com base enumerável tem tamanho no máximo contínuo ${ }^{3}$. Para tanto, note que o Jogador I possui estratégia vencedora em qualquer espaço métrico ${ }^{4}$ e podemos supor que todas as coberturas jogadas pelo mesmo são

1 Um espaço topológico $X$ é dito ser c.c.c. (countable chain condition) se dada qualquer coleção de abertos dois a dois disjuntos essa coleção possui cardinalidade no máximo enumerável. Um exemplo bem fácil de um espaço que possui essa propriedade é reta com a topologia usual. Se a reta não fosse c.c.c. conseguiríamos uma injeção de uma família não enumerável em $\mathbb{Q}$.

2 Existe uma sequência de abertos enumerável de abertos $\left\{V_{n}: n \in \omega\right\}$ de $X \times X$ tal que $\Delta=\bigcap\left\{V_{n}: n \in \omega\right\}=$ $\bigcap\left\{\overline{V_{n}}: n \in \omega\right\}$.

3 Isso é também uma consequência do artigo de (ARHANGEL'SKII, 1969). Neste trabalho é dito que um espaço satisfazendo o primeiro axioma de enumerabilidade e Lindelöf possui tamanho no máximo contínuo.

4 Basta que, na $n$-ésima rodada, o Jogador I jogue $\mathscr{C}_{n}=\{B(x, 1 / n+1): x \in X\}$. 
compostas de abertos básicos. Seja $M$ um espaço métrico e fixe $x \in M$ e para cada cobertura $\mathscr{C}_{n}$ jogada pelo Jogador I o Jogador II responde escolhendo $C_{n} \in \mathscr{C}_{n}$ tal que $x \in C_{n} \operatorname{logo} \bigcap\left\{C_{n}: n \in\right.$ $\omega\}=\{x\}$. Com isso concluímos que cada ponto $x \in M$ pode ser escrito como uma sequência enumerável de elementos da base. Como a base é enumerável, segue que $M$ possui tamanho no máximo contínuo 5 .

Vamos definir um jogo auxiliar que será útil na demonstração da Proposição 5.1.1:

Definição 5.1.2. Considere $G_{1}^{*}(\mathscr{O}, \mathscr{H})$ o seguinte jogo: Na n-ésima rodada, o Jogador I joga a cobertura $\mathscr{C}_{n} \in \mathscr{O}$ e o Jogador II escolhe $C_{n} \in \mathscr{C}_{n}$. No final do jogo, o Jogador II vence se existe um $k \in \omega$ tal que $\left|\bigcap\left\{C_{n}: k \leq n\right\}\right| \geq 2$.

Proposição 5.1.3. Se o Jogador I possui estratégia vencedora em $G_{1}(\mathscr{O}, \mathscr{H})$ então existe uma estratégia vencedora para o Jogador I em $G_{1}^{*}(\mathscr{O}, \mathscr{H})$.

Demonstração. De fato, seja $\sigma$ uma estratégia vencedora para o Jogador I em $G_{1}(\mathscr{O}, \mathscr{H})$. Agora, vamos definir uma estratégia para o Jogador $\operatorname{I}$ em $G_{1}^{*}(\mathscr{O}, \mathscr{H})$ da seguinte maneira. Na $n$-ésima rodada, o Jogador I joga:

- $\sigma(\emptyset)$, se $n=p$ em que $p$ é um número primo.

- $\sigma\left(C_{p}, \ldots, C_{p^{k-1}}\right)$, se $n=p^{k}$ para $p$ um número primo e para algum $k \in \omega, \operatorname{com} k>1$.

- $\sigma(\emptyset)$, se $n$ não é uma potência de algum número primo.

Observe que, na $n$-ésima rodada, o Jogador II escolhe $C_{n}$. Então, para qualquer $k \in \omega$, existe um número primo tal que $p>k$, então

$$
\left|\bigcap_{n \geq k} C_{n}\right| \leq\left|\bigcap_{n \geq p} C_{n}\right| \leq\left|\bigcap_{n \geq 1} C_{p^{n}}\right| \leq 1
$$

Definição 5.1.4. Seja $(X, \tau)$ um espaço topológico. Seja $\mathscr{S}=\left\{\left(S_{n}: n \in \omega\right): S_{n} \in \tau \backslash\{\emptyset\}\right\}$. Vamos denotar a sequência $\left(S_{n}: n \in \omega\right)$ apenas por $S$. Para cada $A, B \in \mathscr{S}$ com $A \neq B$ seja $d: \mathscr{S} \times \mathscr{S} \rightarrow[0,1]$ uma função tal que $d(A, B)=1 /(n+1)$ em que $n=\min \left\{k \in \omega: A_{k} \neq B_{k}\right\}$ e d $(A, A)=0$.

Agora, vejamos se essa função satisfaz a desigualdade triangular:

Sejam $A, B, C \in \mathscr{S}$ tal que $d(A, B)=1 /(n+1)$ e d $(B, C)=1 /(m+1)$.

- Se $n<m$ temos que $A_{i}=C_{i}$ para $i \leq n-1$ e como $A_{n} \neq B_{n}=C_{n}$ temos que $A_{n} \neq C_{n} e$, então, $d(A, C)=1 /(n+1)$ e, portanto, $d(A, C) \leq d(A, B)+d(B, C)$.

\footnotetext{
$\overline{5}$ Seja $\mathscr{B}$ uma base enumerável para $M$. Então $|\wp(\mathscr{B})|=|\wp(\omega)|=2^{\omega}$.
} 
- Se $n>m$ temos que $B_{i}=C_{i}$ para $i \leq m-1$ e como $=A_{m}=B_{m} \neq C_{n}$ temos que $A_{m} \neq C_{m}$ $e$, então, $d(A, C)=1 /(m+1)$ e, portanto, $d(A, C) \leq d(A, B)+d(B, C)$.

Portanto $(\mathscr{S}, d)$ é um espaço métrico.

Agora temos todas as ferramentas necessárias para demonstrar a Proposição 5.1.1.

Demonstração da Proposição 5.1.1. Seja $\sigma$ a estratégia vencedora para o Jogador I. De maneira análoga ao que foi mostrado no Lema 3.2.7 podemos supor que as coberturas jogadas pelo Jogador I são ponto-finitas. Para cada $x \in X$ seja

$$
S(x, \emptyset)=\{C \in \sigma(\emptyset): x \in C\}
$$

$\mathrm{e}$

$$
S\left(x, C_{0}, \ldots, C_{n-1}\right)=\left\{C_{n} \in \sigma\left(C_{0}, \ldots, C_{n-1}\right): C_{n-1} \in S\left(x, C_{0}, \ldots, C_{n-2}\right), \ldots, C_{0} \in S(x, \emptyset), x \in C_{n}\right\}
$$

Para cada $x \in X$ seja

$$
\mathscr{S}_{x}=\left\{R \in \mathscr{S}: R_{n} \in \sigma\left(R_{0}, \ldots, R_{n-1}\right), \ldots, R_{0} \in \sigma(\emptyset), \bigcap R=\{x\}\right\} .
$$

e para cada $n \in \omega$ seja

$$
S_{n}^{x}=\bigcup\left\{S\left(x, C_{0}, \ldots, C_{n}\right): C_{n} \in \sigma\left(C_{0}, \ldots, C_{n-1}\right), . ., C_{0} \in S(x, \emptyset)\right\}
$$

Para cada $x \in X$ e para cada $k \in \omega$ seja

$$
\mathscr{U}_{x}^{k}=\left\{R \in \mathscr{S}: R_{n} \in S_{n}^{x} \text { se } n \leq k \text { e } R_{n}=A_{n} \text { se } n>k \text { para algum } A \in \mathscr{S}_{x}\right\}
$$

Cada conjunto $\mathscr{U}_{x}^{k}$ é uma coleção de ramos com liberdade de "bagunçar" até o $k$-ésimo passo. Ou seja, até o $k$-ésimo passo podemos escolher à vontade elementos de $S\left(x, C_{0}, \ldots, C_{k}\right)$ para $k \leq n$, pois, a Proposição 5.1.3 nos garante que a intersecção de cada um desses ramos dará o elemento $x$.

Seja $\mathscr{U}_{x}=\bigcup\left\{\mathscr{U}_{x}^{k}: k \in \omega\right\}$ e seja $\mathscr{U}=\bigcup\left\{\mathscr{U}_{x}: x \in X\right\}$. Note que $(\mathscr{U}, d\lceil\mathscr{U})$ é um espaço métrico e que existe uma função sobrejetora $g: \mathscr{U} \rightarrow X$ tal que $g(U)=\bigcap U$.

Seja $D$ um subconjunto enumerável e denso de $X$. Para cada $d \in D$, fixe um elemento $A^{d} \in \mathscr{S}_{d}$ e considere

$$
\mathscr{D}_{d}^{n}=\left\{H \in \mathscr{U}_{d}: H_{k}=A_{k}^{d} \text { para cada } k \geq n\right\} \text { e } \mathscr{D}_{d}=\bigcup\left\{\mathscr{D}_{d}^{n}: n \in \omega\right\}
$$

e seja $\mathscr{D}=\bigcup\left\{\mathscr{D}_{d}: d \in D\right\}$. Observe que $\mathscr{D}$ é um subconjunto enumerável de $\mathscr{U}$.

Vamos mostrar que $\overline{\mathscr{D}}=\mathscr{U}$. Seja $Y \in \mathscr{U}$ então, existe $y \in X$ tal que $Y \in \mathscr{U}_{y}$ vamos mostrar que $B(Y, 1 /(n+1)) \cap \mathscr{D} \neq \emptyset$, em que $B(Y, 1 /(n+1))$ é uma bola aberta de centro $Y$ e raio $1 /(n+1)$. Para cada $x \in X$ e $k \in \omega$ seja 


$$
V_{k}^{x}=\bigcap\left\{\bigcap S\left(x, C_{0}, \ldots, C_{k-1}\right): C_{k-1} \in S\left(x, C_{0}, \ldots, C_{k-1}\right), \ldots, C_{0} \in S(x, \emptyset)\right\}
$$

Como $X$ é metacompacto, temos que $\bigcap\left\{V_{k}^{y}: k \leq n\right\}$ é um aberto não vazio, então seja $d \in\left(\bigcap\left\{V_{k}^{y}: k \leq n\right\}\right) \cap D$. Finalmente, definimos $H=\left(H_{n}: n \in \omega\right) \in \mathscr{D}$ dado por $H_{k}=Y_{k}$ para $k \leq n$ e seja $H_{k}=A_{k}^{d}$ para $k>n$. Portanto $H \in B(Y, 1 /(n+1)) \cap \mathscr{D}$. Como $\mathscr{U}$ é um espaço métrico e separável então possui base enumerável. Sendo assim, $|\mathscr{U}| \leq 2^{\omega}$ e como $g: \mathscr{U} \rightarrow X$ é sobrejetora temos o resultado desejado.

Observação 5.1.5. Observe que a demonstração da Proposição 5.1.1 não funcionaria se tomássemos $\mathscr{U}=\bigcup\left\{\mathscr{U}_{x}: x \in X\right\}$ e $\mathscr{D}=\bigcup\left\{\mathscr{D}_{d}: d \in D\right\}$, onde $D \subset X$ é denso, pois $|\mathscr{D}|>\omega$. E se definirmos $\mathscr{D}=\left\{A^{d}: d \in D\right\}$, onde $A^{d} \in \mathscr{S}_{d}$ está fixado para cada $d \in D$. Agora temos que $|\mathscr{D}|=\omega$, seja $Y \in \mathscr{U}_{y}$ para algum $y \in X$, considere a bola $B(Y, 1 /(n+1))$ e seja $d \in\left(\bigcap\left\{V_{k}^{y}: k \leq n\right\}\right) \cap D$. Temos que $S(y, \emptyset) \subset S(d, \emptyset)$, porém, nada nos garante que $Y_{0}=A_{0}^{d}$.

Se já soubermos de antemão um limite para o tamanho das subcoberturas abertas para o espaço $X$ então através do jogo $G_{1}(\mathscr{O}, \mathscr{H})$ conseguimos majorar o tamanho do espaço.

Definição 5.1.6 ((ENGELKING, 1989)). Sejam X um espaço topológico. Dizemos que X possui grau de Lindelöf igual a $\kappa$ se $\kappa$ é menor o cardinal tal que toda cobertura aberta para o espaço $X$ possua um refinamento aberto de cardinalidade menor ou igual a $\kappa$.

Proposição 5.1.7. Seja $\kappa$ o grau de Lindelöf do espaço X. Se o Jogador I possuir estratégia vencedora em $G_{1}(\mathscr{O}, \mathscr{H})$ então $|X| \leq \kappa^{\omega}$.

Demonstração. Seja $\mathscr{B}$ uma base para a topologia do espaço $X$. Como o grau de Lidelöf de $X$ é $\kappa$, sem perda de generalidade, podemos supor que $|\mathscr{B}| \leq \kappa$ Seja $x \in X$. Em cada rodada o Jogador I joga um cobertura abertas $\mathscr{C}_{n}$ e o Jogador II escolhe um aberto $C_{n} \in \mathscr{C}_{n}$ contenha o ponto $x$. Então, como o Jogador I possui estratégia vencedora em $G_{1}(\mathscr{O}, \mathscr{H})$ temos que $\bigcap\left\{C_{n}: n \in \omega\right\}=\{x\}$. Como $|\wp(\mathscr{B})| \leq \kappa^{\omega}$ isso implica que $|X| \leq \kappa^{\omega}$.

Como corolário desse teorema temos algo bem parecido com o resultado do artigo de (ARHANGEL'SKII, 1969) mencionado acima.

Corolário 5.1.8. Seja X um espaço de Lindelöf. Se o Jogador I possui estratégia vencedora em $G_{1}(\mathscr{O}, \mathscr{H})$ então $|X| \leq 2^{\omega}$

Agora veremos alguns resultados interessantes obtidos ao modificarmos a quantidade de escolhas feitas no princípio seletivo $S_{1}(\mathscr{O}, \mathscr{H})$ e o que ocorrerá no jogo induzido por tal mudança.

Seja $\kappa$ um cardinal infinito. Seja $(X, \tau)$ um espaço topológico e seja $A \subset X$, dizemos que $A$ é um subconjunto $G_{\kappa}$ de $X$ se $A=\bigcap\left\{A_{\xi}: \xi<\kappa\right\}$, onde $A_{\xi}$ é um subconjunto aberto de $X$ para cada $\xi<\kappa$. 
Considere o princípio de selecão $S_{1}^{\kappa}(\mathscr{O}, \mathscr{H})$ dado pela seguinte afirmação:

Dado $\left(\mathscr{C}_{\xi}: \xi<\kappa\right) \subset \mathscr{O}$, para cada $\xi<\kappa$ existe um $C_{\xi} \in \mathscr{C}_{\xi}$ tal que $\left|\bigcap\left\{C_{\xi}: \xi<\kappa\right\}\right| \geq 2$.

Novamente, temos assossiado a esse princípio o jogo $G_{1}^{\kappa}(\mathscr{O}, \mathscr{H})$ como definido a seguir: $\mathrm{Na} \xi$-ésima rodada, o Jogador I joga uma cobertura $\mathscr{C}_{\xi} \in \mathscr{O}$ e o Jogador II escolhe um aberto $C_{\xi} \in \mathscr{C}_{\xi}$. No final do jogo, o Jogador II vence se $\left|\bigcap\left\{C_{\xi}: \xi<\kappa\right\}\right| \geq 2$.

Note que:

$$
\Delta \text { é } G_{\kappa} \text { em } X^{2} \Leftrightarrow \neg S_{1}^{\kappa}(\mathscr{O}, \mathscr{H}) \Rightarrow \mathrm{I} \uparrow G_{1}^{\kappa}(\mathscr{O}, \mathscr{H})
$$

Agora iremos ver quais são os possíveis valores para $\kappa$ para que possamos obter algo parecido com a recíproca da segunda implicação.

Proposição 5.1.9. Seja $\kappa$ o grau de Lindelöf do espaço X. Se o Jogador I possui estratégia vencedora em $G_{1}(\mathscr{O}, \mathscr{H})$ então $S_{1}^{\kappa}(\mathscr{O}, \mathscr{H})$ não vale.

Demonstração. Sem perda de generalidade, podemos assumir que em cada rodada o Jogador I joga coberturas abertas de tamanho $\kappa$. Considere uma estratégia vencedora para o Jogador I dada por $\left\{\mathscr{C}_{\rho}: \rho \in \kappa^{<\omega}\right\}$ tal que $\mathscr{C}_{\rho}=\left\{A_{\rho^{-} \xi}: \xi<\kappa\right\}, \bigcup\left\{A_{\rho^{-} \xi}: \xi<\kappa\right\}=X$ e $\left|\cap\left\{A_{f \mid \xi}: \xi<\kappa\right\}\right| \leq 1$ para cada $f \in \kappa^{\omega}$.

Note que $\left|\kappa^{<\omega}\right|=\kappa$. Suponha que o princípio $S_{1}^{\kappa}(\mathscr{O}, \mathscr{H})$ valha, ou seja, que existam $x, y \in X \operatorname{com} x \neq y$ tal que para cada $\rho \in \kappa^{<\omega}$ temos que $y \in S t\left(x, \mathscr{C}_{\rho}\right)$. Então existe uma $g \in \kappa^{\omega}$ tal que $x, y \in A_{g \mid \xi}$ para cada $\xi<\kappa$, então $\left|\bigcap\left\{A_{g \mid \xi}: \xi<\kappa\right\}\right| \geq 2$. Portanto, isso contradiz o fato do Jogador I possuir estratégia vencedora em $G_{1}(\mathscr{O}, \mathscr{H})$.

Observe que se o Jogador I possuir estratégia vencedora em $G_{1}(\mathscr{O}, \mathscr{H})$ isso nos dá um limitante do tamanho que $\kappa$ para que o princípio seletivo $S_{1}^{\kappa}(\mathscr{O}, \mathscr{H})$ valha. De fato, seja $\alpha>\kappa$ se o princípio $S_{1}^{\kappa}(\mathscr{O}, \mathscr{H})$ não vale então então existe uma sequência de coberturas abertas $\left(\mathscr{C}_{\xi}: \xi<\kappa\right)$ tal que para cada $\xi<\kappa$ e para qualquer $C_{\xi} \in \mathscr{C}_{\xi}$ temos que $\left|\bigcap\left\{C_{\xi}: \xi<\kappa\right\}\right| \leq 1$. Seja $\left(\mathscr{A}_{\xi}: \xi<\alpha\right)$ uma sequência de coberturas abertas tal que para $\xi<\kappa$ temos que $\mathscr{A}_{\xi}=\mathscr{C}_{\xi}$. Então, para cada $\xi<\alpha$ e para qualquer $A_{\xi} \in \mathscr{A}_{\xi}$ temos que $\left|\bigcap\left\{A_{\xi}: \xi<\kappa\right\}\right| \leq 1$.

\subsection{Aplicações do jogo $G(X)$}

Definimos o jogo $G(X)$ no capítulo anterior e mostramos algumas relações que ele possui com outros jogos. Nessa seção mostraremos duas aplicações desse jogo. Na primeira subseção mostraremos que se o Jogador I possui estratégia vencedora em $G(X)$ então haverá um resultado bem interessante com relação à continuidade de funções que saem de um produto de espaços 
topológicos. Na segunda subseção mostraremos que se $X$ for um espaço métrico e se o Jogador I possuir estratégia vencedora em $G(X)$ então o espaço $X$ é completo.

\subsubsection{Substituição de $\sigma$-Choquet por $G(X)$}

Considere as seguintes definições:

Definição 5.2.1. Seja $\sigma$-Choquet o seguinte jogo: Na 0-ésima rodada o Jogador I joga um aberto não vazio $A_{0} e$, por sua vez, o Jogador II joga um aberto não vazio $B_{0} \subset A_{0}$ e, escolhe um ponto $x_{0} \in B_{0}$. Na n-ésima rodada o Jogador I joga um aberto não vazio $A_{n} \subset B_{n-1}$ e o Jogador II escolhe $B_{n} \subset A_{n}$ aberto não vazio e, além disso, toma um ponto $x_{n} \in B_{n}$. Dizemos que o Jogador II vence se para qualquer subsequência $\left(x_{p_{n}}: n \in \omega\right)$ de $\left(x_{n}: n \in \omega\right)$ tem pelo menos um ponto de acumulação em $\bigcap\left\{A_{n}: n \in \omega\right\}=\bigcap\left\{B_{n}: n \in \omega\right\} \neq \emptyset$.

Note que se o Jogador II possuir estratégia vencedora no jogo $\sigma$-Choquet então o Jogador II também possuirá estratégia vencedora no jogo de Choquet.

Definição 5.2.2. Seja $f: X \times Y \rightarrow Z$ uma função, dizemos que $f$ é separadamente contínua se para todo $x \in X, g: Y \rightarrow Z$ onde $g(y)=f(x, y)$ for contínua e se, para todo $y \in Y, h: X \rightarrow Z$ for contínua, onde $h(x)=f(x, y)$.

Em (CHRISTENSEN, 1981) é mostrado que

Teorema 5.2.3. Seja uma função $f: X \times Y \rightarrow Z$ separadamente contínua. Se o Jogador II possuir estratégia vencedora no jogo $\sigma$-Choquet em $X$ com $Y$ compacto Hausdorff e $Z$ métrico então existe $A \subset X$ denso e $G_{\delta}$ tal que $f \uparrow(A \times Y): A \times Y \rightarrow Z$ é contínua.

O que faremos nessa seção é mostrar que conseguimos o mesmo resultado com o jogo $G(X)$ da seguinte forma:

Proposição 5.2.4. Seja $(X, \tau)$ um espaço topológico regular. Se o Jogador I possui estratégia vencedora em $G(X)$ então o Jogador II possui estratégia vencedora no jogo $\sigma$-Choquet. Porém a recíproca não é verdadeira.

Demonstração. Seja $\sigma$ uma estratégia para o Jogador I em $G(X)$.

Sem perda de generalidade, podemos considerar que as jogadas do Jogador I não contém pontos isolados. Caso contrário, basta o Jogador II escolher um ponto isolado dentro do aberto que o Jogador I jogou.

No jogo $\sigma$-Choquet na 0 -ésima rodada o Jogador I joga um aberto não vazio $A_{0}$. Em $G(X)$ suponha que o Jogador I tenha jogado $\sigma(\emptyset)$, então existe $C_{0} \in \sigma(\emptyset)$ tal que $C_{0} \cap A_{0} \neq \emptyset$. Então, suponha que o Jogador II joga $C_{0} \in \sigma(\emptyset)$. Logo, pela regularidade de $X$, existe um aberto 
não vazio $B_{0}$ tal que $B_{0} \subset \overline{B_{0}} \subset C_{0} \cap A_{0}$. Voltando para o jogo $\sigma$-Choquet o Jogador II toma $B_{0} \subset A_{0}$ e um ponto $x_{0} \in B_{0}$.

Na próxima rodada, no jogo $\sigma$-Choquet o Jogador I joga um aberto não vazio $A_{1} \subset$ $B_{0}$. Em $G(X)$ suponha que o Jogador I tenha jogado $\sigma\left(C_{0}\right)$, então existe $C_{1} \in \sigma\left(C_{0}\right)$ tal que $C_{1} \cap A_{1} \neq \emptyset$. Então, suponha que o Jogador II joga $C_{1} \in \sigma\left(C_{0}\right)$. Logo, pela regularidade de $X$ e a Observação 4.1.9, existe um aberto não vazio $B_{1}$ tal que $B_{1} \subset \overline{B_{1}} \subset C_{1} \cap A_{1}$ e $x_{0} \in B_{0} \backslash \overline{B_{1}}$. Voltando para o jogo $\sigma$-Choquet o Jogador II toma $B_{1} \subset A_{1}$ e um ponto $x_{1} \in B_{1}$.

Agora, na $n$-ésima rodada, no jogo $\sigma$-Choquet o Jogador I joga $A_{n} \subset B_{n-1}$. Novamente, em $G(X)$, o Jogador I joga $\sigma\left(C_{0}, \ldots, C_{n-1}\right)$, então existe $C_{n} \in \sigma\left(C_{0}, \ldots, C_{n-1}\right)$ tal que $C_{n} \cap A_{n} \neq \emptyset$. Então, novamente, suponha que o Jogador II joga $C_{n} \in \sigma\left(C_{0}, \ldots, C_{n-1}\right)$. Usando a regularidade do espaço $X$ e a Observação 4.1.9 existe um aberto não vazio $B_{n}$ tal que $B_{n} \subset \overline{B_{n}} \subset C_{n} \cap A_{n} \mathrm{e}$ $x_{n-1} \in B_{n-1} \backslash \overline{B_{n}} \neq \emptyset$. Então, no jogo $\sigma$-Choquet o Jogador II toma $B_{n} \subset A_{n}$ e um ponto $x_{n} \in B_{n}$.

Então, $\left(B_{n}: n \in \omega\right)$ e $\left(x_{n}: n \in \omega\right)$ garantem a vitória para o Jogador II no jogo $\sigma$-Choquet. Caso contrário, teremos dois casos:

1. Se $\bigcap\left\{B_{n}: n \in \omega\right\}=\emptyset$. Basta tomar $\mathscr{C}=\left\{X \backslash \overline{B_{1}}\right\} \cup\left\{B_{n} \backslash \overline{B_{n+2}}: n \in \omega\right\}$. Observe que $\mathscr{C}$ é de fato uma cobertura. Seja $x \in X$, se $x \notin B_{0}$ ou $x \notin \overline{B_{1}}$ então $x \in X \backslash \overline{B_{1}}$. Caso contrário, como $\bigcap_{n \in \omega} B_{n}=\emptyset$ existe $k \in \omega$ tal que $k$ é o menor índice onde $x \notin \overline{B_{k+2}}$. Logo, $x \in \overline{B_{k+1}}$ e, portanto, $x \in B_{k}$. Assim, $x \in B_{k} \backslash \overline{B_{k+2}}$.

Para cada $n \in \omega$, temos que $x_{n} \in B_{n} \backslash \overline{B_{n+2}}$ e $x_{k} \notin B_{n} \backslash \overline{B_{n+2}}$ para $k \geq n+2$. Isso contradiz o fato do Jogador I possuir estratégia vencedora em $G(X)$. Portanto, o Jogador II vence em $G(X)$.

2. Se $\bigcap\left\{B_{n}: n \in \omega\right\} \neq \emptyset$ e existe uma subsequência $\left(x_{p_{n}}: n \in \omega\right)$ de $\left(x_{n}: n \in \omega\right)$ tal que cada $x \in \bigcap_{n \in \omega} B_{n}$ não é ponto de acumulação de $\left(x_{p_{n}}: n \in \omega\right)$. Ou seja, existe $V_{x} \in \tau$ tal que $x \in V_{x}$ e $V_{x} \cap\left\{x_{p_{n}}: n \in \omega\right\}=\emptyset^{6} . \operatorname{Logo}, \mathscr{C}=\left\{X \backslash \overline{B_{p_{1}}}\right\} \cup\left\{B_{p_{n}} \backslash \overline{B_{p_{n}+2}}: n \in \omega\right\} \cup\left\{V_{x}: x \in\right.$ $\left.\bigcap_{n \in \omega} B_{n}\right\}$ é uma cobertura para $X$. Novamente, isso contradiz o fato do Jogador I possuir estratégia vencedora em $G(X)$. Portanto, o Jogador II vence em $G(X)$.

Quanto a recíproca, considere a reta de Sorgenfrey. Em tal espaço, temos que o Jogador II possui estratégia vencedora no jogo $\sigma$-Choquet. De fato, para cada jogada $A_{n}$ que o Jogador I fizer o Jogador II responde com $\left[a_{n}, b_{n}\left[\varsubsetneqq A_{n}\right.\right.$ e toma $a_{n} \in\left[a_{n}, b_{n}\right.$ [. Então, pela Observação 4.1.5, temos que $\bigcap\left\{A_{n}: n \in \omega\right\}=\bigcap\left\{\left[a_{n}, b_{n}[: n \in \omega\}=\{c\}\right.\right.$, para algum $c \in \mathbb{R}$. Logo, o ponto $c$ é o único ponto de acumulação da sequência $\left\{a_{n}: n \in \omega\right\}$.

Todavia, o Jogador II possui estratégia vencedora em $G\left(\mathbb{R}_{S}\right)$. Basta repetir o que foi feito no Exemplo 4.1.6 e considerarmos a sequência $\left\{a_{n}: n \in \omega\right\}$. Daí temos que para cada $n \in \omega$ o elemento $a_{n}$ está contido em um único elemento de $\mathscr{C}$.

$\overline{6}$ Como $x$ não é ponto de acumulação de $\left(x_{p_{n}}: n \in \omega\right)$ temos que existe $V$ vizinhança de $x$ tal que $(V \backslash\{x\}) \cap\left\{x_{p_{n}}\right.$ : $n \in \omega\}=\left\{x_{\alpha_{1}}, \ldots, x_{\alpha_{k}}\right\}$. Seja $V_{x}=V \backslash\left\{x, x_{\alpha_{1}}, \ldots, x_{\alpha_{k}}\right\}$. 


\subsubsection{Aplicação de $G(X)$ em espaços métricos}

Definição 5.2.5. Dizemos que um espaço métrico $(M, d)$ é completamente metrizável se existe uma métrica $d^{\prime}$ sobre $M$ tal que de $d^{\prime}$ são equivalentes e $\left(M, d^{\prime}\right)$ é completo.

A Proposição 17 da página 186 de (LIMA, 2007) nos diz que um espaço métrico é completamente metrizável se, e somente se, é um subconjunto $G_{\delta}$ em seu completamento ${ }^{7}$. A próxima proposição nos dará uma caracterização interna para espaços métricos completamente metrizáveis.

Proposição 5.2.6. Seja $(X, d)$ um espaço métrico e $(Y, d)$ o seu completamento. O Jogador I possui estratégia vencedora em $G(X)$ se, e somente se, $(X, d)$ é um $G_{\delta}$ em $(Y, d)$.

Demonstração. Suponha que $(X, d)$ não seja um $G_{\delta}$ em $(Y, d)$. Seja $\sigma$ estratégia vencedora para o Jogador I em $G(X)$. Então $\sigma(\emptyset)$ é uma cobertura de abertos para $X$. Podemos considerar tal cobertura como sendo compostas por bolas abertas da seguinte forma: $\sigma(\emptyset)=\left\{B\left(x, r_{x}\right) \cap X: r_{x} \leq\right.$ $\left.1, x \in Z_{1} \subset X\right\}$, para algum $Z_{1} \subset X$ e com o raio $r_{x}$ dependendo do ponto $x$. Como $B\left(x, r_{x}\right) \subset Y$, considere também o seguinte conjunto $\tilde{\sigma}(\emptyset)=\left\{B\left(x, r_{x}\right): r_{x} \leq 1, x \in Z_{1} \subset X\right\}$ e seja $A_{1}=\bigcup \tilde{\sigma}(\emptyset)$. Observe que $A_{1}$ é aberto com $X \subsetneq A_{1}$, pois estamos supondo que $X$ não é um $G_{\delta}$ em $Y$.

Para cada $C_{1} \in \sigma(\emptyset)$ seja $\sigma\left(C_{1}\right)$ uma uma cobertura de abertos para $C_{1}$, que novamente, podemos considerar tal cobertura como sendo formada por bolas abertas da seguinte forma: $\sigma\left(C_{1}\right)=\left\{B\left(x, r_{x}\right) \cap X: r_{x} \leq 1 / 2, x \in Z_{2} \subset C_{1}\right\}$, para algum $Z_{2} \subset C_{1}$ com o raio $r_{x}$ dependendo de $x \in Z_{2}$. Considere também $\tilde{\sigma}\left(C_{1}\right)=\left\{B\left(x, r_{x}\right): r \leq 1 / 2\right.$ e $\left.x \in Z_{2} \subset C_{1}\right\}$. Seja $A_{2}=\bigcup\left\{\bigcup \tilde{\sigma}\left(C_{1}\right)\right.$ : $\left.C_{1} \in \sigma(\emptyset)\right\}$. Observe que $A_{2}$ é aberto $\operatorname{com} X \subsetneq A_{2}$, pois $X$ não é um $G_{\delta}$ em $Y$.

Finalmente, para cada $C_{n} \in \sigma\left(C_{1}, \ldots, C_{n-1}\right), \sigma\left(C_{1}, \ldots, C_{n-1}, C_{n}\right)$ é uma uma cobertura de abertos para $C_{n}$, que podemos considerar tal cobertura como sendo de bolas abertas da seguinte forma: $\sigma\left(C_{1}, \ldots, C_{n-1}, C_{n}\right)=\left\{B\left(x, r_{x}\right) \cap X: r_{x} \leq 1 / n\right.$ e $\left.x \in Z_{n} \subset C_{n}\right\}$, para algum $Z_{n} \subset C_{n}$ com o raio $r$ dependendo de $x \in Z_{n}$. Considere também $\tilde{\sigma}\left(C_{1}, \ldots, C_{n-1}, C_{n}\right)=\left\{B\left(x, r_{x}\right)\right.$ : $r_{x} \leq 1 / n$ e $\left.x \in Z_{n} \subset C_{n}\right\}$. Seja $A_{n}=\bigcup\left\{\bigcup \tilde{\sigma}\left(C_{1}, \ldots, C_{n-1}, C_{n}\right): C_{n} \in \sigma\left(C_{1}, \ldots, C_{n-1}\right), C_{n-1} \in\right.$ $\left.\left(C_{1}, \ldots, C_{n-2}\right), \ldots, C_{1} \in \sigma(\emptyset)\right\}$. Temos que $A_{n}$ é aberto com $X \subsetneq A_{n}$, pois $X$ não é um $G_{\delta}$ em $Y$.

Seja $A=\bigcap_{n \in \omega} A_{n}$, observe que $X \subsetneq A$, então existe $y \in A \backslash X$ e isso implica também que $y \in A_{n}$ para todo $n \in \omega$.

Agora, vejamos o jogo $G(X)$. Na 0-ésima rodada o Jogador I joga $\sigma(\emptyset)$. Em seguida o Jogador II enxerga a jogada dada por $\tilde{\sigma}(\emptyset)$ e escolhe $B\left(x_{1}, r_{1}\right)$ que contém $y$ e joga $C_{1}:=$ $B\left(x_{1}, r_{x_{1}}\right) \cap X$. Na próxima rodada o Jogador I joga $\sigma\left(C_{1}\right)$. Então o Jogador II enxerga a jogada

\footnotetext{
7 Nessa referência o autor chama de completamente metrizável como sendo topologicamente completo
} 
feita pelo Jogador I como sendo $\tilde{\sigma}\left(C_{1}\right)$ e escolhe $B\left(x_{2}, r_{x_{2}}\right)$ que contém $y$ e joga $C_{2}:=B\left(x_{2}, r_{x_{2}}\right) \cap$ $X$. E o restante das rodadas se dão dessa maneira.

Para cada $n \in \omega$ tome $z_{n} \in C_{n}$ e note que $\left(z_{n}: n \in \omega\right)$ é de Cauchy pois, dado $\varepsilon>0$, existe $m \in \omega$ tal que $1 / m<\varepsilon$ e então $d\left(z_{n}, z_{k}\right)<\varepsilon$ para $n, k \geq m+1$. Olhando $\left(z_{n}: n \in \omega\right)$ em $Y$, existe $z \in Y$ tal que $\lim \left\{z_{n}: n \in \omega\right\}=z$. Afirmamos que $z=y$, caso contrário existiria $R>0$ e $\ell \in \omega$ tal que $B(y, R) \cap\left\{z_{n}: n \geq \ell\right\}=\emptyset$. Seja $p \in \omega$ tal que $r_{p}<\min \{R / 2, \ell / 2\}$ e seja $z_{p} \in\left\{z_{n}: n \in \omega\right\}$ tal que $z_{p} \in B\left(x_{p}, r_{p}\right) \cap X$. Porém $y \in B\left(x_{p}, r_{p}\right) \operatorname{logo} z_{p} \in B(y, R)$ com $p \geq \ell$ o que é um absurdo.

Agora seja $\mathscr{C}=\left\{B\left(x, r_{x}\right) \cap X: x \in X, r_{x}=1 / 2 d(x, y)\right\}$ uma cobertura para $X$. Seja $r=\min \left\{r_{x}: x \in X\right\}, s=r / 2$ e considere $B(y, s)$. Observe que $B\left(x, r_{x}\right) \cap B(y, s)=\emptyset$ para todo $x \in X$. Note que $z_{n} \in B(y, s)$ para $n>s / 2$. Logo não existe $C \in \mathscr{C}$ tal que $z_{n} \in C \operatorname{com} n \geq m$ para algum $m \in \omega$. Portanto o Jogador I não possui estratégia vencedora em $G(X)$.

Reciprocamente, se $(X, d)$ é um $G_{\delta}$ em $(Y, d)$ então existe uma métrica $\left(X, d^{\prime}\right)$ que deixa o espaço completo. Considere o seguinte jogo em $\left(X, d^{\prime}\right)$ : Na $n$-ésima rodada o Jogador I joga $\mathscr{C}_{n}=\{B(x, 1 / n+1): x \in X\}$ e o Jogador II toma $B\left(x_{n}, 1 / n+1\right) \in \mathscr{C}_{n}$. Note que todas a bolas das coberturas jogadas pelo Jogador I são em relação à métrica $d^{\prime}$ que deixa o espaço $X$ completo.

Para cada $n \in \omega$ tome $y_{n} \in B\left(x_{n}, 1 / n+1\right)$. Note que $\left(y_{n}: n \in \omega\right)$ é uma sequência de Cauchy. Logo existe $y \in X$ tal que $\lim \left\{y_{n}: n \in \omega\right\}=y$. Logo $\bigcap\left\{B\left(x_{n}: 1 / n+1\right): n \in \omega\right\}=\{y\}$. Portanto o Jogador I possui estratégia vencedora em $G(X)$. 



\section{CONSIDERAÇÕES FINAIS}

Espero que essa pequena contribuição seja útil aos atuais e futuros pesquisadores. Neste trabalho foi mostrada uma maneira diferente de enxergar algumas propriedades derivadas de espaços métricos.

Durante a confecção desse trabalho surgiram algumas questões:

Num espaço $X$, se o Jogador I possui estratégia vencedora em $G_{1}(\mathscr{O}, \mathscr{H})$, conclui-se que os pontos desse espaço são $G_{\delta}$. Para enxergar isso basta fixar um ponto e fazer o Jogador II escolher os abertos que contenha esse ponto. Por sua vez temos que a propriedade da diagonal $G_{\delta}$ implica que o Jogador I possui estratégia vencedora em $G_{1}(\mathscr{O}, \mathscr{H})$. Logo, a classe dos espaços em que o Jogador I possui estratégia vencedora em $G_{1}(\mathscr{O}, \mathscr{H})$ é uma classe intermediária entre as classes dos espaços que possuem a propriedade da diagonal $G_{\delta}$ e a classe dos espaços onde todos os seus pontos são $G_{\delta}$. Ainda não sabemos se a classe dos espaços em que o Jogador I possui estratégia vencedora no jogo $G_{1}(\mathscr{O}, \mathscr{H})$ está contida propriamente na clase dos espaços cujo os pontos são $G_{\delta}$.

Sabemos que separabilidade implica em c.c.c., porém a implicação contrária não vale sempre (e.g. para $\kappa>2^{\omega}$ temos que $2^{\kappa}$ satisfaz o c.c.c., mas não é separável). Será possível melhorar a Proposição 5.1.1? Por exemplo, trocar a hipótese de separabilidade por satisfazer a propriedade c.c.c.? Em certo momento do doutorado os esforços foram focados nessa questão. Para demonstrar a Proposição 5.1.1 construímos um espaço métrico onde cada elemento desse espaço são sequências enumeráveis de abertos jogadas pelo Jogador II em uma partida. Temos uma sobrejeção natural desse espaço métrico em $X$. Logo, nosso foco seria em como trasportar a propriedade do c.c.c. para o espaço métrico.

As propriedades de recobrimento estão intimamente relacionadas ao jogo $G_{1}(\mathscr{O}, \mathscr{H})$, inclusive em pequenas variações deste. Junto com o que foi proposto anteriormente estudaremos essas pertubações. Muito ainda pode ser feito com os jogos $G_{1}^{\kappa}(\mathscr{O}, \mathscr{H}), G_{k}^{\kappa}(\mathscr{O}, \mathscr{H})$ para $k \in \omega$, ou $G_{\text {fin }}^{\kappa}(\mathscr{O}, \mathscr{H})$, onde $\kappa$ é o grau de Lindelöf do espaço. 
Ainda estamos em busca de um espaço que não seja regular onde o Jogador I possua estratégia vencedora em $P(X)$ e que em $G_{1}(\mathscr{O}, \mathscr{H})$ o Jogador I não possua estratégia vencedora. Ou em provar a recíproca da Proposição 3.2.3 para outra classe de espaços topológicos que não sejam regulares.

Para deixar mais claro as relações que foram encontradas entre os jogos que foram trabalhados neste texto construímos um diagrama. Os números que acompanham as setas indicam onde foram provadas estas implicações. Os números que estão entre parentesis indicam os contra-exemplos que mostram que a implicação contrária não é válida. As setas pontilhadas indicam que o espaço precisa ser regular para termos a implicação em questão. 


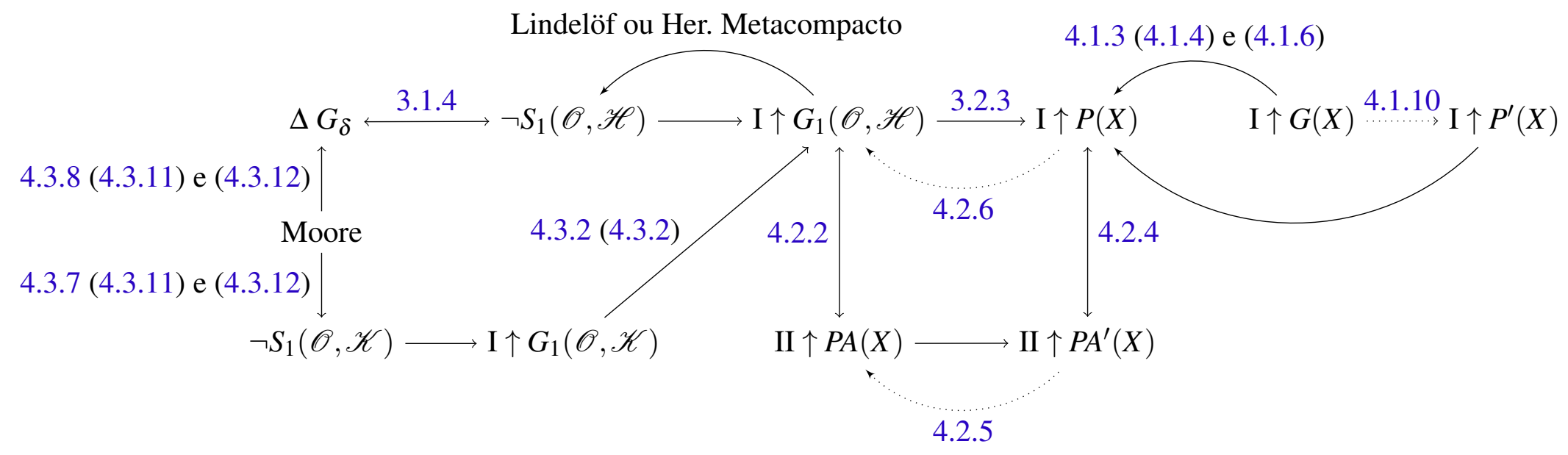


Observe que $\neg S_{1}(\mathscr{O}, \mathscr{H})$ implica em I $\uparrow G_{1}(\mathscr{O}, \mathscr{H})$ e implica em II $\uparrow P A(X)$ devido ao fato do jogo $G_{1}(\mathscr{O}, \mathscr{H})$ ser dual do jogo $P A(X)$. O mesmo ocorrendo com $\mathrm{I} \uparrow G(X)$ implicando em $\mathrm{I} \uparrow P(X)$ e em II $\uparrow P A^{\prime}(X)$ pelo fato do jogo $P(X)$ ser dual do jogo $P A^{\prime}(X)$. 
ARHANGEL'SKII, A. V. On the cardinality of bicompacta satisfying the first axiom of countability. Soviet Mat. Dokl., v. 10, p. 951-955, 1969. Citado 2 vezes nas páginas 61 e 64.

AURICHI, L. Introdução ao forcing. Disponível em: https://www.dropbox.com/s/ o8jczrk2mpz9o09/notas.pdf?dl=0, 2014. Acesso em: 08/08/2016. Citado na página 22.

AURICHI, L. F.; LARA, D. A. Relations between a topological game and the $g_{\delta}$-diagonal property. Disponível em: https://arxiv.org/abs/1602.07002, 2016. Acesso em: 08/08/2016. Citado 4 vezes nas páginas $14,15,37$ e 61 .

BUZYAKOVA, R. Z. Cardinalities of ccc-spaces with regular $G_{\delta}$-diagonals. Topology Appl., v. 153, n. 11, p. 1696-1698, 2006. ISSN 0166-8641. Disponível em: <http://dx.doi.org/10.1016/ j.topol.2005.06.004>. Citado 2 vezes nas páginas 15 e 61.

CEDER, J. G. Some generalizations of metric spaces. Pacific J. Math., v. 11, p. 105-125, 1961. ISSN 0030-8730. Citado na página 38.

CHABER, J. Conditions which imply compactness in countably compact spaces. Bull. Acad. Pol. Sci. Ser. Math., v. 24, p. 993-998, 1976. Citado na página 42.

CHRISTENSEN, J. P. R. Joint continuity of separately continuous functions. Proc. Amer. Math. Soc., v. 82, n. 3, p. 455-461, 1981. ISSN 0002-9939. Disponível em: <http://dx.doi.org/10.2307/ 2043960>. Citado na página 66.

COHEN, P. E. Products of Baire spaces. Proc. Amer. Math. Soc., v. 55, n. 1, p. 119-124, 1976. ISSN 0002-9939. Citado na página 35.

ENGELKING, R. General topology. [S.1.]: Heldermann Verlag, 1989. (Sigma series in pure mathematics). ISBN 9783885380061. Citado 4 vezes nas páginas 17, 42, 60 e 64.

GALVIN, F. Indeterminacy of point-open games. Bull. Acad. Polon. Sci. Sér. Sci. Math. Astronom. Phys., v. 26, n. 5, p. 445-449, 1978. ISSN 0001-4117. Citado na página 52.

JECH, T. Set theory. [S.1.]: Springer, 2003. (Springer monographs in mathematics). ISBN 9783540440857. Citado 4 vezes nas páginas 17, 20, 22 e 57.

KECHRIS, A. Classical descriptive set theory. [S.1.]: Springer-Verlag, 1995. (Graduate texts in mathematics). ISBN 9780387943749. Citado na página 17.

KÖNIG, D. Sur les correspondances multivoques des ensembles. Fundamenta Mathematicae, v. 8, p. 114-134, 1926. Citado na página 24.

KUNEN, K. Set Theory. [S.1.]: College Publications, 2011. (Studies in logic). ISBN 9781848900509. Citado 6 vezes nas páginas 17, 19, 20, 22, 45 e 57.

LIMA, E. Espaços métricos. 4a . ed. [S.1.]: Instituto de Matemática Pura e Aplicada, CNPq, 2007. (Projeto Euclides). Citado na página 68. 
OKUYAMA, A. On metrizability of $M$-spaces. Proc. Japan Acad., v. 40, p. 176-179, 1964. ISSN 0021-4280. Citado na página 37.

PAWLIKOWSKI, J. Undetermined sets of point-open games. Fund. Math., v. 144, n. 3, p. 279-285, 1994. ISSN 0016-2736. Citado na página 32.

ŠNEIDER, V. E. Continuous images of Suslin and Borel sets. Metrization theorems. Doklady Akad. Nauk SSSR (N.S.), v. 50, p. 77-79, 1945. Citado 2 vezes nas páginas 14 e 37.

STEEN, L.; SEEBACH, J. Counterexamples in Topology. [S.1.]: Dover Publications, 1995. (Dover books on mathematics). ISBN 9780486687353. Citado na página 44.

TELGÁRSKY, R. Topological games: on the 50th anniversary of the Banach-Mazur game. Rocky Mountain J. Math., v. 17, n. 2, p. 227-276, 1987. ISSN 0035-7596. Disponível em: <http://dx.doi.org/10.1216/RMJ-1987-17-2-227>. Citado na página 13. 
$G_{\delta}, 37$

$T_{0}$

espaço, 30

$T_{1}$

espaço, 30

$T_{2}$

espaço, 30

ínfimo, 19

ínfimo de um conjunto de ordinais, 20

árvore, 22

árvore bem podada, 25

Šneider

teorema de, 37

anticadeia, 19

no sentido de árvore, 24

Baire

espaço de, 34

Teorema de, 36

base para uma topologia, 27

bem ordenado

conjunto, 18

boa ordem, 18

cadeia, 19

cardinal

número, 20

regular, 21

sucessor, 20

Ceder

lema de, 38

Choquet

espaço de, 33

club, 45 cobertura, 29

cobertura aberta, 29

compacto

espaço, 29

conjunto

estacionário, 45

conjunto aberto, 26

conjunto fechado, 28

conjunto ordenado, 17

conjunto parcialmente ordenado, 17

conjunto pré-ordenado, 17

conjunto totalmente ordenado, 17

coparáveis

elementos, 19

denso

conjunto, 19

desenvolvimento forte, 57

elemento mínimo, 18

elemento máximo, 18

elemento maximal, 18

elemento minimal, 18

espaço

hereditariamente metacompacto, 44

metacompacto, 44

espaço conexo, 27

espaço regular, 30

espaço topológico, 26

estratégia, 31

estratégia vencedora, 31

família dominante, 57

família ilimitada, 57

fecho de um conjunto, 29 
função ilimitada, 21

função regressiva, 45

Hausdorff

espaço, 30

Hipótese do Contínuo, 21

incompatíveis

elementos, 19

jogo

$G(X), 49$

$G_{1}(\mathscr{O}, \mathscr{K}), 57$

$G_{1}(\mathscr{D}, \mathscr{D}), 32$

$G_{1}(\mathscr{O}, \mathscr{H}), 39$

$G_{1}^{*}(\mathscr{O}, \mathscr{H}), 62$

$P^{\prime}(X), 51$

$P(X), 44$

$P A^{\prime}(X), 54$

$P A(X), 53$

de Choquet, 31

de Menger, 32

de Rothberger, 32

Lema de Zorn, 19

Lema do Pressing Down, 45

Lidelöf

grau de, 64

limitante inferior, 18

limitante superior, 18

Lindelöf

espaço de , 29

localmente compacto

espaço , 29

localmente finito

conjunto, 29

Moore

espaço de, 57

Okuyama

teorema de, 37 ordem, 17

topologia da, 27

ordem $\leq^{*}, 57$

ordem estrita, 18

ordem reversa, 25

ordinal

cofinalidade de um, 21

limite, 19

número, 19

sucessor, 19

Oxtoby

teorema de, 34

paracompacto

espaço, 29

pré ordem, 17

princípio da boa ordem, 18

princípio seletivo

$$
\begin{aligned}
& S_{1}(\mathscr{O}, \mathscr{K}), 59 \\
& S_{1}(\mathscr{O}, \mathscr{O}), 32 \\
& S_{1}(\mathscr{D}, \mathscr{D}), 32 \\
& S_{1}(\mathscr{O}, \mathscr{H}), 39
\end{aligned}
$$

princípios seletivos, 31

propriedade da diagonal $G_{\delta}, 37$

propriedade da intersecção finita (p.i.f), 36

raíz de uma árvore, 23

ramo de uma árvore, 23

refinamento de uma cobertura aberta, 29

regular

espaço, 30

separável

espaço, 30

Sorgenfrey

reta de, 27

sub-árvore, 25

sucessor, 24

supremo, 19

supremo de um conjunto de ordinais, 20 
Teorema da indução transfinita, 20

topologia fraca, 28

topologia gerada, 26

topologia produto, 28

transitivo

conjunto, 19

vizinhança de um ponto, 26 